\title{
Minimum Legal Drinking Age and the Social Gradient in Binge Drinking
}

by

\author{
Alexander AHAMMER \\ Stefan BAUERNSCHUSTER \\ Martin HALLA \\ Hannah LACHENMAIER
}

Working Paper No. 2025

First version: December 2020

This version: October 2021

Johannes Kepler University of Linz Department of Economics Altenberger Strasse 69 A-4040 Linz - Auhof, Austria www.econ.jku.at 


\title{
Minimum Legal Drinking Age and the Social Gradient in Binge Drinking ${ }^{\dagger}$
}

\author{
Alexander Ahammer ${ }^{\mathrm{a}, \mathrm{b}}$, Stefan Bauernschuster ${ }^{\mathrm{c}, \mathrm{d}, \mathrm{e}}$, Martin Halla ${ }^{\mathrm{a}, \mathrm{b}, \mathrm{d}, \mathrm{f}}$, Hannah \\ Lachenmaier $^{\mathrm{c}}$ \\ a Johannes Kepler University Linz, Austria \\ ${ }^{\mathrm{b}}$ Christian Doppler Laboratory Aging, Health, and the Labor Market, Linz \\ ${ }^{\mathrm{c}}$ University of Passau, Germany \\ ${ }^{\mathrm{d}}$ IZA, Institute for the Study of Labor, Bonn \\ ${ }^{\mathrm{e}}$ CESifo, Munich \\ ${ }^{\mathrm{f}} G \ddot{O} G$, Austrian Public Health Institute, Vienna
}

forthcoming in:

Journal of Health Economics

Last update: October 29, 2021

\begin{abstract}
Low minimum legal drinking ages (MLDAs), as prevalent in many European countries, are severely understudied. We use rich survey and administrative data to estimate the impact of the Austrian MLDA of 16 on teenage drinking behavior and morbidity. Regression discontinuity estimates show that legal access to alcohol increases the frequency and intensity of drinking, which results in more hospital admissions due to alcohol intoxication. The effects are stronger for boys and teenagers with low socioeconomic background. Evidence suggests that the policy's impact cannot be fully explained by access. Data from an annual large-scale field study show that about 25 percent of retailers sell even hard liquor to underage customers. More generally, perceived access to alcohol is very high and hardly changes at the MLDA. However, teenagers consider binge drinking at weekends to be less harmful after gaining legal access.
\end{abstract}

JEL Classification: I12, I18, H75, J13.

Keywords: Alcohol, minimum legal drinking age, morbidity.

\footnotetext{
${ }^{\dagger}$ Corresponding author: Alexander Ahammer, Department of Economics, Johannes Kepler University Linz, Altenberger Strasse 69, 4040 Linz, Austria, email: alexander. ahammer@jku. at. We thank the editor Christopher Carpenter and three anonymous referees for their excellent suggestions that improved the paper a lot. For helpful discussions and comments we also would like to thank John Cawley, Carlos Dobkin, and seminar participants at the Virtual Seminar on the Economics of Risky Health Behaviors, the University of Passau, the University of Linz, and the Vienna University of Economics and Business. Jasmin Anderlik, Helene Käferböck, Manuel Pannier, Eva-Maria Schaupp, and Rene Wiesinger provided valuable research assistance. We thank the Upper Austrian State Government and the Institut Suchtprävention - pro Mente Oberösterreich for providing us with anonymized micro data from large-scale mystery shopping studies. Financial support from the Christian Doppler Laboratory "Aging, Health and the Labor Market" is gratefully acknowledged. The usual disclaimer applies.
} 


\section{INTRODUCTION}

Europe has the highest level of alcohol consumption in the world. In 2016, more than 10.3 million disability-adjusted life-years were lost due to alcohol abuse in the EU+ (European Union member states, Norway and Switzerland) (World Health Organization, 2019). More than 10 percent of all deaths in Europe are attributable to alcohol abuse (World Health Organization, 2018). ${ }^{1}$ The comparatively low minimum legal drinking ages (MLDA) in Europe are often considered as one explanation for the higher prevalence of teenage binge drinking relative to the US. While most European countries uphold an MLDA of 18 years, some countries, such as Austria, Belgium, Denmark, Germany, or Switzerland, allow on- and off-premise sales of beer and wine to teenagers as young as 16 years of age. Critics of a low MLDA argue that an early onset of drinking can have detrimental long-run effects on both physical and mental health, since the developing brain is particularly vulnerable to the impact of alcohol (Ewing et al., 2014). In contrast, proponents argue that allowing teenagers the experience of drinking at an earlier age results in more responsible alcohol consumption.

Over the last decade, we have witnessed rising interest in the impact of MLDA regulation on risky behavior and health. Many studies use survey data to investigate the impact of the MLDA on alcohol and drug consumption (Carpenter et al., 2007; Crost and Guerrero, 2012; Yörük and Yörük, 2011, 2013; Crost and Rees, 2013; Deza, 2015). Studies that use administrative data typically focus on the impact of the MLDA on mortality, in particular fatal accidents (Dee, 1999; Carpenter and Dobkin, 2009; Carpenter et al., 2016), but also crime (Carpenter and Dobkin, 2015; Hansen and Waddell, 2018; Chalfin et al., 2019) or schooling (Carrell et al., 2011; Lindo et al., 2013). Due to data constraints, only few studies were able to investigate morbidity effects of the MLDA, although these effects constitute a major cost factor in health systems (Carpenter and Dobkin, 2017; Callaghan et al., 2013). Moreover, the existing evidence on the effects of MLDA regulation stems almost exclusively from the US or Canada, where the MLDA is considerably higher than in Europe. ${ }^{2}$ Finally, even though MLDA regulation might have varying impacts across the socioeconomic distribution, little is known about these potentially heterogeneous effects. This is not least due to a lack of access to administrative data on teenage health outcomes that can be linked to data on parental characteristics.

We apply a regression discontinuity (RD) design to comprehensively study the impact of a particularly low MLDA of 16 years in Austria, a country with very high alcohol consump-

\footnotetext{
${ }^{1}$ There is a larger literature on the detrimental effects of heavy alcohol use. Recent design-based studies evaluate its impact on hospitalizations among young people (Marcus and Siedler, 2015); accidents, emergency attendances, and arrests (Francesconi and James, 2019); as well as mortality (Bhattacharya et al., 2013; Yakovlev, 2018; Kueng and Yakovlev, 2021). Nilsson (2017) examines the effect of prenatal exposure to heavy drinking on longterm economic outcomes.

${ }^{2}$ The notable exceptions analyze the impact of a decrease in the MLDA from 20 to 18 in New Zealand (Boes and Stillman, 2013, 2017; Conover and Scrimgeour, 2013), the impact of an MLDA of 18 in Australia (Lindo et al., 2016), and the impact of a two-part MLDA of 18 and 20 in Sweden (Heckley et al., 2018) on hospitalizations and mortality. Only recently, the first papers appeared that investigate MLDA effects in European countries with a low MLDA of 16 (Datta-Gupta and Nilsson, 2020; Dehos, 2020; Kamalow and Siedler, 2019).
} 
tion by international comparison. We start with rich survey data from the European School Survey Project on Alcohol and Other Drugs (ESPAD) to understand the impact of the MLDA on teenagers' self-reported drinking behavior. The detailed information provided in the survey data allows us to go beyond average effects and estimate MLDA effects along the quantity and frequency of drinking distribution. In a next step, we use administrative data from a universal health insurance provider to investigate the effects of the MLDA on alcohol-related hospitalizations. In all analyses, we study heterogeneous effects by socioeconomic background and gender. In a final step, we provide evidence on the mechanisms underlying these effects. In particular, we ask to what degree the MLDA restricts access to alcohol. To this end, we obtained data from an annual large-scale field study, which sends underage test buyers to retailers in an attempt to buy alcohol. Additionally, we examine information provided in the ESPAD on teenagers' perceived access to alcohol as well as attitudes towards alcohol.

Our results show that, upon gaining legal access to alcohol, teenagers significantly increase the frequency and intensity of drinking, which results in negative health effects. The probability of drinking alcohol on at least one day during the last week increases by around 12 percentage points, the probability of drinking at least two days increases by 9 percentage points, and the probability of drinking on at least three days increases by 4 percentage points. In terms of quantities, we find that the probability of consuming at least 180 to 240 grams of pure alcohol (which corresponds to an extra nine to twelve pints of beer) during the last week increases by 10 percentage points. The MLDA effects are larger for boys and for teenagers with low socioeconomic background. This change in drinking behavior results in negative health effects. We find that the probability of being hospitalized with an alcohol intoxication increases by 0.036 percentage points or 42 percent at the MLDA cutoff. Again, these effects are larger for boys and for teenagers with low socioeconomic background. Interestingly, these socioeconomic gradients are not visible prior to gaining legal access to alcohol. Instead, they emerge at the MLDA cutoff, become statistically significant and economically meaningful, and then remain visible until the age of 22 . These results are robust to using different functional forms and kernel weighting techniques. Teenagers in families with a history of severe alcohol abuse seem to be a special case: we present evidence that suggests that they imitate their parents' behavior and engage more often in excessive drinking, regardless of whether they have already reached the MLDA.

Investigating the mechanisms behind these effects, we show that MLDA legislation does not severely impede teenagers' access to alcohol. The mystery shopping data indicate that about 25 percent of retailers sell even hard liquor to underage customers. When asking teenagers more generally how difficult it is to access alcohol, the MLDA legislation seems to be even less binding: Roughly 85 percent of teenagers below 16 years of age perceive access to non-distilled alcohol as easy. This set of results suggests that the negative impact of MDLA legislation on alcohol consumption can hardly be fully explained by restrictions to alcohol access. Interestingly, the share of teenagers who perceive regular heavy drinking at weekends as risky significantly 
declines from 70 to 60 percent at the MLDA cutoff too. We argue that this might reflect a normative impact of the legislation. Teenagers below 16 years of age may simply feel obliged to obey and abstain from drinking despite its availability. Once drinking becomes legally allowed and also socially more accepted, teenagers change their attitudes towards alcohol and drink more frequently and more intensely.

Comparing our findings to the US literature, we find that the jump in binge drinking at the low MLDA of 16 in Austria is about 25 percent larger than the jump at the MLDA of 21 in the US. At the same time the binge drinking incidence for teenagers slightly below the MLDA cutoffs is clearly higher in Austria than in the US (in Austria, the incidence below the age-16 cutoff is 50 percent, in the US it is 33 percent below the age- 21 cutoff). This pattern speaks against the argument that a low MLDA helps teenagers to ease into drinking and consume alcohol responsibly (Wechsler and Nelson, 2006).

Most closely related to our work are the recent papers by Datta-Gupta and Nilsson (2020), Dehos (2020), and Kamalow and Siedler (2019) who investigate MLDA effects in European countries with a low MLDA of 16. Datta-Gupta and Nilsson (2020) show that the introduction of a low MLDA of 15 in Denmark and the following increases to 16 and 18 (for hard liquor) reduced injuries but had no significant impact on alcohol intoxication. The authors find different responses for boys and girls, but no consistent differences across socioeconomic groups. An important difference between Datta-Gupta and Nilsson (2020) and our setting is that alcohol is very cheap in Austria, in particular in comparison to Denmark and the other Scandinavian countries, which should be particularly relevant for the consumption decision of teenagers whose budget is limited. Moreover, Datta-Gupta and Nilsson (2020) use a difference-in-differences setup to estimate the impact of changes in the MLDA. In contrast, we apply an RD design and thus exploit a different margin of the MLDA treatment. Dehos (2020) and Kamalow and Siedler (2019) study the German case with very similar MLDA regulations as Austria. Alcohol prices are lower in Germany than in Denmark, which makes Germany more comparable to Austria. Similar to our paper, Dehos (2020) and Kamalow and Siedler (2019) use an RD approach to estimate the MLDA effects. Kamalow and Siedler (2019) find at most minor impacts of the MLDA on alcohol-related traffic fatalities and other causes of death in administrative data, although they do find a significant change in drinking behavior using survey data. Dehos (2020) uses survey data to confirm the significant change in drinking behavior at the MLDA. Furthermore, using administrative crime records from two German states, he provides evidence for an increase of crime under the influence of alcohol at the MLDA cutoff. While Dehos (2020) and Kamalow and Siedler (2019) focus on crime and mortality, respectively, we analyze alcoholrelated morbidity. Further, we add to these papers by investigating heterogeneities by gender and socioeconomic status. Finally, we combine survey and administrative data with unique data from a field study with mystery shoppers to better understand the mechanisms.

The remainder of the paper is structured as follows. Section II provides background information on alcohol consumption and MLDA laws in Austria. Section III introduces the survey 
and administrative data used, while Section IV presents the RD design that we apply to estimate the causal effects of the MLDA on drinking and health. In Section V, we present the empirical results. In Section VI, we compare adolescent drinking behavior in Austria and the US. This helps to relate our results to the existing US-dominated literature. Section VII concludes the paper.

\section{BACKGROUND}

\section{II.1. Alcohol consumption in Austria}

Over the past 60 years, alcohol consumption has markedly converged across countries. The left panel of Figure 1 plots per capita consumption of pure alcohol in liters for several Western industrialized countries from 1960 to 2014 . $^{3}$ While France and Italy started at very high levels, they have substantially reduced alcohol consumption between 1960 and 2014. Great Britain and the US, on the other hand, started at lower levels, but have seen increasing consumption over this period.

To better understand the intensity of drinking among people who generally drink alcohol, it is worthwhile to investigate patterns of binge drinking. A common measure used to this end is the share of drinkers ( 15 years and older), who have had at least 60 grams of pure alcohol on at least one occasion during the past 30 days. Note that 60 grams of alcohol correspond to six standard drinks or to roughly half-a-litre of wine or three pints of beer, respectively. The right panel of Figure 1 shows that the share of people having had a binge drinking incidence during the past month varies substantially across countries. ${ }^{4}$ While binge drinking is rather uncommon in New Zealand or Italy, around a quarter of adults in the US experienced at least one heavy drinking incidence during the past month. In Great Britain, even every third person who drinks alcohol had at least one binge drinking incidence during the past month.

Figure 1 shows that Austria stands out in both average alcohol consumption and the occurrence of binge drinking among regular drinkers. In the left panel, we observe that Austria's per capita consumption of pure alcohol was already at a rather high level of 8.7 liters in 1960 and has increased even further over the following decades. With a per capita consumption of 10.4 liters in 2014, Austria has a higher alcohol consumption level than any other country depicted in this figure. In the right panel, we see that more than 50 percent of all drinkers aged 15 and older in Austria had at least one binge drinking incidence during the past month. This number is considerably higher than in any other country listed in this figure. These facts make Austria a particularly interesting country to study the impact of a low MLDA on alcohol abuse.

\footnotetext{
${ }^{3}$ The per capita consumption variable does not exclude children. Consequently, average alcohol consumption levels of adults are clearly higher than depicted here. The data have been collected by Holmes and Anderson (2017).

${ }^{4}$ The data from 2010 are published by World Health Organization Global Health Observatory (GHO).
} 
FIGURE 1 - Alcohol consumption: international comparison
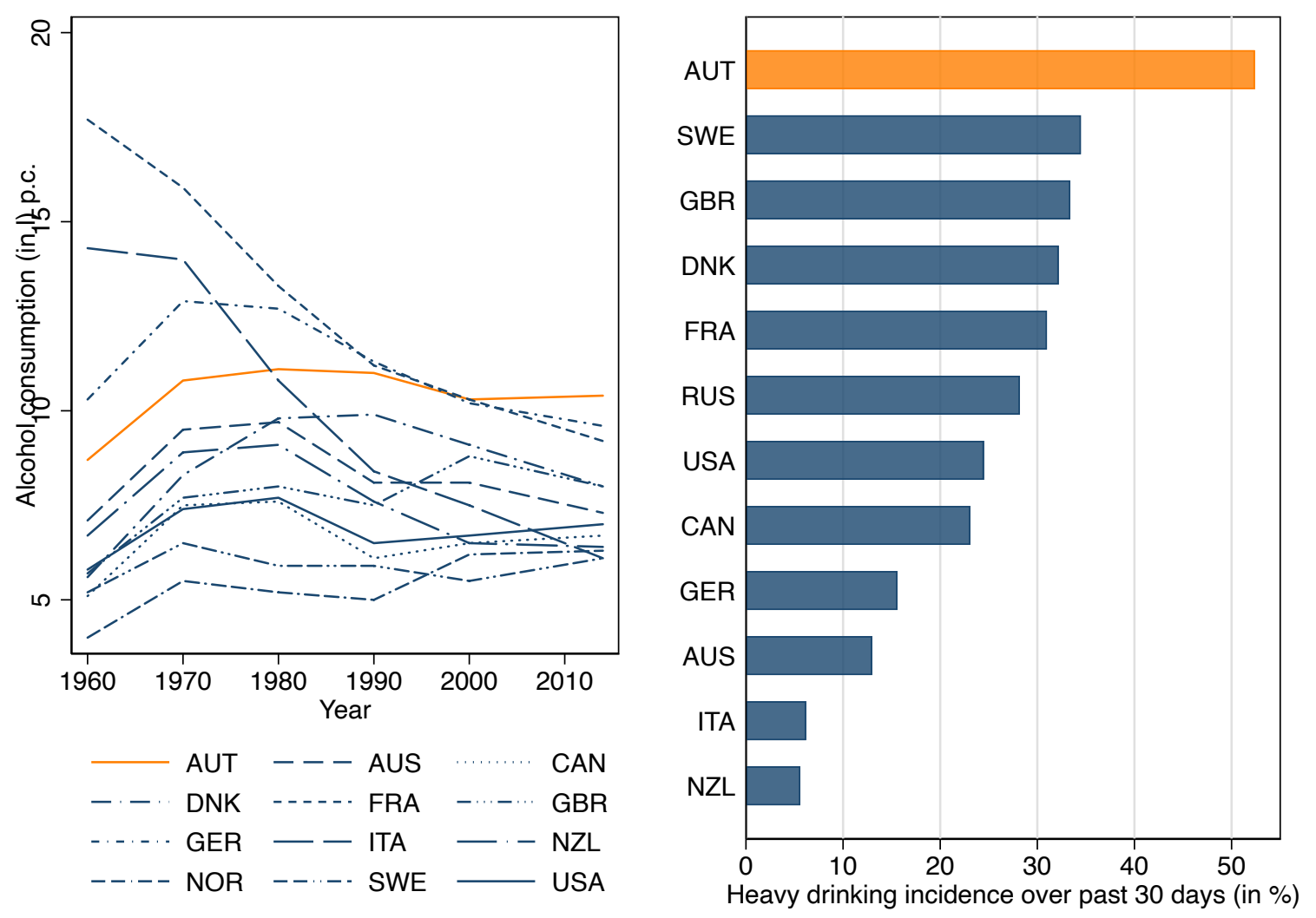

Notes: Our World in Data. The left panel depicts per capita alcohol consumption in liters across countries from 1960 to 2014. The right panel shows the incidence of heavy drinking among adult drinkers in percent over the last 30 days across countries in 2010.

\section{II.2. Austria's MLDA laws}

In Austria, legal access to alcohol is regulated by MLDA laws as part of the Law for the Protection of Children and Young People. Before the laws were harmonized in 2019, MLDAs varied across the nine Austrian federal states. Most states permitted teenagers to legally access non-distilled alcohol, such as beer and wine, at the age of 16, and distilled alcohol at the age of 18. ${ }^{5}$ The states of Burgenland, Lower Austria, and Vienna allowed universal legal access to both non-distilled and distilled alcohol at the age of 16 (to be discussed in detail below). As part of the harmonization process in 2019, the age limits were set to 16 for non-distilled alcohol and 18 for distilled alcohol country-wide.

Violations of the law are classified as an administrative offense, and state-specific laws define sanctions in case of non-compliance. The severity of these sanctions vary depending on whether minors, adults, or entrepreneurs violate the law (see Uhl et al., 2020, Table 5.2). Noncompliance of teenagers is defined as acquiring or consuming alcoholic beverages below the

\footnotetext{
${ }^{5}$ This gradual access to alcohol depending on its alcohol content can also be found in other European countries such as Belgium, Denmark, Germany, or Sweden (see https://fra.europa.eu/en/publication/2017/ mapping-minimum-age-requirements/purchase-consumption-alcohol).
} 
MLDA threshold, or providing other teenagers younger than the threshold with alcoholic beverages. Adults violate the law if they provide minors with alcohol or if they neglect their obligations as legal guardian or person in charge. In case of violation of the law, authorities may require teenagers to participate in a consultation meeting or to do community service. Moreover, monetary fines between Euro 200 and 500 can be imposed. For adults and entrepreneurs, the legally defined maximum penalty is significantly higher (up to Euro 20,000). ${ }^{6}$ In case of non-provision, jail sentences of up to six weeks can be imposed. Moreover, repeated violations by entrepreneurs and event organizers must be disclosed to the authorities providing business and event licenses. Importantly, according to police statements, first-time offending minors typically have to participate in a consultation meeting or pay a small fine if they fail to attend the meeting (about Euro 50), while adults and entrepreneurs providing alcohol are usually hard to prosecute.

\section{DATA}

\section{III.1. Survey data}

To investigate the impact of Austria's MLDA on teenage drinking behavior, we rely on data from the European School Survey Project on Alcohol and other Drugs (ESPAD). ${ }^{7}$ When ESPAD started in 1995, 20 countries took part in this project that aims at collecting cross-country information on teenage substance use. By 2015, the number of participating countries has increased to 35 . ESPAD conducts surveys every four years. For our empirical analysis, we use data from the Austrian country sample of 2015-that is, from the fifth wave of ESPAD.

Our country sample consists of pupils in the $9^{\text {th }}$ and $10^{\text {th }}$ grades from all types of schools (except for special needs schools) who were born between 1997 and 2001. Given the dual system of vocational education in Austria, where apprentices attend vocational school once per week while already being employed in a company, we do not only observe pupils who stay in school but also those who choose a vocational track. ${ }^{8}$ The survey was conducted via an online questionnaire between March and July 2015. ${ }^{9}$ Since the survey was conducted in school, only teenagers who were present at the day of the survey are observed. ${ }^{10}$

\footnotetext{
${ }^{6}$ The maximum fine for for adults varies between Euro 700 and 20,000, for adults with the intention of making a profit from providing alcohol between Euro 2,500 and 20,000. For entrepreneurs and event organizers, fines range from Euro 3,630 to 20,000.

${ }^{7}$ See Guttormsson et al. (2016) for more details on the methodology of ESPAD.

${ }^{8}$ The latter we observe in grade 9 in pre-vocational schools (ISCED level 3G) and in grade 10 in vocational schools for apprentices (ISCED level 3V). We only miss pupils who drop out after grade 9 (which is the end of compulsory schooling) and neither continue school nor start a vocational training. This applies only to a small share of pupils. In Appendix Figure A.1, we plot the number of students in the school year 2019/2020 in Upper Austria by age. The number of teenagers in any school is roughly constant through ages 15 and 16, suggesting that few students leave school at that age (assuming similar cohort sizes).

${ }^{9}$ Note that, due to ESPAD being collected in Spring/Summer, it may not be representative for all-year round drinking habits. However, our administrative data are available for the whole year, and we find little evidence for seasonality in these data.

${ }^{10}$ Strizek et al. (2016) explain the details of the ESPAD 2015 Austrian country sample.
} 
TABLE 1 - Summary statistics of the ESPAD data

\begin{tabular}{|c|c|c|c|c|c|c|c|c|c|}
\hline & \multicolumn{3}{|c|}{ All } & \multicolumn{3}{|c|}{ Age $<16$} & \multicolumn{3}{|c|}{ Age $>16$} \\
\hline & Mean & S.D. & $n$ & Mean & S.D. & $n$ & Mean & S.D. & $n$ \\
\hline Days drinking $(7 \mathrm{~d})$ & 0.85 & 1.16 & 7,289 & 0.70 & 1.04 & 4,191 & 1.06 & 1.26 & 3,098 \\
\hline Grams pure alcohol (7d) & 77.66 & 158.42 & 7,289 & 53.77 & 118.96 & 4,191 & 109.98 & 195.19 & 3,098 \\
\hline Heavy drinking (30d) & 0.53 & 0.50 & 7,727 & 0.45 & 0.50 & 4,450 & 0.62 & 0.48 & 3,277 \\
\hline Daily drinking risky & 0.64 & 0.48 & 7,428 & 0.63 & 0.48 & 4,287 & 0.66 & 0.47 & 3,141 \\
\hline Heavy drinking risky & 0.67 & 0.47 & 7,306 & 0.71 & 0.46 & 4,210 & 0.62 & 0.49 & 3,096 \\
\hline Easy access non-distilled alc. & 0.88 & 0.33 & 7,712 & 0.84 & 0.37 & 4,441 & 0.93 & 0.25 & 3,271 \\
\hline Easy access distilled alc. & 0.70 & 0.46 & 7,706 & 0.63 & 0.48 & 4,436 & 0.78 & 0.42 & 3,270 \\
\hline Age (years) & 15.90 & 0.76 & 7,748 & 15.36 & 0.37 & 4,462 & 16.64 & 0.47 & 3,286 \\
\hline Female & 0.53 & 0.50 & 7,748 & 0.54 & 0.50 & 4,462 & 0.51 & 0.50 & 3,286 \\
\hline High SES & 0.64 & 0.48 & 5,801 & 0.65 & 0.48 & 3,292 & 0.61 & 0.49 & 2,509 \\
\hline
\end{tabular}

Notes: ESPAD 2015, Austria. The table presents summary statistics of under and over 16 year olds. Survey participants that turn 16 in the month of the interview are dropped from the sample.

Descriptive statistics of the outcome variables and covariates used in the empirical analysis can be found in Table 1. Respondents are, on average, 16 years old, all are at least 14 and younger than 18 years, ${ }^{11} 53$ percent are girls, and 64 percent state that their mother completed at least upper secondary schooling. The latter we use as a proxy for high socioeconomic background. We also have information on the type of school, and schools and classes within schools can be identified uniquely. Moreover, the data include information on the state in which the school is located. Since we did not find any statistically significant differences in the MLDA effects on drinking behavior between states with sharp (non-distilled and distilled alcohol at age 16) and staggered (non-distilled alcohol at age 16, distilled alcohol at age 18) MLDA regimes (see Appendix Table A.1), we pool all states in the following analyses. While the ESPAD sample is not huge, power calculations (Schochet, 2009) show reasonable minimum detectable effect sizes. ${ }^{12}$

The data set is suitable for our research question because students are explicitly asked about their drinking behavior, their perception of related risks and harms, and how easy their access is to non-distilled and distilled alcohol. In particular, students state on how many of the last seven days prior to the survey they consumed alcoholic beverages; they also list the quantity and type of alcoholic beverages. The Austrian ESPAD staff uses this information and computes grams of pure alcohol consumed during the last seven days assuming an average alcoholic content of 5 percent for beer, 4.5 percent for alcopops, 12 percent for wine, and 38 percent for spirits. Additionally, students are asked how often they had five or more alcoholic drinks during the last 30 days. We generate a dichotomous variable that indicates whether a student had five or more alcoholic drinks in one occasion at least once during the last 30 days. Students also assess the risk of daily drinking, i.e., having one or more drinks every day, and the risk of heavy

\footnotetext{
${ }^{11}$ See Appendix Figure A.2 for a detailed frequency distribution over age in months.

${ }^{12}$ For instance, assuming a power level of 0.8 , a significance level of 0.05 , and sample sizes of 4,462 on the left side and 3,286 on the right side of the cutoff, the minimum detectable effect size for past-week drinking days is only 0.01 . This variable has a sample mean of 0.85 and a standard deviation of 1.16 .
} 
drinking at weekends, i.e., having five or more drinks nearly every weekend, by picking one out of four categories (no risk, slight risk, moderate risk, great risk). We create an indicator variable that takes on the value of one if students select the category "moderate risk" or "great risk", and zero otherwise. Finally, students evaluate how difficult it would be for them to get access to non-distilled and distilled alcohol by picking one out of five categories (impossible, very difficult, difficult, rather easy, very easy). We construct an indicator variable equal to unity if they deemed it "rather easy" or "very easy" to obtain the respective type of alcohol, and zero otherwise.

To avoid that students give socially desirable answers and under-report (or exaggerate) drinking, the initiators of ESPAD made sure that data collection is truly anonymous. This is indeed one of the most important design features, since it is at the very heart of the ESPAD survey to obtain reliable information on teenage drug and alcohol use. The data from Austria were collected via a web survey at school and immediately stored on a central server that could only be accessed by ESPAD's research team. To preserve anonymity, students used anonymous passwords. The teachers were told to explicitly stress the anonymity of data collection. Moreover, teachers were instructed to not walk around in the classroom while the students completed the survey. Anonymity was handled in a satisfactory way in all countries and students did not raise any serious doubts with respect to anonymity issues (Guttormsson et al., 2016). Finally, the survey contains several questions that allow checking for logical consistency, the likelihood of over-reporting, and the likelihood of under-reporting. For Austria, as for most other countries taking part in the ESPAD survey, there is no evidence that under- or over-reporting is a serious issue that might invalidate the results of the survey. ${ }^{13}$ Also, the fact that drinking and even binge drinking rates of children below the MLDA are so high shows that the children in the ESPAD sample have no problem reporting behavior that is, in fact, illegal. This suggests that desirability bias does not seem to play a large role here.

\section{III.2. Administrative data}

In addition to the survey data, we use administrative data from the Austrian healthcare system. Austria has a Bismarckian welfare system which provides universal access to high-quality healthcare. Austrian residents have mandatory health insurance administered through nine federal state-specific regional health insurance funds. We use information from the Upper Austrian Health Insurance Fund (UAHIF). ${ }^{14}$ The UAHIF covers all private-sector workers, their dependents, and all non-employed residents. It provides insurance for around 1 million people, which

\footnotetext{
${ }^{13}$ The share of students who claim having consumed the dummy drug 'Relevin' is as low as 0.3 percent in the Austrian sample. Moreover, survey respondents are asked whether they would truly report cannabis consumption in the questionnaire if they really consumed it. The share of respondents who would definitely or rather not report drug use is roughly 15 percent; yet, we do not observe any discontinuity in this share at the cutoff age of 16 .

${ }^{14}$ Upper Austria is one of nine federal states in Austria and comprises about one sixth of the Austrian population and work force.
} 
represent 75 percent of the Upper Austrian population. ${ }^{15}$

We compile a panel data set for the universe of live births between 1991 and 1995 in Upper Austria. ${ }^{16}$ This gives us a sample of 91,208 teenagers, whom we observe between the age of 13 and 22. Our panel data set comprises up to 54 entries, one for every two-month age bin in which the teenager is insured with the UAHIF. Although we follow teenagers over a relatively long time span, sample attrition is low. We observe 89.8 percent of teenagers over the entire age range, 93.2 percent we can track for at least 8 out of 9 years. The main reason for panel attrition is parents switching to an employer in a different federal state or leaving the private sector.

The UAHIF data include detailed information on inpatient and outpatient healthcare services at the individual level. Our main outcome is whether the teenager is hospitalized with an alcohol intoxication. This is indicated by two ICD-10 diagnosis codes: T51 ('Toxic effect of alcohol') and F10.0 ('Acute intoxication due to use of alcohol'). Importantly, the ICD-10 codes are recorded for inpatient treatments only, which means that we cannot observe alcohol intoxications that were treated in an ambulatory setting. ${ }^{17}$ We note that this may cause our estimates to be biased towards zero because we only observe more serious cases that require hospitalization. Moreover, we only observe primary diagnosis codes. Notably, reimbursement rates for inpatient care are not age-specific and, thus, do not change discontinuously at age 16.

If friends fail to call an ambulance for an underage intoxicated drinker because of fear of reprisal, we could mechanically observe more cases above the age of 16 . While we cannot quantify the number of cases friends fail to call the ambulance, we are not worried that this drives our results. First and foremost, the survey-based evidence, which is not affected by this problem, provides equivalent results. Second, the legal consequences for not calling an ambulance are comparably more severe. Since Austria has a duty to rescue law, friends present at the scene who fail to call the ambulance render themselves liable for prosecution. Thus, for the friends, the "right" thing would be to call help - even if they are below 16 years of age and drunk themselves.

In total, we observe 3,391 intoxications for the teenagers in our data. The unconditional probability that a teenager is hospitalized at least once between age 13 and 22 is 3.2 percent. Of those teenagers that had an intoxication, 89 percent had only one recorded intoxication. Table 2 provides descriptive statistics for our data set. The unconditional probability of having an alcohol intoxication in a specific bimonthly bin is 0.09 percent. This corresponds to roughly 31 teenagers per month. Around 48 percent of the sample are girls, the mothers' average age

\footnotetext{
${ }^{15}$ The remaining 25 percent are civil servants, self-employed, and distinct occupational groups, such as farmers or public teachers. These groups are insured with other statutory health insurance providers.

${ }^{16}$ It should be noted that there is a small discrepancy in the birth cohorts between the survey data (1997 to 2001) and administrative data (1991 to 1995).

${ }^{17}$ The relevant (if not only) points of access for alcohol intoxications are public hospitals. However, this does not mean that all cases come through emergency rooms. All public hospitals in Austria have hospital outpatient departments through which they receive patients (even at night and on weekends). These patients then either receive an outpatient treatment or are admitted to the hospital. Unfortunately, we were unable to find statistics on what share of patients with alcohol intoxications receive outpatient versus inpatient treatment.
} 
TABLE 2 - Summary statistics of the administrative data

\begin{tabular}{|c|c|c|c|c|c|c|c|c|c|}
\hline & \multicolumn{3}{|c|}{ All } & \multicolumn{3}{|c|}{ Age $<16$} & \multicolumn{3}{|c|}{ Age $\geq 16$} \\
\hline & Mean & S.D. & $n$ & Mean & S.D. & $n$ & Mean & S.D. & $n$ \\
\hline Prob. alcohol intoxication $\times 100$ & 0.09 & 2.92 & $3,981,294$ & 0.04 & 2.01 & $1,315,019$ & 0.11 & 3.27 & $2,666,275$ \\
\hline \multicolumn{10}{|l|}{ Covariates } \\
\hline Mother age at birth & 27.34 & 4.77 & $3,981,294$ & 27.27 & 4.77 & $1,315,019$ & 27.38 & 4.77 & $2,666,275$ \\
\hline Girl & 0.48 & 0.50 & $3,981,294$ & 0.49 & 0.50 & $1,315,019$ & 0.48 & 0.50 & $2,666,275$ \\
\hline High SES & 0.69 & 0.46 & $3,981,294$ & 0.69 & 0.46 & $1,315,019$ & 0.70 & 0.46 & $2,666,275$ \\
\hline
\end{tabular}

Notes: UAHIF panel. The table presents summary statistics for 91,208 children observed bimonthly between age 13 and 22 . We distinguish between observations from below the age of 16 and from age 16 and above.

at birth is 27.3 years, and 69 percent of mothers have high socioeconomic status. The latter is determined based on the mother's highest completed education. We define low socioeconomic status as having only compulsory education.

\section{ESTIMATION STRATEGY}

To estimate the causal effect of Austria's low MLDA on teenage drinking behavior and health, we employ a sharp RD design. The estimation equation can be expressed as follows:

$$
Y_{i}=\tau D_{i}+f\left(\text { age }_{i}\right)+\mathbf{x}_{i} \boldsymbol{\beta}+\varepsilon_{i},
$$

where $Y_{i}$ is the outcome variable of teenager $i, f\left(a g e_{i}\right)$ is a smooth function of our running variable age, $D_{i}$ is a dichotomous variable equal to one if teenager $i$ is older than 16 years, and zero else. To construct our preferred estimates, we adopt linear and quadratic specification for $f\left(a g e_{i}\right)$, where we allow the slope terms to be different on each side of the age cutoff. Additionally, we fit nonparametric local linear models as in Hahn et al. (2001). Finally, $\mathbf{x}_{i}$ comprises a set of covariates specified in the results section, and $\varepsilon_{i}$ is a mean-zero error term. Standard errors are clustered at the age (in months) level when using the cross-sectional ESPAD data; when using the administrative data panel, we apply two-way clustering at the individual and the bimonthly age level.

The parameter $\hat{\tau}$ identifies the causal effect of the low MLDA under the assumption that treatment status jumps deterministically and discretely at the threshold of 16 years, whereas all other determinants of $Y_{i}$ run smoothly across the age threshold. The MLDA laws clearly state that in all Austrian states teenagers gain legal access to non-distilled alcohol at their $16^{\text {th }}$ birthday, i.e., treatment jumps deterministically and discretely at age 16 . However, we have to make sure that we assign teenagers correctly to the left or to the right of the MLDA threshold. This means that we need to precisely measure the teenagers' age. The administrative data allow us to do so, since we have information on the exact date of birth and the exact date of any hospitalization with acute alcohol intoxication for all teenagers. Yet, in the ESPAD survey data, we only know the participants' year and month of birth. To avoid wrong treatment assignment, we drop all teenagers who turn 16 at some (unknown) day in the month of the ESPAD interview. 
Lee and Lemieux (2010) discuss RD settings like ours that exploit discontinuities in age with inevitable treatment. Three points are worth discussing. First, since all individuals get treated at age 16, our RD approach does not allow for estimating long-run effects of the MLDA. Second, since we observe the same individuals over time in our administrative panel data set, balancing tests would not be meaningful. Third, and probably most importantly, we would overestimate the effect of gaining legal access to alcohol if teenagers systematically reduced drinking in the last weeks prior to their $16^{\text {th }}$ birthday. As we will show later, we do not find any evidence for such behavior.

The RD approach would yield biased estimates if other age-based regulations confound the MLDA at age 16. While Austria has a number of age-based regulations other than the MLDA, none of them can plausibly cause a discontinuity in alcohol-related outcomes at age 16. Appendix Table A.2 provides an overview. Several important age-based regulations do not kick in at age 16. In particular, the general age of consent is 14 , compulsory schooling ends after nine grades, when students are about 15 years of age; the minimum age for a driver's license for mopeds is 15 , for large motorcycles it is 18 , for all motorcycles it is $20 / 24$, and for cars it is $18 .{ }^{18}$ In contrast, the following age-based regulations are at age 16 . We discuss why we do not see them as a threat to our identification strategy.

Smoking Smoking was legal at age 16 during our sample period (later the minimum age was raised to 18). However, based on ESPAD data we do not find any evidence for an increase in smoking at age 16, neither at the extensive nor at the intensive margin (see Appendix Figure A.3). ${ }^{19}$

Minimum age for a driver's license for small motorcycles Since 2013, teenagers are allowed to drive small motorcycles (A1, scooters) from age 16. However, the number of 16 year-olds with a driver's license for these small motorcycles is low. From 2013 to 2015, on average only 174 teenagers gained such a license at age 16 . In comparison, approximately 7,400 adolescents gained a driver's license for mopeds (AM) at age 15, and 7,194 teenagers gained a driver's license for cars (B) at age 18. When we exclude data from 2013 to 2016 from our observation period, our point estimates remain virtually unchanged (see Appendix Table A.3).

Legal age for marriage The legal age for marriage (for either sex) is 18 years of age. Persons at least 16 years of age may also marry upon presentation of written, notarized consent from both parents, provided their spouse is at least 18 years old. However, marriages below 18 years of age are very rare in Austria (see Appendix Table A.4). Between 2010 and 2020, only 9 marriages were recorded where at least one spouse was 16 years old.

\footnotetext{
${ }^{18}$ Teenagers who want to start driving before the age of 18 may undergo so-called L17 training (car license at 17, "early permission to drive vehicles"). In this case, lessons at a driving school can be started from the age of 15 years and 6 months, and a driver's license can be issued at the age of 17 (at the earliest). Since this option is comparably more complicated, and also more costly, most teenagers start to drive at age 18. From 2013-2015, an average of 7,196 Upper Austrian teenagers gained a driver's license for cars (B) at an age of 18, but only 4,895 teenagers gained the "early permission to drive vehicles" at age 17.

${ }^{19}$ This is in line with the evidence provided by Meier et al. (2019), who find no significant effect of minimum legal tobacco purchase age laws on the smoking prevalence among teens in Switzerland or the EU.
} 
Voting age In 2007, the voting age in Austria was reduced from 18 to 16 in Austria. This is also the year when the first cohort in our data (1991) turns 16. However, we consider it highly unlikely that the eligibility to vote could cause a discrete change in drinking behavior; especially since election day and $16^{\text {th }}$ birthday coincide only for a very small share of teenagers.

Curfew hours Until 2019, curfews differed slightly across federal states for teenagers below 16 years (see Appendix Table A.5 for a detailed overview of the regulations in 2017 and before). From 14 years, teenagers are allowed to be out until $11 \mathrm{pm}$, or up to $1 \mathrm{am}$, depending on the federal state. Teenagers between 16 to 18 years of age did (and do) not face curfews, with the exception of the state of Vorarlberg. Thus, there is a small change in curfew hours at age 16 in most states. Outside the curfew hours, teenagers are allowed to be in public spaces (including bars and restaurants). The access to nightclubs and brothels is legal starting from 18 years of age in all states. To provide some evidence whether the change in curfews at age 16 has an impact on our estimates, we exploit the particularity of the state of Vorarlberg. In 2015, the year of the ESPAD interview, Vorarlberg had a curfew from 2 am to 5 am in place for teenagers between 16 to 18 years of age, while all other states did not. Unfortunately, Vorarlberg only accounts for 391 observations in the ESPAD data. Nevertheless, we have analyzed whether the MLDA effects are systematically different in Vorarlberg than in all other states. To this end, we run our RD model and introduce an interaction term between our treatment indicator $D$ and an indicator limited for Vorarlberg, while also allowing the relationship between the running variable and the outcome to differ between Vorarlberg and the other states. Appendix Table A.6 presents the results of this exercise. The interaction $D \times$ limited is insignificant for all four drinking outcomes. In two cases, the sign is negative, in the other two cases, the sign is even positive. Thus, we do not find any evidence that the MLDA effect is systematically different in Vorarlberg than in the other states. This speaks against curfew hours being a confounding factor. However, it might of course be that the 3-hour curfew difference between Vorarlberg and the other states is simply not large enough to yield heterogeneous effects.

In sum, we are confident that we identify an unbiased effect of the MLDA on alcohol consumption and immediate health consequences in our RD approach.

\section{RESULts}

\section{V.1. Effects on drinking behavior}

In a first step, we investigate by how much the frequency of consuming alcohol changes when gaining legal access at age 16. To this end, we make use of detailed information provided by teenagers in the ESPAD survey. In particular, respondents report on how many of the last seven days they drank alcohol. We use this information as the outcome variable in our RD model. Table 3 shows the results of this analysis.

In column (1) of Table 3, we start with a basic RD linear spline specification and find that 
TABLE 3 - Effects on number of days drinking during the last 7 days

\begin{tabular}{lcccc}
\hline & Lin. Spline & Quad. Spline & Quad. Spline & Quad. Spline \\
& $(1)$ & $(2)$ & $(3)$ & $(4)$ \\
\hline Discontinuity & $0.276^{* * *}$ & $0.270^{* * *}$ & $0.276^{* * *}$ & $0.273^{* * *}$ \\
& $(0.047)$ & $(0.068)$ & $(0.068)$ & $(0.069)$ \\
Sex & No & No & Yes & Yes \\
Maternal education & No & No & No & Yes \\
\hline Number of observations & 7,289 & 7,289 & 7,289 & 7,289 \\
Outcome mean & 0.852 & 0.852 & 0.852 & 0.852 \\
\hline
\end{tabular}

Notes: ESPAD 2015, Austria. The table shows RD estimates of the discontinuous shift in the number of days drinking in the last 7 days at age 16. Respondents who turn 16 in the month of the survey are dropped. Maternal Education includes a set of indicators for the mother's highest completed education. Standard errors are clustered at the age (in months) level and shown in parentheses. * $p<0.10, * * p<0.05, * * * p<0.01$.

the number of days teenagers drank alcohol in the last week increases by 0.276 when gaining legal access to alcohol. This effect is statistically significant and economically meaningful. While the average number of days a week teenagers in our sample drink alcohol is 0.852 , this number is 0.712 for teenagers younger than 16 but older than 15 . Thus, the estimated coefficient measured at the age-16 cutoff suggests an increase in alcohol consumption days by roughly 39 percent, on average. When we use a quadratic spline instead of a linear spline specification, the estimates stay virtually identical (column 2). Moreover, the effect is robust to controlling for the teenagers' gender (column 3) and their mothers' education (column 4).

In Figure 2, we investigate the effects along the frequency of drinking distribution and inspect effect heterogeneities by gender and socioeconomic status. In the upper left panel, we plot the average number of days during the last week teenagers drank alcohol by age in months. The resulting discontinuity at the age-16 cutoff provides a graphical depiction of the average effect identified in the RD estimation of Table 3. This graph also provides clear evidence that the jump at the cutoff is not just a birthday party effect. Indeed, the notable and discontinuous level shift in drinking is persistent for many months. In the remaining panels, we report estimates from $\mathrm{RD}$ linear spline distribution regressions. In the upper right panel, we find that the probability of having consumed alcohol on at least one day during the last week increases by roughly 12 percentage points after gaining legal access to alcohol. At the same time, it becomes evident that the effect is not just driven by teenagers now drinking once a week. Rather, we find that the probability of drinking on at least two out of the last seven days significantly increases by around 9 percentage points, while the probability of drinking on at least three out of the last seven days still significantly increases by around 4 percentage points.

The lower two panels of Figure 2 depict these RD distribution regression effects by gender and socioeconomic status. If we focus on a dichotomous variable that only measures whether teenagers consumed alcohol or not during the last seven days, we hardly find any difference between males and females. However, once we inspect effects along the frequency of drink- 
FIGURE 2 - Effect on number of days drinking during the last 7 days
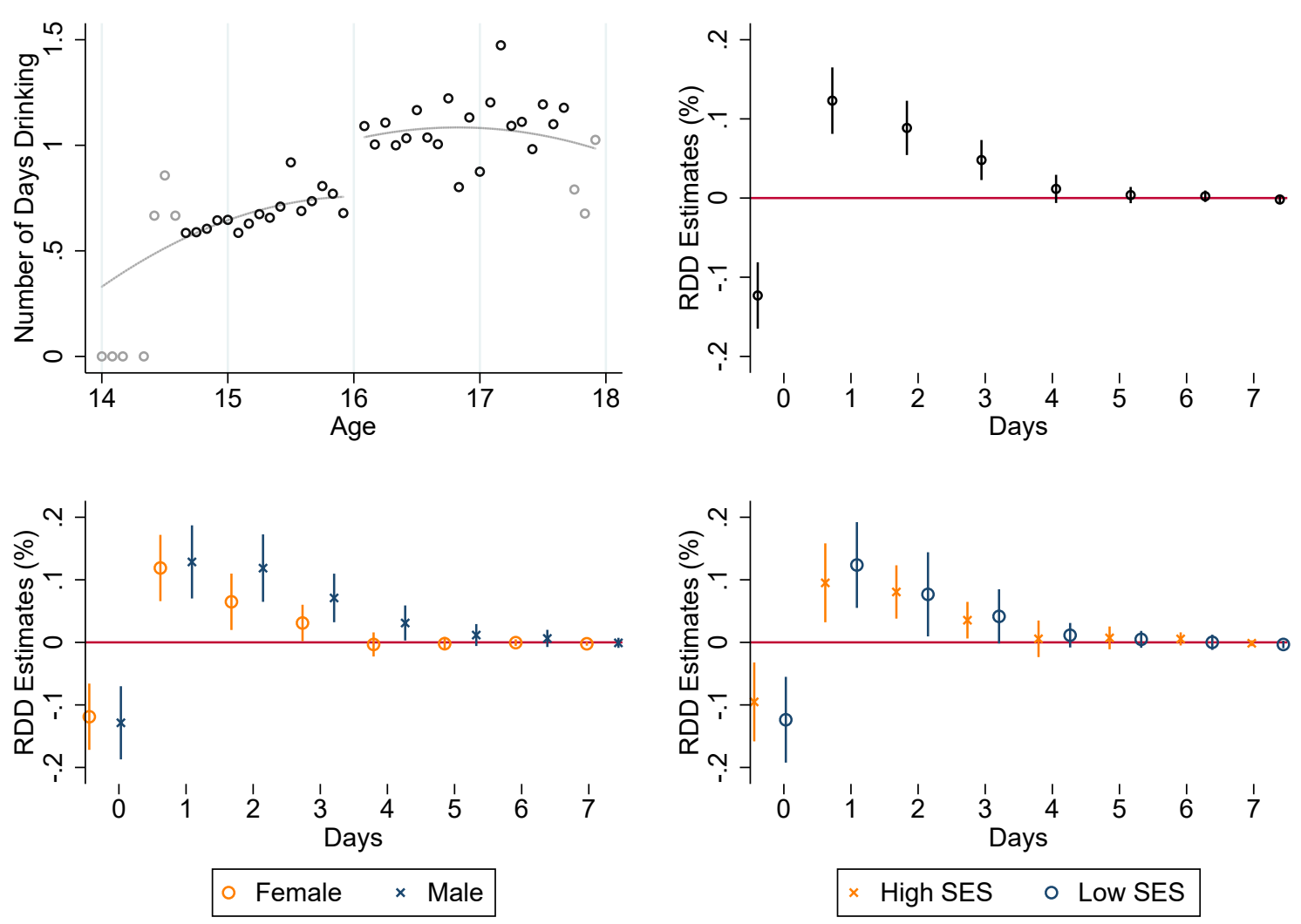

Notes: ESPAD 2015, Austria. The upper left panel plots the average number of days drinking during the last 7 days by age (in months) bins. Respondents who turn 16 in the month of the interview are dropped. Grey circles indicate that the number of observations from the respective age (in months) bin is in the lower quintile of the frequency distribution. The upper right panel shows RD estimates of the effects of the MLDA on $\operatorname{Pr}($ Frequency $\geq X)$ with $X$ being the respective number of days. The bottom left panel shows RD estimates of the effects on $\operatorname{Pr}($ Frequency $\geq$ $X$ ) by gender. The bottom right panel shows RD estimates of the effects on $\operatorname{Pr}($ Frequency $\geq X)$ by socioeconomic status. All regressions include linear age (in months) trends that might be different to the left and to the right of the cutoff (linear spline). Standard errors are clustered at the age (in months) level. The whiskers indicate 95 percent confidence intervals.

ing distribution, we find that gaining legal access to alcohol at age 16 induces boys to drink more often than girls. For example, while the probability of having drunk alcohol on at least two (three) of the last seven days increases by roughly 12 (7) percentage points for boys, it increases by only 6 (3) percentage points for girls. The differences by socioeconomic status are less pronounced than the differences by gender. If at all, it seems that the effect of having drunk alcohol on at least one out the last seven days is slightly larger for low than for high socioeconomic status teenagers. These differences diminish as we move up the frequency of drinking distribution.

Apart from investigating the frequency of drinking, we also look at the quantity of alcohol consumed by teenagers over the last seven days. Survey respondents state the number and types of drinks they had over the last seven days. From this information, one can compute how many 
grams of pure alcohol was consumed during this period. In the upper left panel of Figure 3, we plot the average grams consumed by age in months. We observe a clear and discontinuous jump right at age 16. When gaining legal access, the consumption of pure alcohol increases by around 50 grams, which corresponds to an increase of 90 percent compared to the pre-16 level of 55 grams. These positive effects appear along the whole drinking intensity distribution as can be seen in the upper right panel of Figure 3. For example, the probability of consuming at least 180 to 240 grams of pure alcohol (which corresponds to an extra nine to twelve pints of beer) during the last seven days significantly increases by 10 percentage points. If we just look at a simple indicator variable that is one if no alcohol at all was consumed, and zero if any alcohol was consumed, we do not detect any differences between boys and girls or between high and low socioeconomic background teenagers. However, if we inspect effects across the whole distribution of grams of pure alcohol, a different pattern emerges, as can be seen in the lower two panels of Figure 3. For consumption levels of at least 120 to 240 grams of alcohol and for some very high consumption level categories, the effects are larger for boys than for girls. For consumption levels of at least 20 to 480 grams of alcohol, the effects are larger for teenagers with low socioeconomic background than for teenagers with high socioeconomic background.

To learn more about the impact of the MLDA law on the intensity of drinking, we now look at reported incidences of binge drinking. ESPAD participants state how many times they had five or more alcoholic drinks on one occasion during the last 30 days. The upper left panel of Figure 4 suggests some increase in the incidence of binge drinking at the MLDA cutoff. This is supported by the RD estimates presented in the upper right panel. We find that the likelihood of having had at least one binge drinking occasion during the last 30 days significantly increases by 10 percentage points, while the probability of having had at least three to five occasions significantly increases by 8 percentage points. We even find somewhat smaller yet still significant effects for at least six to nine binge drinking occasions. The graph in the lower left panel shows that boys and girls do not differ in the MLDA effect of having at least one binge drinking occasion in the last 30 days. However, legal access to alcohol induces boys to clearly more often binge drink than girls. The probability of at least three to five binge drinking occasions significantly increases by 10 percentage points for boys but only by 5 percentage points for girls. The heterogeneity with respect to socioeconomic background is somewhat less clear as can be seen in the lower right panel of Figure 4.

A battery of robustness tests and validity checks corroborates our findings. First, we do not find any jumps at placebo cutoffs at ages 15.5 and 16.5 (see Appendix Figure A.4). Second, we perform balancing tests to check that background characteristics of the pupils and their families run smoothly across the cutoff (see Appendix Figures A.5 and A.6). Third, we show that the share of missings in our outcome variables is low and does not change discontinuously at the cutoff (see Appendix Figure A.7). Fourth, we show that the results are robust to using nonparametric methods and alternative ways of calculating confidence intervals following Calonico et al. (2014) and Kolesár and Rothe (2018) (see Appendix Table A.7). 
FIGURE 3 - Effects on grams of pure alcohol consumed during the last 7 days
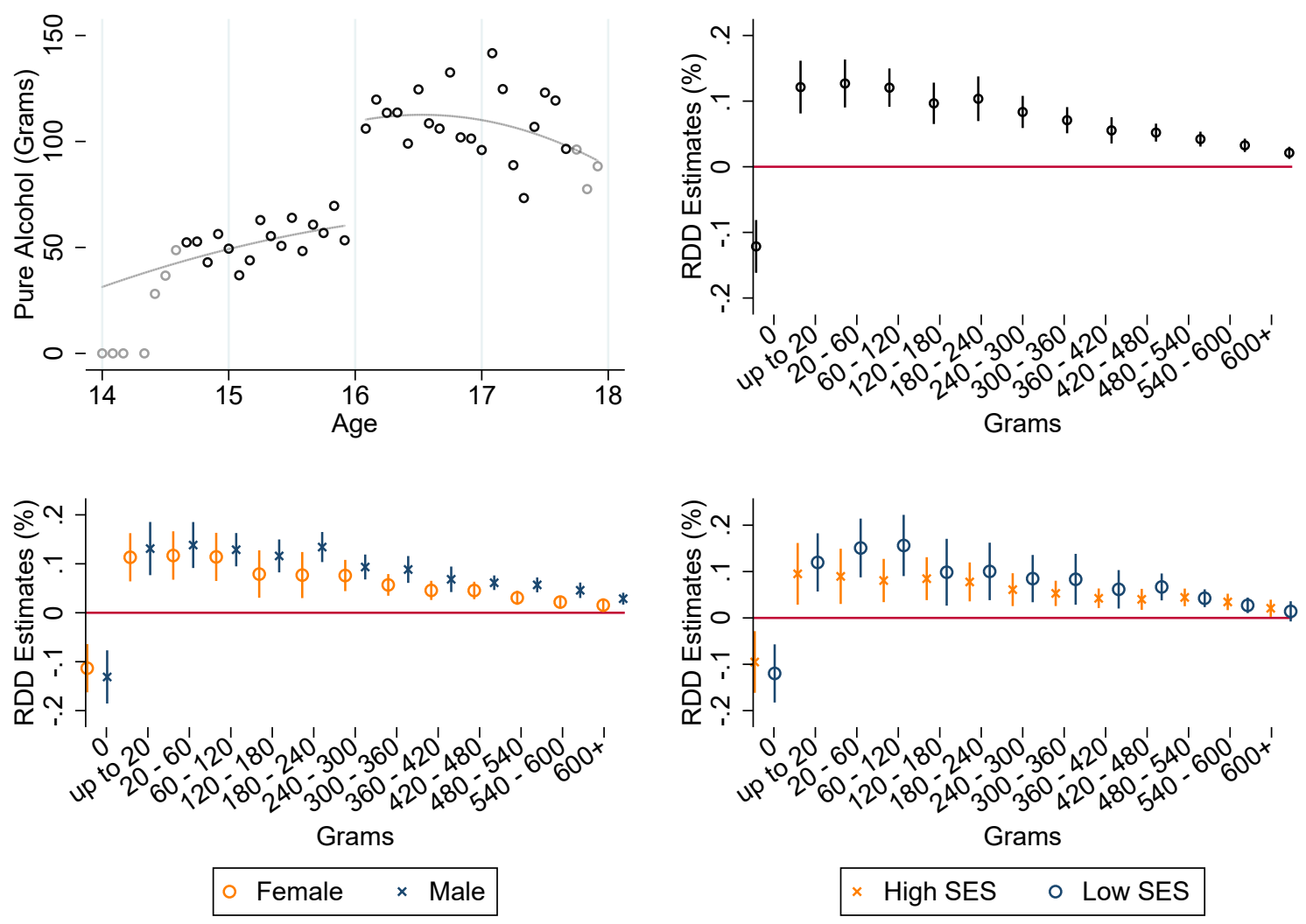

Notes: ESPAD 2015, Austria. The upper left panel plots the average grams of pure alcohol consumed during the last 7 days by age (in months) bins. Respondents who turn 16 in the month of the interview are dropped. Grey circles indicate that the number of observations from the respective age (in months) bin is in the lower quintile of the frequency distribution. The upper right panel shows RD estimates of the effects of the MLDA on $\operatorname{Pr}(\operatorname{Quantity} \geq X)$ with $X$ being the respective category of the amount of pure alcohol in grams. The bottom left panel shows RD estimates of the effects on $\operatorname{Pr}($ Quantity $\geq X)$ by gender. The bottom right panel shows RD estimates of the effects on $\operatorname{Pr}($ Quantity $\geq X)$ by socioeconomic status. All regressions include linear age (in months) trends that might be different to the left and to the right of the cutoff (linear spline). Standard errors are clustered at the age (in months) level. The whiskers indicate 95 percent confidence intervals.

Although the survey data allow us to inspect interesting aspects of teenage drinking behavior, they also come with some drawbacks. In particular, teenagers might under-report alcohol consumption at ages younger than 16, where buying and consuming any kind of alcohol is illegal. At the same time, they might boast and over-report alcohol consumption at ages above 16. As mentioned before, however, the ESPAD initiators took great care that the survey was conducted in a truly anonymous way. Although we do not have any evidence for underor over-reporting from consistency questions that are included in the survey, we cannot fully exclude the possibility of under- or over-reporting. In particular, teenagers might not correctly remember their drinking behavior in the last seven or or even thirty days. This recall bias might systematically differ between treatment and control group if more students under the age of 16 do not drink alcohol at all. To circumvent these problems, we now use administrative data on 
FIGURE 4 - Effects on binge drinking during the last 30 days
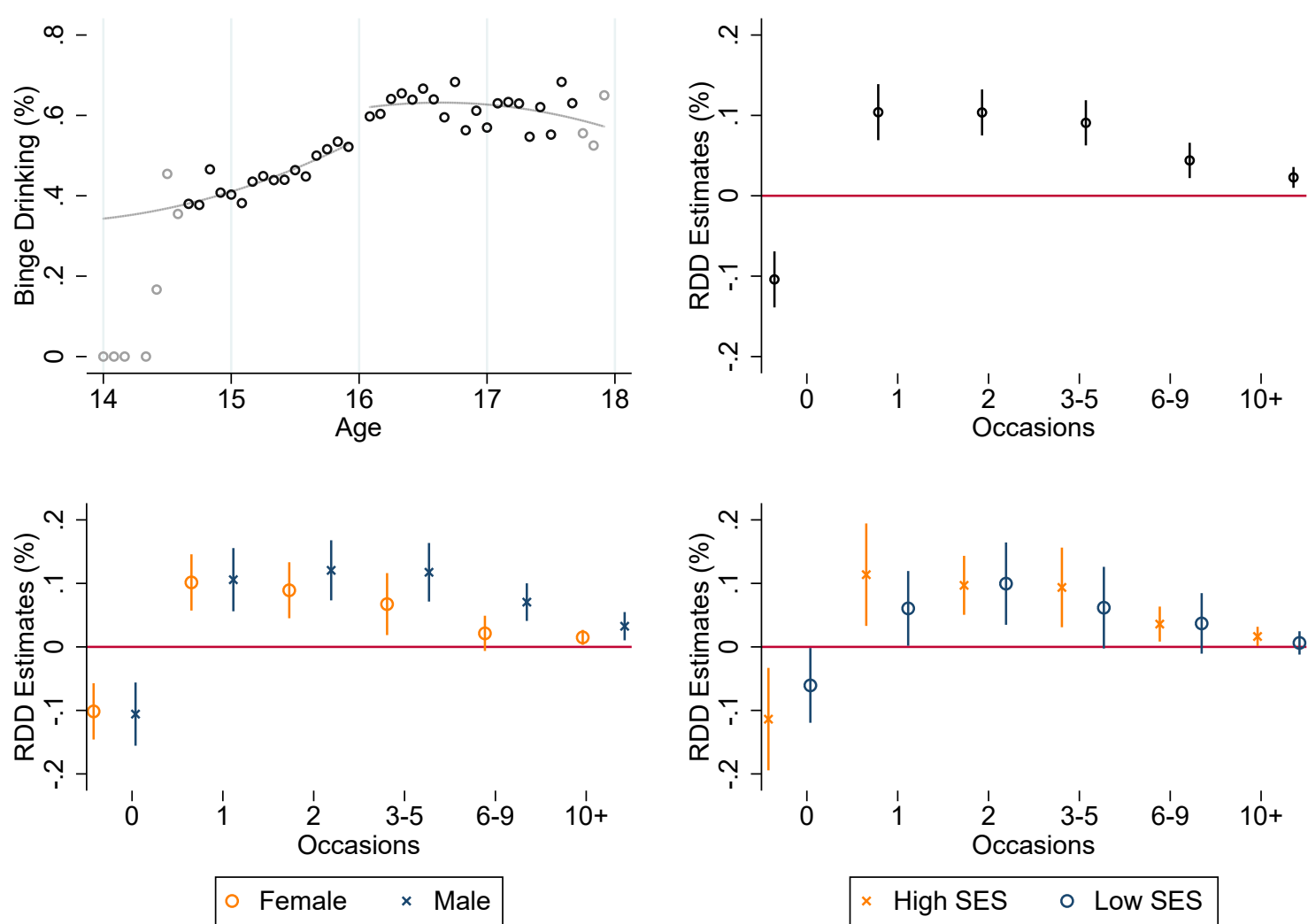

Notes: ESPAD 2015, Austria. The upper left panel plots the share of respondents who report any incidence of binge drinking (five or more drinks in one single occasion) during the last 30 days by age (in months) bins. Respondents who turn 16 in the month of the interview are dropped. Grey circles indicate that the number of observations from the respective age (in months) bin is in the lower quintile of the frequency distribution. The upper right panel shows RD estimates of the effects of the MLDA on $\operatorname{Pr}($ Frequency $\geq X)$ with $X$ being the respective category of the number of binge drinking occasions. The bottom left panel shows RD estimates of the effects on $\operatorname{Pr}($ Frequency $\geq X)$ by gender. The bottom right panel shows RD estimates of the effects on $\operatorname{Pr}($ Frequency $\geq X)$ by socioeconomic status. All regressions include linear age (in months) trends that might be different to the left and to the right of the cutoff (linear spline). Standard errors are clustered at the age (in months) level. The whiskers indicate 95 percent confidence intervals.

hospitalizations due to alcohol intoxication. This morbidity variable is surely a rather drastic and rare health consequence of alcohol consumption - around one in thousand teenagers is admitted to hospital every two months due to alcohol intoxication. However, it is also a relevant and immediate outcome of alcohol abuse and less prone to biases due to misreporting or false recalling.

\section{V.2. Effects on hospitalizations due to alcohol intoxication}

\section{V.2.1. Main results}

Using the administrative data from Upper Austria, we start with a simple graphical depiction of probabilities of being hospitalized with an alcohol intoxication by bimonthly age bins. The 
FIGURE 5 - Probability of being hospitalized with an alcohol intoxication

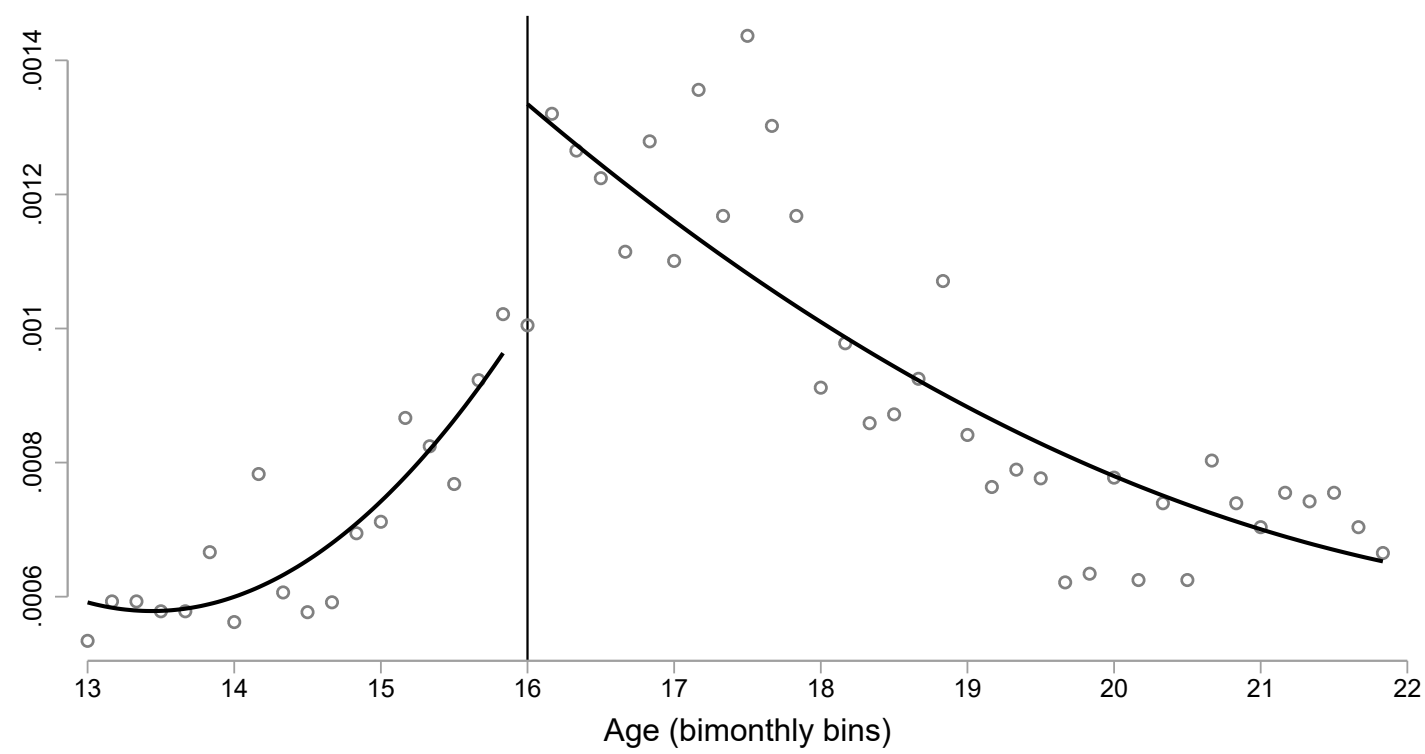

Notes: UAHIF panel. This graph plots mean probabilities of being hospitalized with an alcohol intoxication in a given bimonthly age bin. Probabilities are adjusted for child sex and year fixed effects.

probabilities are computed by dividing the number of hospitalizations due to alcohol intoxication at a given age by the population of teenagers at a given age in Upper Austria (Figure 5). We identify a clear discontinuity right at the cutoff age of 16 at which teenagers gain legal access to non-distilled alcohol. This causes the probability of being hospitalized to jump by roughly 0.04 percentage points. Again, the data clearly show that the level shift in hospitalizations due to alcohol intoxication is not just a birthday party effect, but persists for many months. ${ }^{20}$

To inspect the statistical significance of this first result, we run basic RD regressions as described in Equation (1) and use hospital admission due to alcohol intoxication as an outcome variable. In column (1) of Table 4, we confirm that gaining legal access to alcohol at age 16 increases the probability of being hospitalized with an alcohol intoxication by 0.036 percentage points. This corresponds to a statistically significant and economically meaningful increase of 42 percent. If we distinguish effects by gender, we find that the effect for boys (column 3) is highly significant, and more than two times larger than the marginally significant effect for girls (column 2). At the same time, the discontinuous increase of being hospitalized with an alcohol intoxication is larger for teenagers with low socioeconomic background (column 4) than for those with high socioeconomic background (column 5). Thus, these analyses based on administrative data confirm the drinking behavior pattern we saw in the ESPAD survey data. Particularly boys and low socioeconomic background teenagers react to gaining legal access to alcohol by increasing the frequency and intensity of alcohol consumption, which results in an increased probability of being hospitalized with an alcohol intoxication.

\footnotetext{
${ }^{20}$ Note that hospital staff does not have any incentives to hide alcohol intoxications of underage children; they are, for example, not required to report these intoxications to the police. Thus, the effects cannot driven by misreporting of diagnoses.
} 
TABLE $4-$ Effects on the probability of being hospitalized with an alcohol intoxication

\begin{tabular}{lccccc}
\hline & All & Girls & Boys & Low SES & High SES \\
& $(1)$ & $(2)$ & $(3)$ & $(4)$ & $(5)$ \\
\hline Discontinuity & $0.036^{* * *}$ & $0.023^{*}$ & $0.048^{* * *}$ & $0.042^{* *}$ & $0.033^{* * *}$ \\
& $(0.010)$ & $(0.013)$ & $(0.015)$ & $(0.020)$ & $(0.011)$ \\
Sex & Yes & No & No & Yes & Yes \\
Age at birth fixed effects & Yes & Yes & Yes & Yes & Yes \\
Year fixed effects & Yes & Yes & Yes & Yes & Yes \\
\hline Number of observations & $3,981,294$ & $1,922,550$ & $2,058,744$ & $1,219,008$ & $2,762,286$ \\
Outcome mean & 0.085 & 0.061 & 0.108 & 0.103 & 0.077 \\
\hline
\end{tabular}

Notes: UAHIF panel. Estimates for the discontinuous shift in the probability of having an alcohol intoxication at age 16. All regressions are based on a bimonthly age-bin panel and includes quadratic trends that might be different to the left and to the right of the cutoff (quadratic spline). The RD coefficients are multiplied by 100 to improve readability. Standard errors shown in parentheses are twoway clustered at the individual and the bimonthly age level. $* p<0.10, * * p<0.05, * * * p<0.01$.

In a next step, we inspect the socioeconomic gradient in alcohol intoxications in more detail. Figure 6 shows the discontinuous jump in alcohol intoxications graphically. We plot gender and year fixed effect-adjusted probabilities of being admitted to hospital by socioeconomic status for each age bin. We observe a slightly increasing age trend in the probability of alcohol intoxication that is virtually identical for teenagers with high and low socioeconomic background. At the MLDA cutoff, the discontinuous jump is larger for low socioeconomic background teenagers than for high socioeconomic background teenagers (as we already know from Table 4). Strikingly, this difference by socioeconomic background that emerges at the age of 16 remains observable until the age of 22.

Table 5 tests whether the age-specific socioeconomic differences in the probabilities of being hospitalized with alcohol intoxication are statistically significant. As we saw in Figure 6, these differences are small and far from conventional significance levels below the age of 16 . Once the MLDA is reached, a difference between socioeconomic groups emerges, becomes highly significant at age 17 , and stays statistically significant and of meaningful size until age 22 . At 22, the probability of being hospitalized with alcohol intoxication is 0.104 percent for teenagers with low socioeconomic background and 0.072 percent for teenagers with high socioeconomic background. Thus, the likelihood of being hospitalized with an alcohol intoxication is more than 40 percent higher for teenagers with low than for those with high socioeconomic background.

Figure 7 tests the robustness of the results across four different specifications: a) linear spline regressions, b) quadratic spline regressions, c) nonparametric local linear regressions using uniform kernel weighting, and d) nonparametric local linear regressions using triangular kernel weighting. As can be seen, our findings do not depend on a single specification but are robust to specification changes. 
FIGURE 6 - Probability of being hospitalized with an alcohol intoxication by socioeconomic status

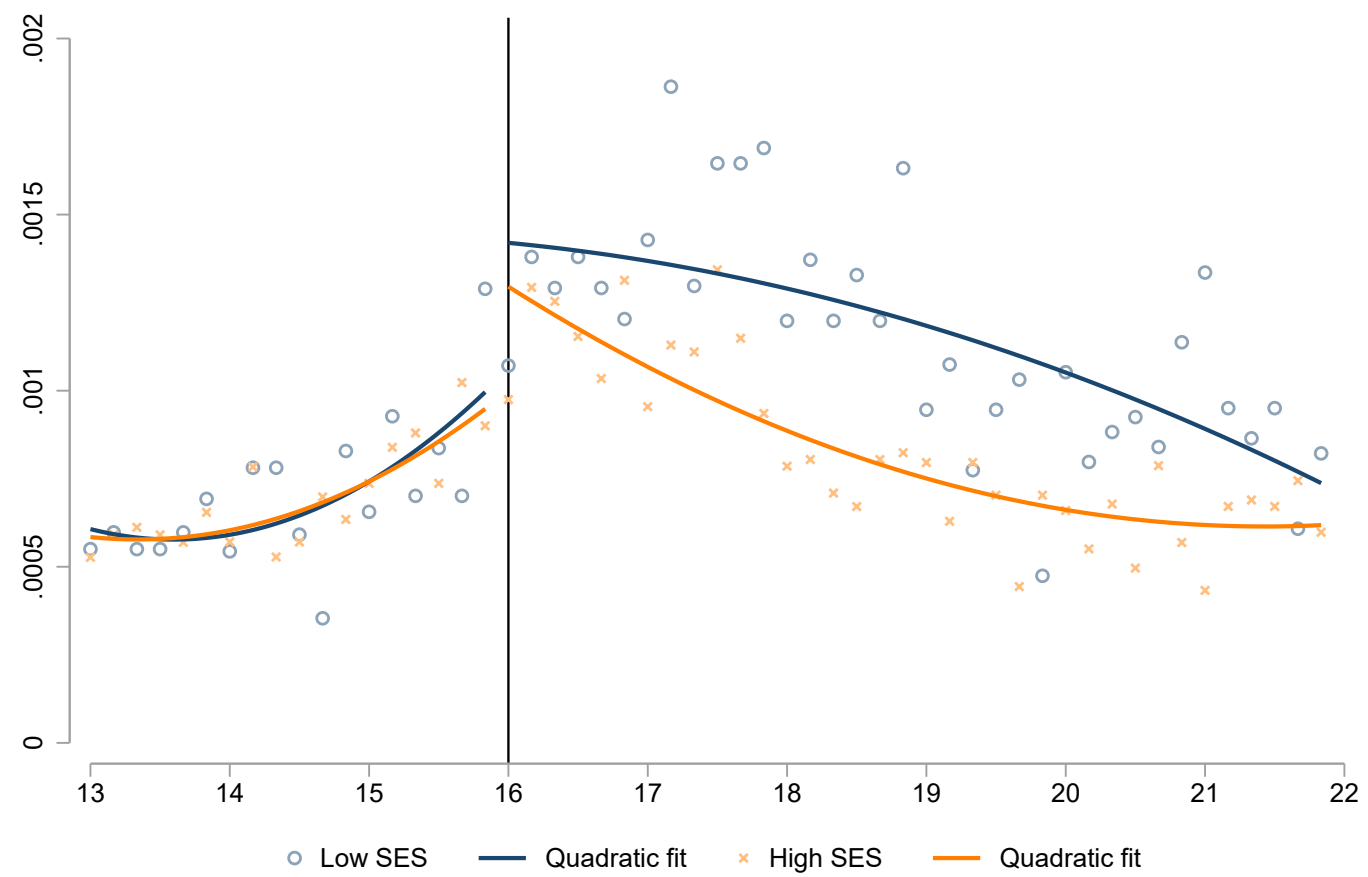

Notes: UAHIF panel. Mean probabilities of being hospitalized with an alcohol intoxication in a given bimonthly age bin by socioeconomic status. Probabilities are adjusted for child sex and year fixed effects.

TABLE $5-t$-tests for socioeconomic differences in alcohol intoxication by age

\begin{tabular}{|c|c|c|c|c|c|}
\hline & \multicolumn{2}{|c|}{ Sample means by SES } & \multicolumn{3}{|c|}{ Tests for difference in means } \\
\hline & $\begin{array}{c}\text { Low SES } \\
\text { (1) }\end{array}$ & $\begin{array}{l}\text { High SES } \\
\text { (2) }\end{array}$ & $\begin{array}{l}\text { Diff. } \\
\text { (3) }\end{array}$ & $\begin{array}{c}t \text {-statistic } \\
\text { (4) }\end{array}$ & $\begin{array}{c}p \text {-value } \\
\text { (5) }\end{array}$ \\
\hline \multicolumn{6}{|c|}{ (a) Non-treated, age range } \\
\hline$[13,14)$ & 0.013 & 0.011 & 0.003 & 0.78 & 0.437 \\
\hline$[14,15)$ & 0.034 & 0.029 & 0.005 & 0.76 & 0.445 \\
\hline$[15,16)$ & 0.069 & 0.067 & 0.003 & 0.30 & 0.764 \\
\hline \multicolumn{6}{|c|}{ (b) Treated, age range } \\
\hline$[16,17)$ & 0.126 & 0.113 & 0.012 & 1.12 & 0.264 \\
\hline$[17,18)$ & 0.173 & 0.122 & 0.052 & 4.30 & $0.000 * * *$ \\
\hline$[18,19)$ & 0.155 & 0.097 & 0.058 & 5.30 & $0.000 * * *$ \\
\hline$[19,20)$ & 0.113 & 0.090 & 0.023 & 2.27 & $0.023 * *$ \\
\hline$[20,21)$ & 0.120 & 0.085 & 0.035 & 3.55 & $0.000 * * *$ \\
\hline$[21,22)$ & 0.104 & 0.072 & 0.033 & 3.59 & $0.000 * * *$ \\
\hline
\end{tabular}

Notes: UAHIF panel. This table reports piece-wise $t$-tests for differences in the probability of having an alcohol intoxication along the child age distribution. Intoxication probabilities are multiplied by 100 to improve readability. $* p<0.10, * * p<0.05$, $* * * p<0.01$. 
FIGURE 7 - Robustness across different RD specifications

- Parametric estimation

- Nonparametric local linear estimation

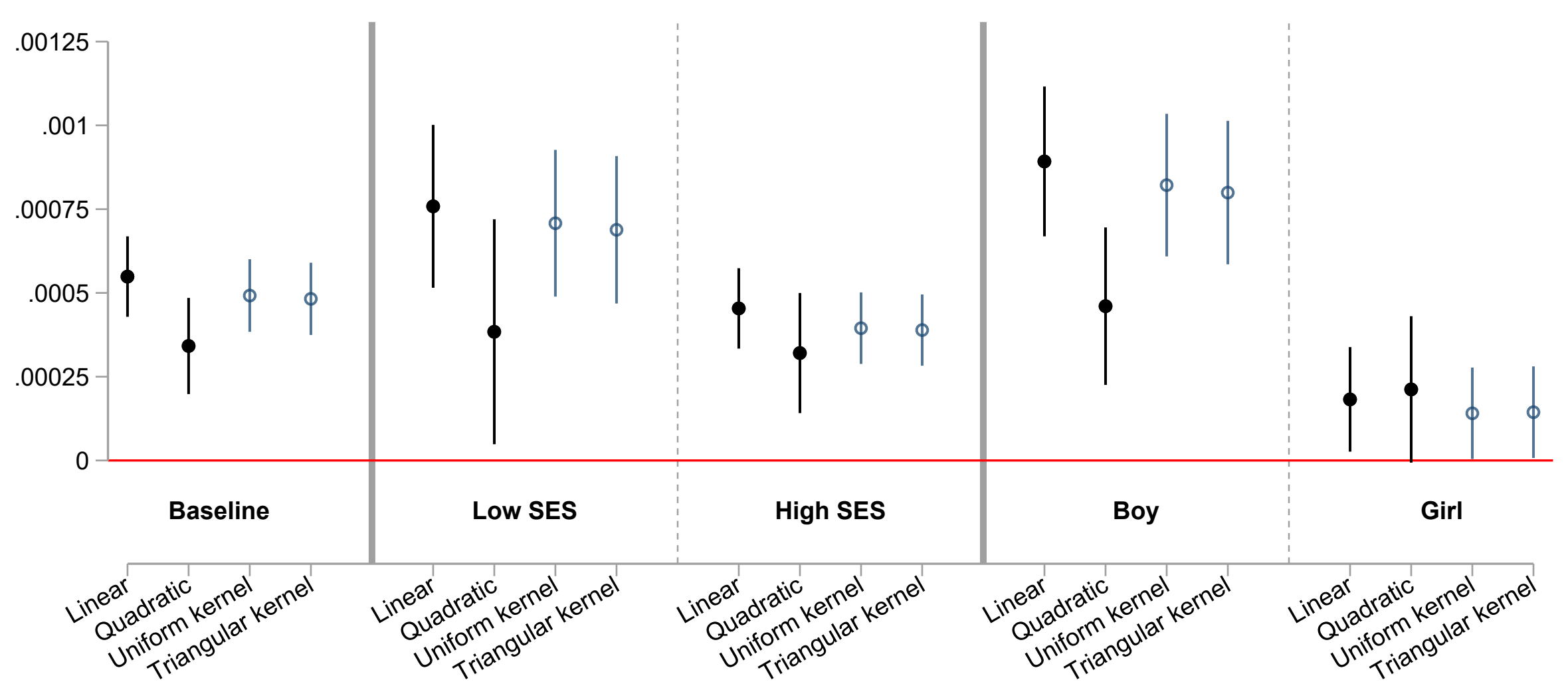

Notes: UAHIF panel. This figure shows estimates for the discontinuous shift in the probability of having an alcohol intoxication at age 16 for different RD specifications: 'Linear' ('Quadratic') uses linear (quadratic) age trends that might be different to the left and to the right of the cutoff (spline regressions) in an RD model, and 'Uniform kernel' ('Triangular kernel') uses a nonparametric local linear regression with a uniform (triangular) kernel function. We estimate these regressions different subsamples, where the baseline is equivalent to Table 4, 'Low SES' and 'High SES' refer to the mother's socioeconomic status, and 'Boy' and 'Girl' refer to child sex. RD coefficients are multiplied by 100 to improve readability. Standard errors are twoway clustered at the individual and the bimonthly age level. The whiskers indicate 95 percent confidence intervals. 
Several additional robustness tests and validity checks corroborate our findings. First, we do not find comparable jumps at other placebo cutoffs between ages 14 to 21 (see Appendix Figure A.8). Second, we show the robustness of our RD plots when we omit donut holes with varying sizes (see Appendix Figure A.9). Third, we show our RD plots with varying bandwiths (see Appendix Figure A.10). Fourth, we show that the results are robust to using alternative ways of calculating confidence intervals following Calonico et al. (2014) and Kolesár and Rothe (2018) (see Appendix Table A.7).

\section{V.2.2. Family history of alcohol abuse}

In a final step, we exploit the fact that the administrative data allow us to identify teenagers whose parents have a history of alcohol abuse. We assume that this is the case when either parent had an alcohol intoxication or had been diagnosed with an alcohol abuse-related disorder (ICD-10 codes T51 and F10), had been prescribed medication assisted alcohol addiction treatment (ATC code N07BB), or had been diagnosed with an alcohol-induced liver cirrhosis (ICD-10 code K70) between 1998-2015. We first run RD regressions on the whole sample and distinguish between families with and without a history of alcohol abuse. Then, we additionally split the sample by socioeconomic status. Table 6 shows that we do not find any statistically significant or economically meaningful effect of reaching MLDA on teenage alcohol intoxications in families with a history of alcohol abuse; this is true for both low and high socioeconomic status families. Yet, although the point estimates are lower and close to zero in families with a history of alcohol abuse, we cannot statistically rule out that the MLDA effects are the same as in families without a history of alcohol abuse. Looking at the alcohol intoxication means across groups, we observe that children in families with a history of alcohol abuse have a considerably higher incidence of alcohol intoxication (by a factor of two). ${ }^{21}$ This finding suggests that, in these families, teenagers imitate their parents' behavior and engage more often in excessive drinking, regardless of whether they have already reached the MLDA. ${ }^{22}$

\section{V.2.3. Substitution behavior and spillovers to other risky behavior}

The increase in alcohol consumption at the MLDA cutoff might go hand in hand with a decline in the consumption of other drugs if adolescents substitute other illegal drugs for legal alcohol. If this is the case, an isolated look at alcohol consumption might give a wrong impression of the overall health consequences of the MLDA cutoff. Indeed, a large literature discusses whether alcohol is a substitute for or a complement to other risky behaviors, such as drug use. Figure A.11 in the Appendix shows RD estimates of reaching the MLDA on a set of

\footnotetext{
${ }^{21}$ These means are significantly different both in the baseline $(t=-11.38, p<0.001)$ and for low $(t=-8.55$, $p<0.001)$ and high $(t=-6.68, p<0.001)$ SES families.

${ }^{22}$ In contrast, Fletcher and Lu (2019) find in US survey data that MLDA effects on binge drinking behavior are concentrated in individuals with high polygenic risk scores for alcohol use. We are not aware of any other comparable studies.
} 
TABLE 6 - Heterogeneity by parents with and without a history of alcohol abuse

\begin{tabular}{lcccc}
\hline & All & No alcohol abuse & Alcohol abuse & $p$-value \\
& $(1)$ & $(2)$ & $(3)$ & $(4)$ \\
\hline Baseline & $0.034^{* * *}$ & $0.036^{* * *}$ & 0.006 & 0.415 \\
& $(0.009)$ & $(0.008)$ & $(0.038)$ & \\
Outcome mean & 0.09 & 0.08 & 0.15 & \\
Number of observations & $3,981,294$ & $3,707,388$ & 273,906 & \\
& & & & \\
Low SES & $0.038^{*}$ & $0.042^{* *}$ & 0.008 & 0.509 \\
& $(0.020)$ & $(0.019)$ & $(0.057)$ & \\
Outcome mean & 0.10 & 0.09 & 0.18 & \\
Number of observations & $1,219,008$ & $1,104,978$ & 114,030 & \\
& & & & \\
High SES & $0.032 * * *$ & $0.034 * * *$ & 0.004 & 0.597 \\
& $(0.011)$ & $(0.011)$ & $(0.054)$ & \\
Outcome mean & 0.08 & 0.07 & 0.12 & \\
Number of observations & $2,762,286$ & $2,602,410$ & 159,876 & \\
\hline
\end{tabular}

Notes: UAHIF panel. This table presents RD estimates for the discontinuous shift in the probability of having an alcohol intoxication at age 16 by socioeconomic status and by whether either of the parents had a history of alcohol abuse between 1998-2015. We assume alcohol abuse if a parent had an alcohol intoxication or had been diagnosed with an alcohol abuse-related disorder (ICD-10 codes T51 and F10), had been prescribed medication assisted alcohol addiction treatment (ATC code N07BB), or had been diagnosed with an alcohol-induced liver cirrhosis (ICD-10 code K70) between 1998-2015. Additionally, we report $p$-values for the differences in coefficients between column (2) and (3). RD coefficients are multiplied by 100 to improve readability. Each regression includes quadratic trends that might be different to the left and to the right of the cutoff (quadratic spline). Standard errors shown in parentheses are twoway clustered at the individual and the bimonthly age level. * $p<0.10$, ** $p<0.05$, *** $p<0.01$.

additional health outcomes ranging from injuries and sexually transmittable diseases to drug prescriptions and drug-related treatments. Again, we distinguish between teenagers from low and high socioeconomic status families. We do not find any robust evidence for a meaningful impact of the MLDA (and the associated increase in alcohol consumption) on health outcomes other than alcohol intoxication.

Moreover, we draw on the Austrian Death Register for the years 1970-2010 to investigate the impact of the MLDA of 16 on fatal accidents. Figure A.12 in the Appendix plots fatalities over the age range 13 to 22 . We observe a small dicontinuous increase in fatalities at age 16, which we cautiously associate with the MLDA. Note that Kamalow and Siedler (2019) find a similar increase in Germany; yet, they show that in their case, the jump in traffic fatalities is the result of a simultaneous increase in driver's licences and thus road participation at age 16. By contrast, in Austria, the age of 16 was not a relevant age for any type of driving licence from 1970-2010. 


\section{V.3. Effects on access to alcohol and risk perceptions}

The discontinuous increase in alcohol consumption at the age of 16 shows that MLDA legislation is successful in preventing many (but not all) underage children from consuming alcohol. In this section, we aim at providing evidence on the underlying mechanism. One obvious channel is restricted physical access to alcohol. We have two data sources to evaluate the importance of this channel. First, we use data from an annual large-scale field study, which sends underage test buyers to retailers to buy alcohol. ${ }^{23}$ Second, we use ESPAD survey responses on perceived access. The former provide us with objective information on alcohol access at retailers, while the latter refers to self-reported overall access, including access provided by siblings and friends. In a final step, we discuss normative values imposed by alcohol legislation as an additional channel. To this end, we use survey questions on risk perceptions about alcohol as a proxy outcome.

\section{V.3.1. Objective access at retailers}

Since 2014, the Upper Austrian government has commissioned the main addiction prevention center (Institut Suchtprävention - pro Mente Oberösterreich) to annually organize a large number of underage alcohol purchase attempts across Upper Austria. The test buyers are all under the age of 16 . They are trained by experts and accompanied by adult custodians during the procedure. The test purchases were carried out in grocery stores, in petrol station shops, and in restaurants across Upper Austria; the test shoppers were instructed to buy a 0.7 liter bottle of hard liquor (Vodka). Since access to hard liquor is legally restricted up to age 18 in Upper Austria, the success rates of test shoppers represent a lower bound of the success rates we would expect for non-distilled alcohol such as beer and wine. ${ }^{24}$ We have access to anonymized micro data on all purchase attempts (except restaurants). Our dataset includes information on the date and place of 4,269 purchase attempts.

On average, 23 percent of all buying attempts were successful. Put differently, only about three-fourths of all vendors complied with MLDA legislation. Figure 8 shows variation in these success rates across years. In 2014, the success rate was about 31 percent. It has dropped thereafter, and has not surpassed 23 percent ever since. A potential explanation for the drop in 2015 is an impact of the large-scale field study itself. Immediately after the purchase, the accompanying staff informs the vendor about its result. If alcohol was sold, the vendor is asked to behave more responsibly and to comply with the legislation in the future. The vendor also receives a feedback letter, including information material, a few weeks after the test. Only after repeated violations, the vendor is reported to the authorities. ${ }^{25}$

\footnotetext{
${ }^{23}$ This is a common method to check the compliance with restrictions on alcohol sales (see, e.g., Gosselt et al., 2007).

${ }^{24}$ Further details on the survey are available here: https://wWw.praevention.at/jugend/ testkaeufe-jugendschutz

${ }^{25}$ Success rates peak in December $(0.35)$ and in summer. We also observe variation across weekdays, with highest success rates on Fridays and Saturdays (about 0.25), and a minimum on Mondays (0.19) (see Appendix
} 
Figure 8 - Average success rate of test shoppers 2014-2018

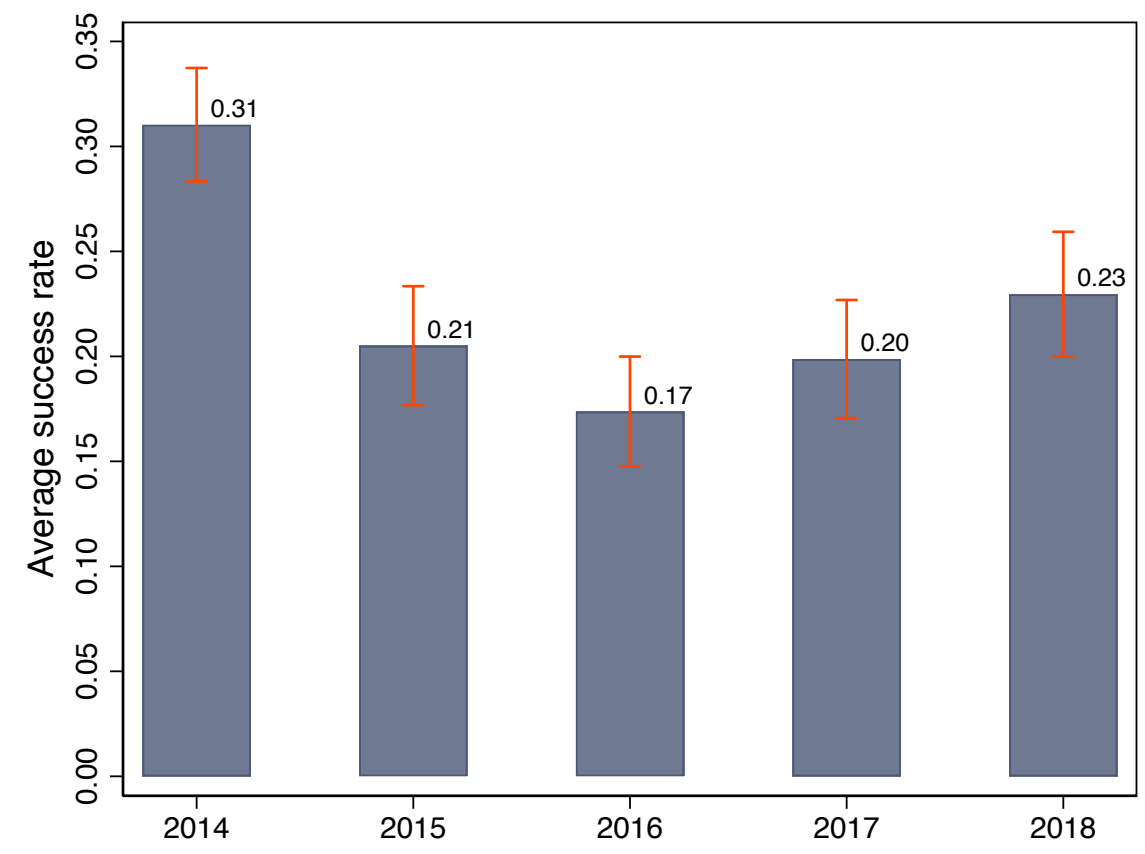

Notes: Figures are based on 4,269 alcohol test purchase attempts in Upper Austrian grocery stores and petrol station shops undertaken by underage test-buyers.

To test whether underage alcohol sales differ across regions with different socioeconomic structure, we merge municipality-level characteristics to the test purchase data. Among others, we use the unemployment rate, the share of adults with a university degree, and the share of foreigners. Conditional on district and year fixed effects, we do not find any significant correlation between socioeconomic characteristics and average success rates (see Appendix Table A.8). Thus, we do not find any evidence that compliance differs by socioeconomic structure of the neighborhood. This finding is in line with the observation that there is no difference in binge drinking before the age of 16 across children from different socioeconomic backgrounds (see the overlapping curves left of the MLDA cutoff in Figure 6).

We now use the median success rate to define high and low MLDA enforcement areas, and re-run our analysis of recorded alcohol intoxications in the resulting subsamples. In Figure 9, we plot age-based intoxication probabilities separately for municipalities with above-median success rates (low enforcement areas) and below-median success rates (high enforcement areas). Two findings are worth noting. First, in the pre-MLDA years, the age trends almost perfectly overlap. This suggests that differences in local MLDA enforcement do not lead to differences in alcohol intoxications. This is consistent with the notion that physical access plays only a minor role in explaining binge drinking behavior. Second, the jump at age 16 seems to be slightly larger in low enforcement areas. However, the discontinuities are, in fact, not

Figures A.13 and A.14). Appendix Figure A.15 depicts the variation in the success rate across Upper Austrian municipalities. 
FIGURE 9 - Probability of being hospitalized with an alcohol intoxication by local enforcement rates

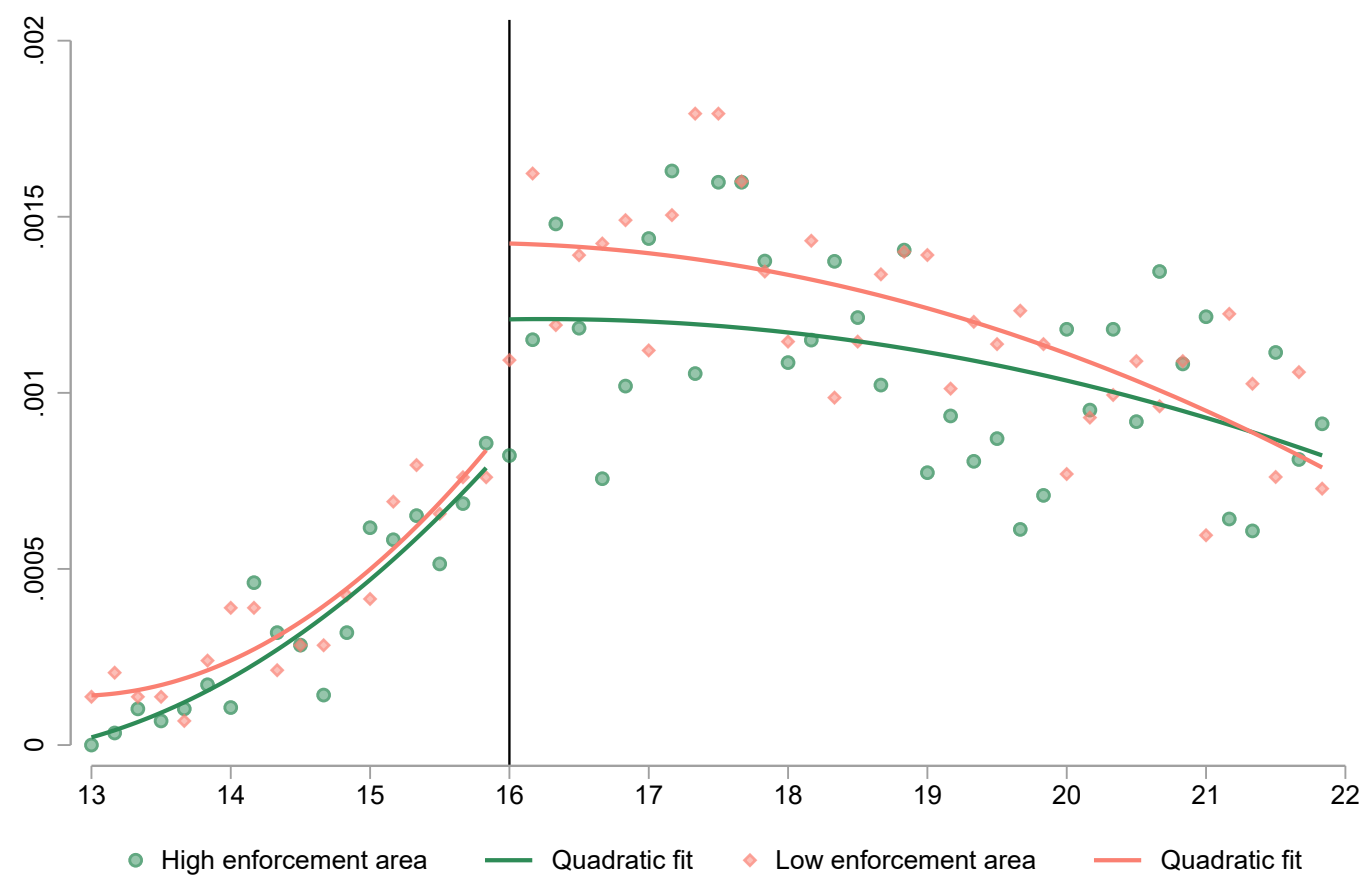

Notes: UAHIF panel linked with mystery shopping data. Mean probabilities of being hospitalized with an alcohol intoxication in a given bimonthly age bin by whether average enforcement in the municipality is above or below the sample median at 22 percent, where enforcement rates are based on 4,269 test purchases in grocery stores and petrol station shops between 2014 to 2018.

statistically different from eachother. To test for the difference in discontinuities, we fully interact the model in equation (1) with a high enforcement dummy. The jump at 16 is estimated to be .051 percentage points for low enforcement areas, while the interaction between $D$ and the high enforcement dummy is statistically not different from zero (-.016 percentage points, $p=0.380)$.

\section{V.3.2. Perceived overall access}

ESPAD survey responses confirm that most teenagers perceive access to non-distilled alcohol as easy even prior to turning 16. In the left panel of Figure 10, we plot the share of teenagers that perceive access to non-distilled alcohol as "rather easy" or "very easy" against age in months. ${ }^{26}$ Although we observe some increase at the 16-year cutoff, as much as 84 percent of all 15 yearolds perceive access to non-distilled alcohol as easy already. For perceived access to distilled alcohol, the shares are lower over the whole age distribution. Interestingly, we find that a discontinuous jump at the 16 year cutoff is clearly visible for states whose MLDA laws granted access to distilled alcohol at age 16 at the time of the interview, while it is absent for states that did not grant access to distilled alcohol before the age of 18 (Figure 11). Remember that

\footnotetext{
${ }^{26}$ Our findings do not depend on this specific choice of dichotomizing the variables (see Appendix Figures A.16 and A.17.
} 
FIGURE 10 - Perceived access to non-distilled and distilled alcohol
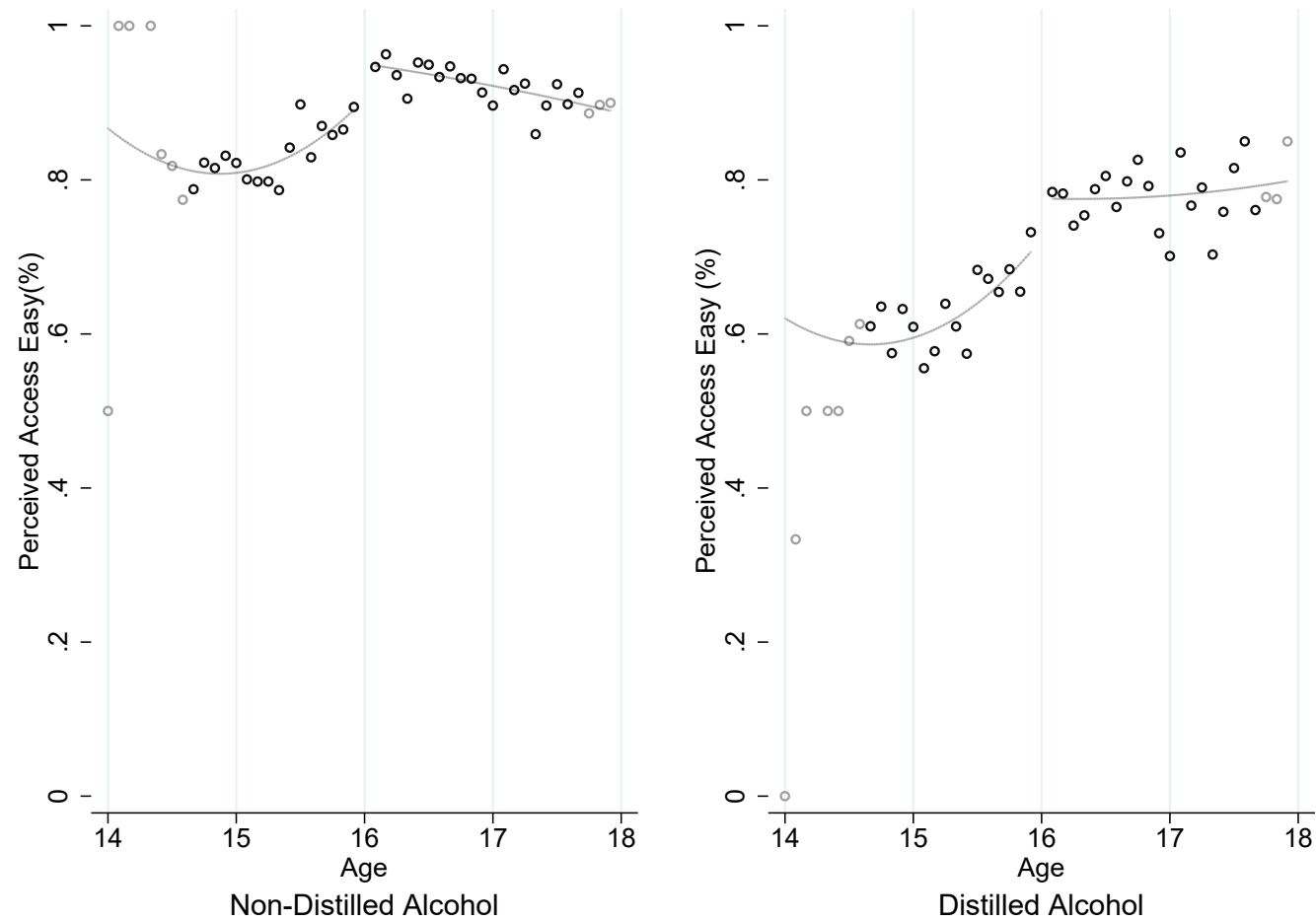

Notes: ESPAD 2015, Austria. The left panel plots the share of respondents by age (in months) bins who perceive access to non-distilled alcohol (beer, wine) as "rather easy" or "very easy". The right panel plots the share of respondents by age (in months) bins who perceive access to distilled alcohol (spirits, alcopops) as "rather easy" or "very easy". Respondents who turn 16 in the month of the interview are dropped. Grey circles indicate that the number of observations from the respective age (in months) bin is in the lower quintile of the frequency distribution.

Upper Austria belongs to the latter group. Taken together, the evidence from the actual purchase attempts in the field study and these survey-based figures suggest that a lack of physical access to alcohol can hardly fully explain the effectiveness of MLDA legislation.

\section{V.3.3. Risk perceptions}

A plausible complementary mechanism behind the effectiveness of the MLDA is that the legislation has established a normative value in the sense that some teenagers below 16 years of age simply feel obliged to obey and abstain from drinking despite its availability. Also parents might play a role here: They may become more lenient when their child reaches the age of 16 and drinking is not just legally allowed but also socially more accepted. Once it becomes more accepted, teenagers change their attitudes towards alcohol and drink more frequently and intensely.

This normative mechanism chain is hard to test empirically. However, the ESPAD includes a question on risk perceptions about alcohol, which provides us with a surrogate outcome variable. The questions reads: "How much do you think people risk harming themselves (physically or in other ways), if they [...]" and distinguishes between risk perceptions of daily drink- 
FIGURE 11 - Perceived access to distilled alcohol by MLDA regime
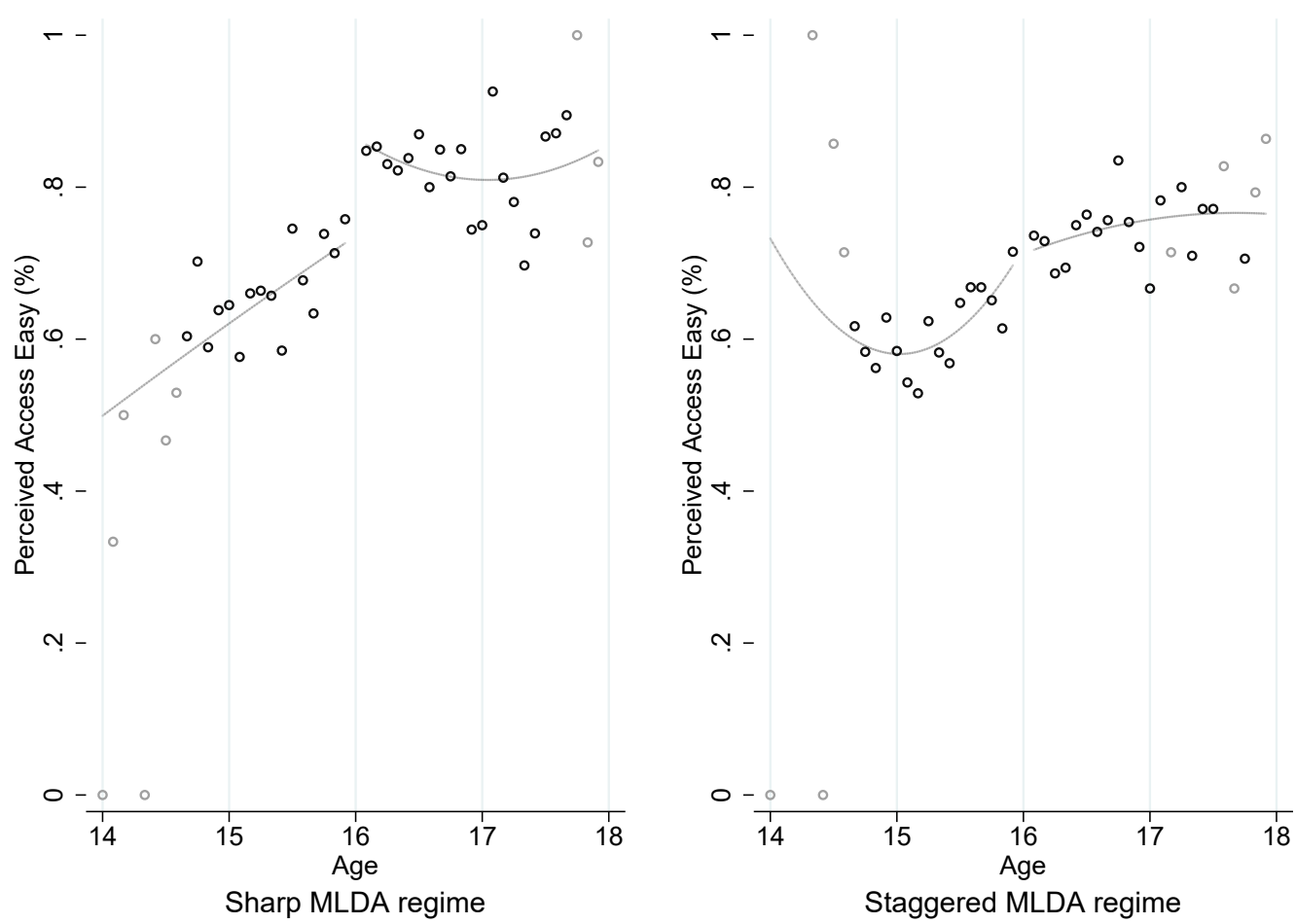

Notes: ESPAD 2015, Austria. The graph plots the share of respondents by age (in months) bins who perceive access to distilled alcohol (spirits, alcopops) "rather easy" or "very easy" by MLDA regime. The left panel plots the shares for Sharp MLDA states, i.e., states which allow legal access to distilled and non-distilled alcohol from age 16. The right panel plots the shares for Staggered MLDA states, i.e., states which allow legal access to nondistilled alcohol from age 16 and to distilled alcohol from age 18. Respondents who turn 16 in the month of the interview are dropped. Grey circles indicate that the number of observations from the respective age (in months) bin is in the lower quintile of the frequency distribution.

ing, i.e., "having one or two drinks nearly every day, and risk perceptions of binge drinking at weekends, i.e., "having five or more drinks on one occasion nearly every weekend. In each case, survey respondents can answer with "no risk", "slight risk", "moderate risk", and "great risk". The framing of this question is geared towards health risk and not legal or disciplinary risks. Thus, in the absence of MLDA legislation, one would expect risk perceptions to be a continuous function of age.

Figure 12 presents evidence on the impact of the MLDA on teenagers' risk perceptions of alcohol. The left panel of Figure 12 plots the share of teenagers considering the risk of daily drinking as "moderate" or "great" by age in months. ${ }^{27}$ Around 65 percent of teenagers believe that daily drinking is risky; this share does not change by gaining legal access to alcohol at age 16. The right panel of Figure 12 performs the same analysis for the share of teenagers that consider regular heavy drinking at weekends to be risky. This share significantly drops from roughly 70 to 60 percent by obtaining legal access to alcohol at age 16 . We interpret this drop

\footnotetext{
${ }^{27}$ Our findings do not depend on this specific choice of dichotomizing the variables (see Appendix Figures A.18 and A.19.
} 
FIGURE 12 - Risk perception of daily drinking and heavy drinking at weekends
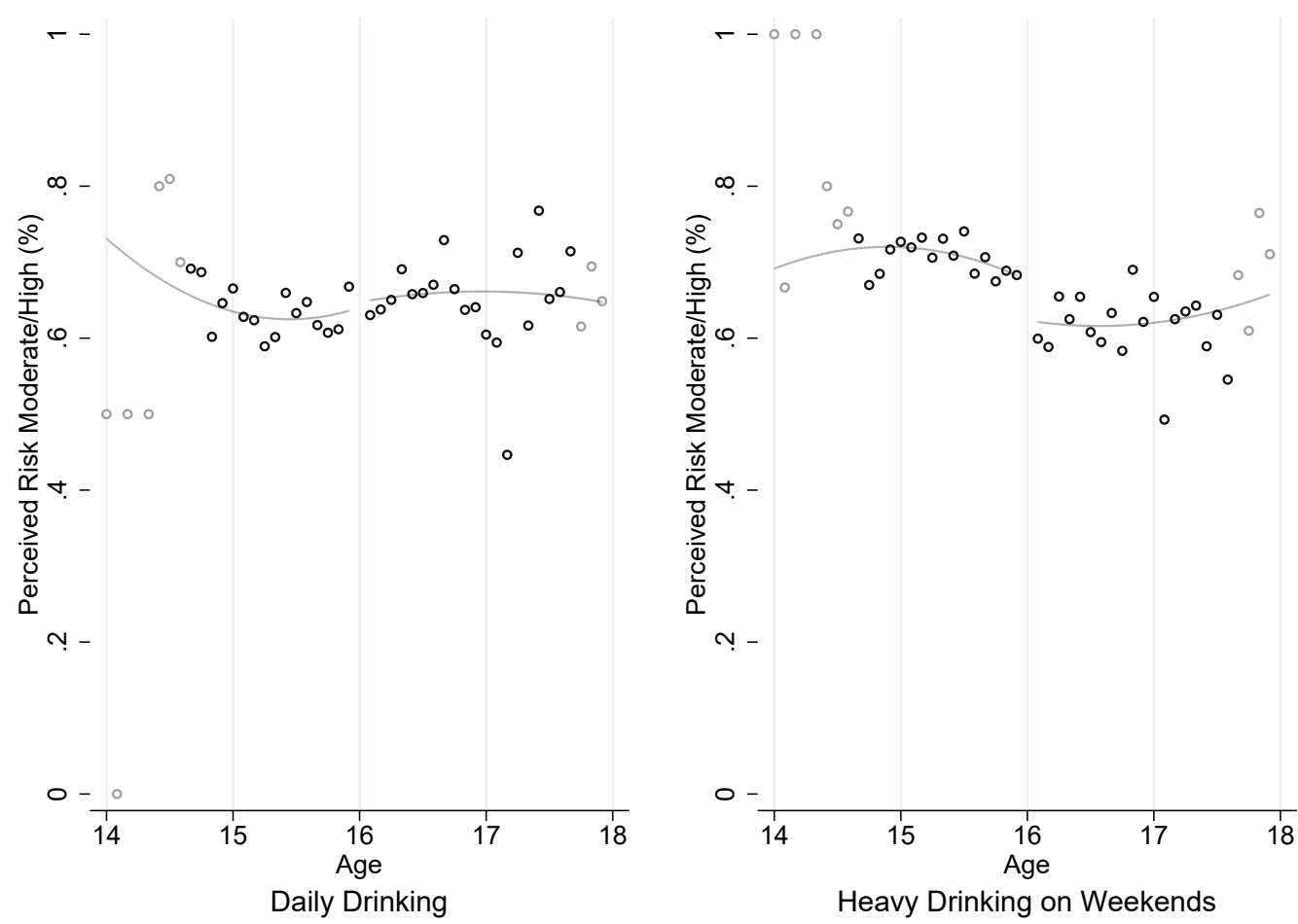

Notes: ESPAD 2015, Austria. The graph plots the share of respondents by age (in months) bins who perceive daily drinking (left panel) or heavy drinking on weekends, i.e., having five or more drinks in one occasion nearly every weekend (right panel) risky. Respondents who turn 16 in the month of the interview are dropped. Grey circles indicate that the number of observations from the respective age (in months) bin is in the lower quintile of the frequency distribution.

as suggestive evidence for a normative impact of the legislation. ${ }^{28}$ Notably, we do not find any change in risk perceptions of drug consumption at the MLDA cutoff (see Figure A.21 in the Appendix). This is in line with the zero effects on hospitalizations due to drugs and other risky health behavior.

\section{A comparison With teEnage dRinking Behavior in the United States}

To put our findings into perspective, we compare teenage drinking behavior in Austria and the US. To this end, we first contrast information from the Austrian ESPAD 2015 data to in-

\footnotetext{
${ }^{28}$ An alternative interpretation for this drop is that teenagers update their perception of risk as they personally engage in heavier alcohol consumption at 16 . Our data, on the other hand, are not consistent with this drop being driven by changes in salience, in the sense that teenagers are more likely to drink themselves if they witness heavy drinking among their peers or other people upon gaining access to bars or clubs. ESPAD asks teenagers whether they have somebody in their peer group that drinks excessively, and we do not see a discontinuous change in the answer to this question at age 16 (Figure A.20). We believe that this is because underage binge drinking is so prevalent in Austria, hence teenagers are likely exposed to plenty of public drinking already before turning 16 . Also remember that we did not find any differences in the MLDA effects between Vorarlberg-where, at age 16, teenagers had no access to bars or clubs between 2 am and $5 \mathrm{am}$ - and the rest of Austria (Appendix Table A.6). This also speaks against the salience channel.
} 
FIGURE 13 - Youth drinking behavior in Austria and in the US

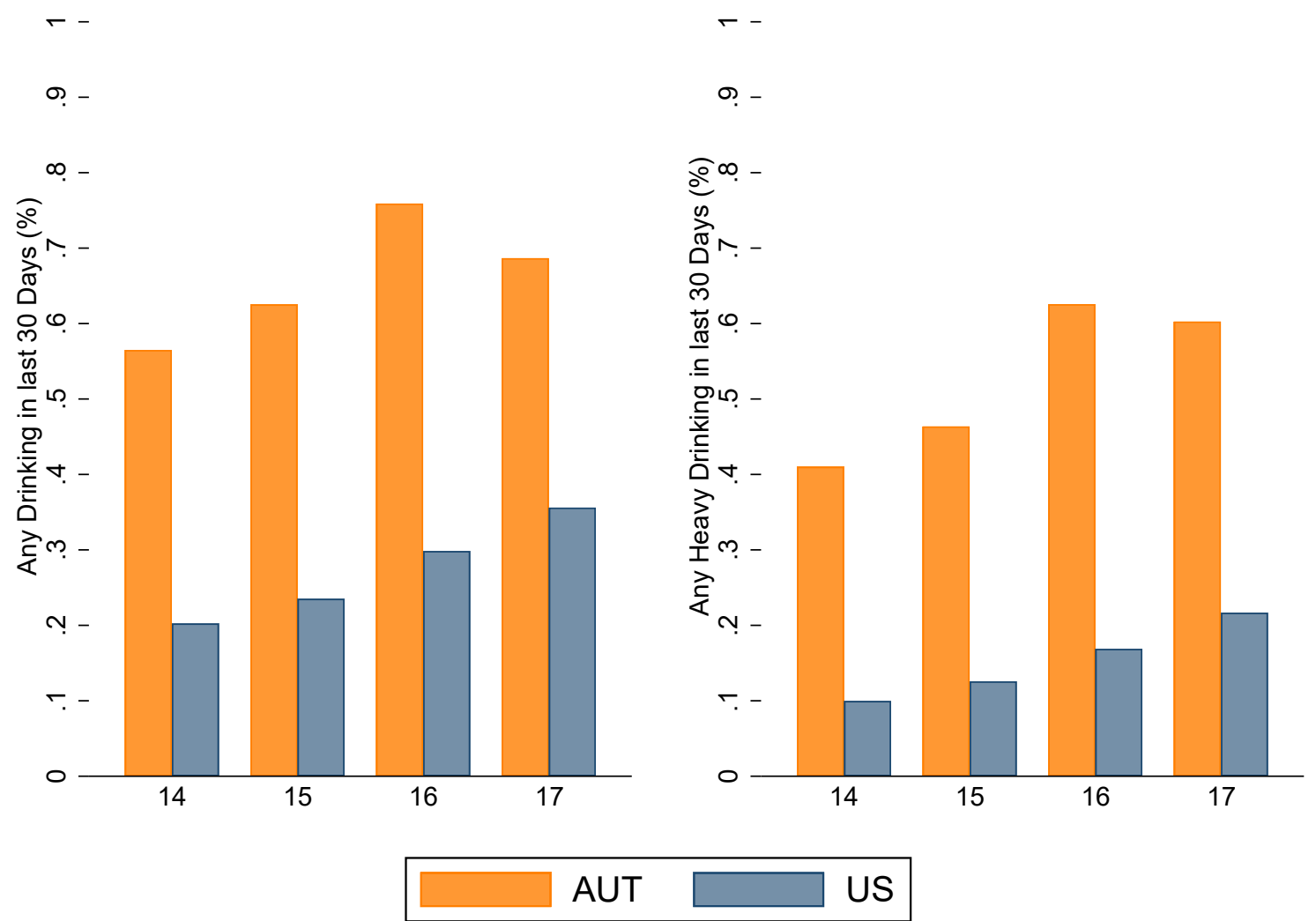

Notes: ESPAD 2015, Austria and YRBSS 2015. The left panel shows the share of respondents by age (in years) who report that they consumed alcohol at least once during the last 30 days. The right panel shows the share of respondents who report that they had at least one binge drinking incidence in the last 30 days, i.e., they consumed five drinks or more in one single occasion.

formation from more than 13,000 adolescents aged 14 to 17 in the US Youth Risk Behavior Surveillance System 2015 (YRBSS). We investigate two questions on drinking behavior that are consistently asked across both surveys. The left panel of Figure 13 plots the share of respondents who report drinking at least once during the last 30 days over age in years for both Austria and the US. The right panel of Figure 13 plots the share of respondents who report at least one binge drinking incident (meaning five or more alcoholic beverages on one occasion) by age for Austria and the US. For both variables, the share is considerably higher in Austria than in the US, and this is the case over the entire age spectrum. More than 40 percent of all 14-15 year olds in Austria report at least one binge drinking incidence during the past 30 days, whereas this number is around 10 percent in the US. After the Austrian MLDA cutoff at 16, we observe a disproportionate increase in the share of teenagers who report drinking or heavy drinking. The jump at age 16 in the share of teenagers who report binge drinking is more than two times larger in Austria than in the US. Appendix Table A.9 shows that the difference in this increase is highly significant and amounts to 9 percentage points. 
Using data from the 2000 to 2006 waves of the National Longitudinal Study of the Youth 1997 (NLSY97), we also inspect the increase in drinking behavior of US youths at the MLDA cutoff at 21 years of age. In contrast to the YRBSS data, the NLSY97 contains information on age in months, which is crucial for the RD setup. Moreover, NLSY97 provides information on maternal education, which we use to proxy for socioeconomic background. The downside of the NLSY97 is that we look at a different cohort, since the respondents were born already between 1980 and 1984. Again, we rely on questions that ask on how many of the last 30 days teenagers consumed any alcoholic drink and on how many days they consumed five or more alcoholic drinks in one occasion; the latter we define as binge drinking. The upper two panels of Figure 14 show RD graphs identifying the impact of the US MLDA of 21 on the probability of having consumed any alcoholic beverage during the last 30 days. While the left panel shows the overall effect, the right panel distinguishes between youths from high and low socioeconomic status. Linear spline regressions yield a highly significant jump of 8.9 percentage points right at the MLDA cutoff, with no clear heterogeneity by socioeconomic status. The lower two panels of Figure 14 show the respective RD graphs for the probability of reporting at least one binge drinking occasion during the last 30 days. Also for this variable we observe a highly significant jump at the MLDA cutoff that amounts to 7.8 percentage points, again without any clear heterogeneity with respect to socioeconomic background.

Note that the jump in binge drinking at the age-16 cutoff in Austria is more than 25 percent higher than the jump at the age-21 cutoff in the US. At the same time, the binge drinking incidence for teenagers slightly below the age-16 cutoff in Austria is 50 percent and thus clearly higher than the incidence for teenagers slightly below the age- 21 cutoff in the US (33 percent). This pattern speaks against the argument that a low MLDA helps teenagers to ease into drinking and consume alcohol responsibly.

\section{Conclusions}

We investigate the impact of a low MLDA of 16 years of age in Austria, a country at the upper end of the world's alcohol consumption and binge drinking distribution. Using rich survey data from the European School Survey Project on Alcohol and Other Drugs (ESPAD) and hospitalization registries, we apply an RD design to estimate the impact of the MLDA on drinking behavior and morbidity.

Our results show that, upon gaining legal access to alcohol, teenagers substantially increase both the frequency and the intensity of drinking. The likelihood of having had at least one drink over the last seven days increases by 12 percentage points. At the same time, the likelihood of having had one to two (three to five) heavy drinking occasions over the last seven days increases by 10 (8) percentage points. As a consequence, we observe a sharp increase in hospitalizations due to alcohol intoxication at the cutoff age of 16 . We show that the effects persist for months and cannot be explained by birthday party effects. These findings contradict the notion that a 

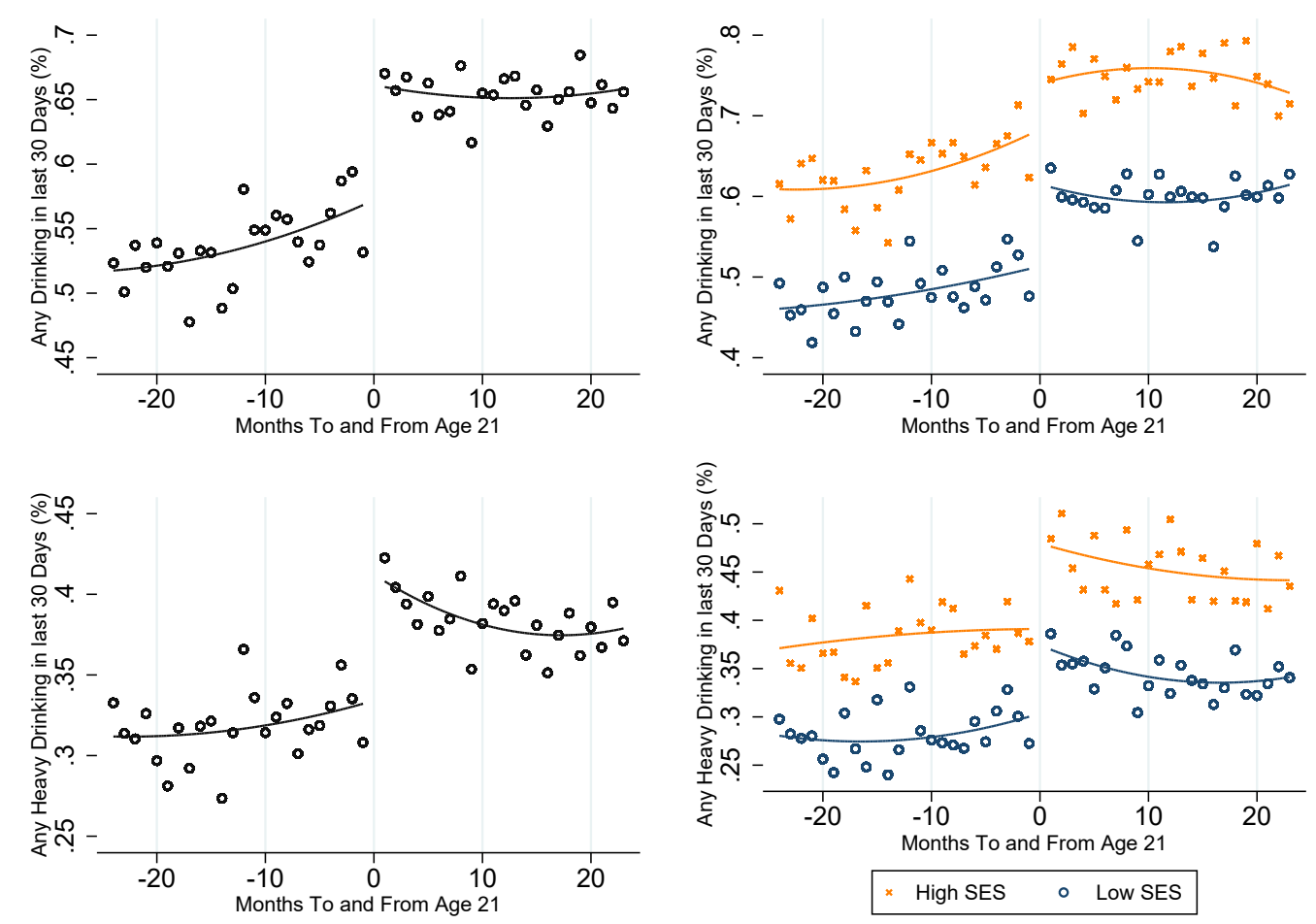

Notes: NLSY97. The upper left panel plots the share of respondents who report that they consumed alcohol at least once during the last 30 days by age (in months) bins. The upper right panel shows these shares by socioeconomic background. The lower left panel plots the share of respondents who report at least one binge drinking incidence (five drinks or more on one occasion) during the last 30 days by age (in months) bins. The lower right panel shows these shares by socioeconomic background. Respondents who turn 21 in the month of the interview are dropped.

low MLDA helps teenagers to ease into drinking (Wechsler and Nelson, 2006).

The effects are stronger for boys and for teenagers with low socioeconomic background. While we do not observe any differences in alcohol intoxications by socioeconomic background before the MLDA is reached, a clear gradient emerges once adolescents reach the MLDA. This gradient is persistent over several years. By age 22, the probability of having been hospitalized with an alcohol intoxication is 0.104 percent for low socioeconomic background teenagers, which is 40 percent higher than for those with high socioeconomic background.

Investigating the channels underlying these results, we observe that most teenagers perceive access to alcohol as easy already before turning 16. Data from large-scale mystery shopping tours suggest that, even at the points of sale, MLDA enforcement is not very strict. At the same time, we do observe a conspicuous decline in the share of teenagers who consider regular heavy drinking at weekends risky right at the MLDA cutoff, while we do not see any change in the share of teenagers who consider daily drinking risky. This result might be suggestive evidence in favor of an additional normative channel MLDA regulation entails. Some teenagers below 16 years of age may simply feel obliged to obey and abstain from drinking, despite its availability. Once drinking becomes legally allowed and socially acceptable, they change their 
attitudes towards alcohol and drink more frequently and more intensely. 


\section{REFERENCES}

Bhattacharya, J., Gathmann, C. and Miller, G. (2013). The Gorbachev Anti-Alcohol Campaign and Russia's Mortality Crisis. American Economic Journal: Applied Economics, 5 (2), 232-260.

Boes, S. and Stillman, S. (2013). Does Changing the Legal Drinking Age Influence Youth Behaviour? IZA Discussion Paper 7522, Institute for the Study of Labor, Bonn, Germany.

- and - (2017). You Drink, You Drive, You Die? The Dynamics of Youth Risk Taking in Response to a Change in the Legal Drinking Age. IZA Discussion Paper 10543, Institute for the Study of Labor, Bonn, Germany.

Callaghan, R. C., Sanches, M., Gatley, J. M. and Cunningham, J. K. (2013). Effects of the Minimum Legal Drinking Age on Alcohol-Related Health Service Use in Hospital Settings in Ontario: A Regression-Discontinuity Approach. American Journal of Public Health, 103 (12), 2284-2291.

Calonico, S., Cattaneo, M. D. and Titiunik, R. (2014). Robust Nonparametric Confidence Intervals for Regression-Discontinuity Designs. Econometrica, 82 (6), 2295-2326.

Carpenter, C. and Dobkin, C. (2009). The Effect of Alcohol Consumption on Mortality: Regression Discontinuity Evidence from the Minimum Drinking Age. American Economic Journal: Applied Economics, 1 (1), 164-182.

- and - (2015). The Minimum Legal Drinking Age and Crime. Review of Economics and Statistics, 98 (2), 254 - 267.

— and - (2017). The Minimum Legal Drinking Age and Morbidity in the United States. Review of Economics and Statistics, 99 (1), 95-104.

- , - and Warman, C. (2016). The Mechanisms of Alcohol Control. Journal of Human Resources, 51 (2), 328-356.

-, Kloska, D. D., O’Malley, P. and Johnston, L. (2007). Alcohol Control Policies and Youth Alcohol Consumption: Evidence from 28 Years of Monitoring the Future. The B.E. Journal of Economic Analysis $\mathcal{F}$ Policy, 7 (1), 1-21.

Carrell, S. E., Hoekstra, M. and West, J. E. (2011). Does Drinking Impair College Performance? Evidence from a Regression Discontinuity Approach. Journal of Public Economics, 95 (1-2), 54-62.

Chalfin, A., Hansen, B. and Ryley, R. (2019). The Minimum Legal Drinking Age and Crime Victimization. NBER Working paper 26051, National Bureau of Economic Research, Cambridge, MA.

Conover, E. and Scrimgeour, D. (2013). Health Consequences of Easier Access to Alcohol: New Zealand Evidence. Journal of Health Economics, 32 (3), 570-585.

Crost, B. and Guerrero, S. (2012). The Effect of Alcohol Availability on Marijuana Use: Evidence from the Minimum Legal Drinking Age. Journal of Health Economics, 31 (1), 112 121. 
— and Rees, D. I. (2013). The Minimum Legal Drinking Age and Marijuana Use: New Estimates from the NLSY97. Journal of Health Economics, 32 (2), 474-476.

Datta-Gupta, N. and Nilsson, A. (2020). Legal Drinking, Injury and Harm: Evidence from the Introduction and Modifications of Age Limits in Denmark. IZA Discussion Paper 13401, Institute for the Study of Labor, Bonn, Germany.

Dee, T. S. (1999). State Alcohol Policies, Teen Drinking and Traffic Fatalities. Journal of Public Economics, 72 (2), 289-315.

Denos, F. T. (2020). Legal Access to Alcohol and Its Impact on Drinking and Crime. Ruhr Economic Papers 884, RWI - Leibniz-Institut für Wirtschaftsforschung, Essen, Germany.

Deza, M. (2015). The Effects of Alcohol on the Consumption of Hard Drugs: Regression Discontinuity Evidence from the National Longitudinal Study of Youth, 1997. Health Economics, 24, 419-438.

Ewing, S. F., Sakhardande, A. and Blakemore, S.-J. (2014). The Effect of Alcohol Consumption on the Adolescent Brain: A Systematic Review of MRI and fMRI Studies of AlcoholUsing Youth. NeuroImage: Clinical, 5, 420-437.

Fletcher, J. M. and Lu, Q. (2019). Health Policy and Genetic Endowments: Understanding Sources of Response to Minimum Legal Drinking Age Laws. Health Economics, 30 (1), 194-203.

Francesconi, M. and James, J. (2019). Liquid Assets? the Short-Run Liabilities of Binge Drinking. Economic Journal, 129 (621), 2090-2136.

Gosselt, J. F., van Hoof, J. J., De Jong, M. D. and Prinsen, S. (2007). Mystery Shopping and Alcohol Sales: Do Supermarkets and Liquor Stores Sell Alcohol to Underage Customers? Journal of Adolescent Health, 41 (3), 302-308.

Guttormsson, U., Leifman, H., Kraus, L., Arpa, S., Molinaro, S., Monshouwer, K., Trapencieris, M., Vicente, J., Englund, A. and Svensson, J. (2016). ESPAD 2015 Methodology. Tech. rep., ESPAD.

Hahn, J., Todd, P. and Van der Klaauw, W. (2001). Identification and Estimation of Treatment Effects with a Regression-Discontinuity Design. Econometrica, 69 (1), 201-209.

Hansen, B. and Waddell, G. R. (2018). Legal Access to Alcohol and Criminality. Journal of Health Economics, 57, 277-289.

Heckley, G., Gerdtham, U. and Jarl, J. (2018). Too Young to Die: Regression Discontinutiy of a Two-Part Minimum Legal Drinking Age Policy and the Causal Effect of Alcohol on Health. Working Paper 2018:4, Lund University, Department of Economics, Lund, Sweden.

Holmes, A. J. and Anderson, K. (2017). Convergence in National Alcohol Consumption Patterns: New Global Indicators. Journal of Wine Economics, 12 (2), 117-148.

Kamalow, R. and Siedler, T. (2019). The Effects of Stepwise Minimum Legal Drinking Age Legislation on Mortality : Evidence from Germany. IZA Discussion Paper 12456, IZA, Bonn, Germany. 
Kolesár, M. and Rothe, C. (2018). Inference in Regression Discontinuity Designs with a Discrete Running Variable. American Economic Review, 108 (8), 2277-2304.

Kueng, L. and Yakovlev, E. (2021). The Long-Run Effects of a Public Policy on Alcohol Tastes and Mortality. American Economic Journal: Economic Policy, 13 (1), 294-328.

Lee, D. and Lemieux, T. (2010). Regression Discontinuity Designs in Economics. Journal of Economic Literature, 48 (2), 281-355.

Lindo, J. M., Siminski, P. and Yerokhin, O. (2016). Breaking the Link between Legal Access to Alcohol and Motor Vehicle Accidents: Evidence from New South Wales. Health Economics, 25, 908-928.

-, Swensen, I. D. and Waddell, G. R. (2013). Alcohol and Student Performance: Estimating the Effect of Legal Access. Journal of Health Economics, 32 (1), 22-32.

Marcus, J. and Siedler, T. (2015). Reducing Binge Drinking? The Effect of a Ban on Latenight Off-premise Alcohol Sales on Alcohol-related Hospital Stays in Germany. Journal of Public Economics, 123, 55-77.

Meier, A. N., Odermatt, R. and Stutzer, A. (2019). Tobacco Sales Prohibition and Teen Smoking. IZA Discussion Paper 12231, Institute for the Study of Labor, Bonn, Germany.

NiLsson, J. P. (2017). Alcohol Availability, Prenatal Conditions, and Long-term Economic Outcomes. Journal of Political Economy, 124 (4), 1149-1207.

Schochet, P. Z. (2009). Statistical Power for Regression Discontinuity Designs in Education Evaluations. Journal of Educational and Behavioral Statistics, 34 (2), 238-266.

Strizek, J., Anzenberger, J., Kadlik, A., Schmutterer, I. and Uhl, A. (2016). ESPAD Oesterreich. European School Survey Project on Alcohol and other Drugs. Band 1: Forschungsbericht. Tech. rep., Gesundheit Oesterreich, Vienna, Austria.

Uhl, A., Bachmayer, S., Schmutterer, I. and Strizek, J. (2020). Handbuch Alkohol - Österreich Band 2: Gesetzliche Grundlagen. Vienna, Austria: Gesundheit Österreich GmbH.

Wechsler, H. and Nelson, T. F. (2006). Will Increasing Alcohol Availability By Lowering the Minimum Legal Drinking Age Decrease Drinking and Related Consequences Among Youths? American Journal of Public Health, 100 (6), 986-992.

World Health Organization (2018). Adolescent Alcohol-Related Behaviours: Trends and Inequalities in the WHO European Region, 2002-2014.

World Health Organization (2019). Status Report on Alcohol Consumption, Harm and Policy Responses in 30 European Countries 2019.

Yakovlev, E. (2018). Demand for Alcohol Consumption in Russia and Its Implication for Mortality. American Economic Journal: Applied Economics, 10 (1), 106-149.

YöRüK, B. K. and YöRüK, C. E. (2011). The Impact of Minimum Legal Drinking Age Laws on Alcohol Consumption, Smoking, and Marijuana Use: Evidence from a Regression Discontinuity Design Using Exact Date of Birth. Journal of Health Economics, 30, 740-752. 
— and YöRüк, C. E. (2013). The Impact of Minimum Legal Drinking Age Laws on Alcohol Consumption, Smoking, and Marijuana Use Revisited. Journal of Health Economics, 32 (2), 477-479. 


\section{A. WEB APPENDIX}

This Web Appendix (not for publication) provides additional material discussed in the unpublished manuscript " Minimum Legal Drinking Age and the Social Gradient in Binge Drinking" by Alexander Ahammer, Stefan Bauernschuster, Martin Halla, and Hannah Lachenmaier.

FIGURE A.1 — Number of students in Upper Austria by age, school year 2019/2020

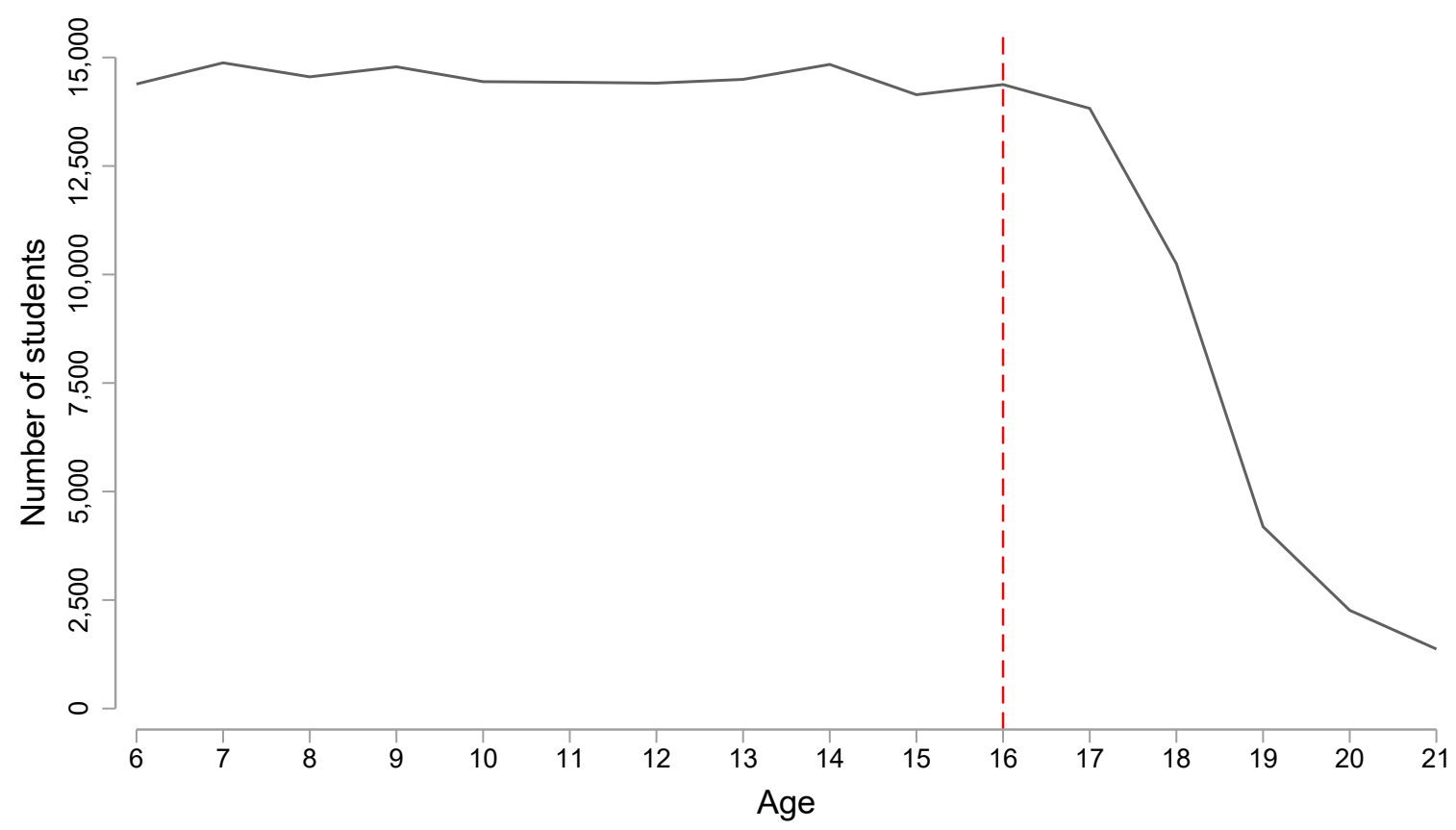

Notes: Statistik Austria, Schülerinnen und Schüler im Schuljahr 2019/20 nach dem Alter - Oberösterreich, URL: https://www.statistik.at/web_de/statistiken/menschen_und_gesellschaft/bildung/ schulen/schulbesuch/index.html, last accessed September 9, 2021. 
FIGURE A.2 - Age in months frequency distribution of the ESPAD sample

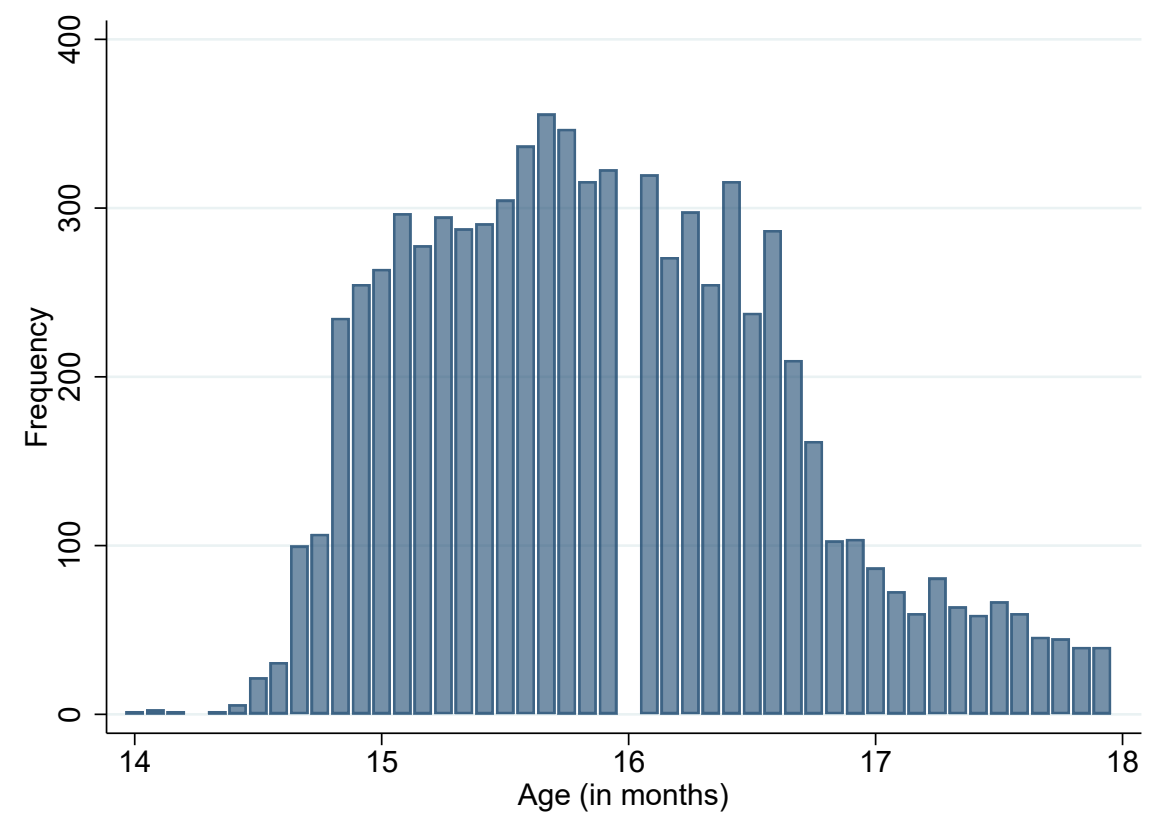

Notes: ESPAD 2015, Austria. This graph shows the frequency distribution of our sample over age in months. Respondents who turn 16 in the month of the interview are dropped to avoid wrong treatment assignment. 
Figure A.3 - Effects on smoking during the last 30 days
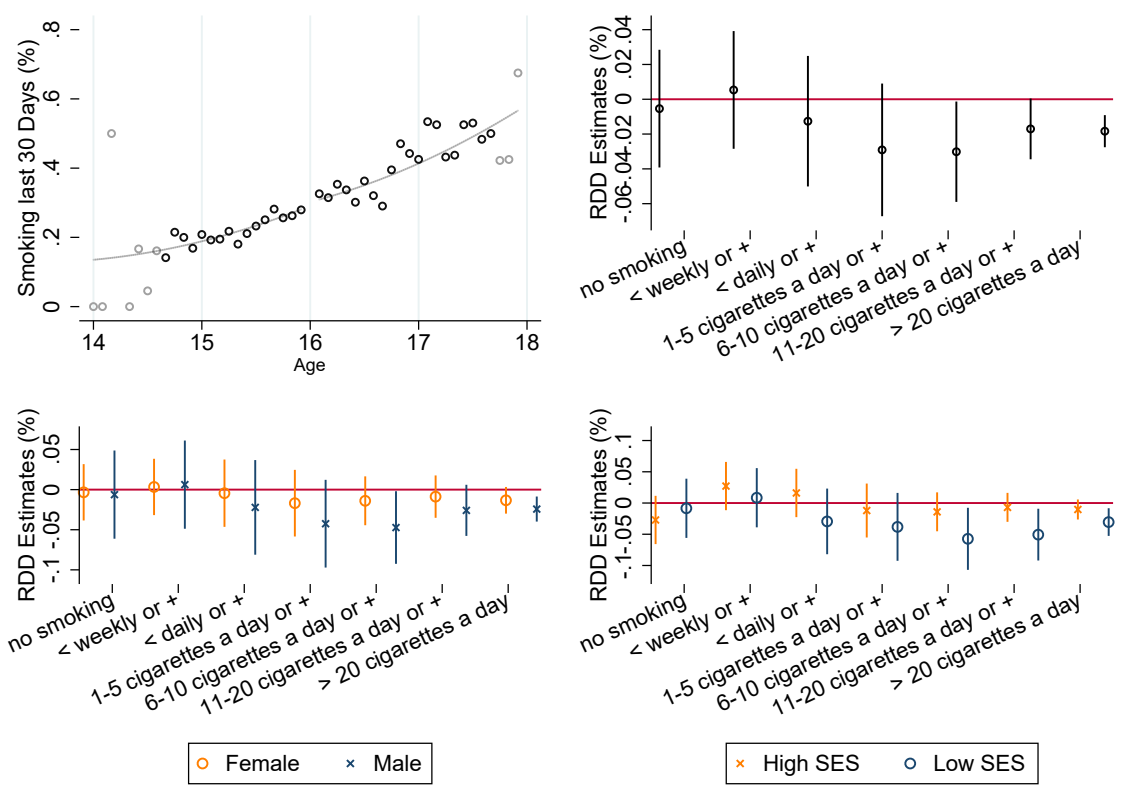

Notes: ESPAD 2015, Austria. The upper left panel plots the share of respondents who report any smoking of cigarettes during the last 30 days by age (in months) bins. Respondents who turn 16 in the month of the interview are dropped. Grey circles indicate that the number of observations from the respective age (in months) bin is in the lower quintile of the frequency distribution. The upper right panel shows RD estimates of the effects of reaching age 16 on $\operatorname{Pr}($ Frequency $\geq X)$ with $X$ being the respective category of the frequency of smoking. The bottom left panel shows RD estimates of the effects on $\operatorname{Pr}($ Frequency $\geq X)$ by gender. The bottom right panel shows RD estimates of the effects on $\operatorname{Pr}($ Frequency $\geq X$ ) by socioeconomic status. All regressions include linear age (in months) trends that might be different to the left and to the right of the cutoff (linear spline). Standard errors are clustered at the age (in months) level. The whiskers indicate 95 percent confidence intervals. 
Figure A.4 - RD plots at placebo cutoffs using raw ESPAD data
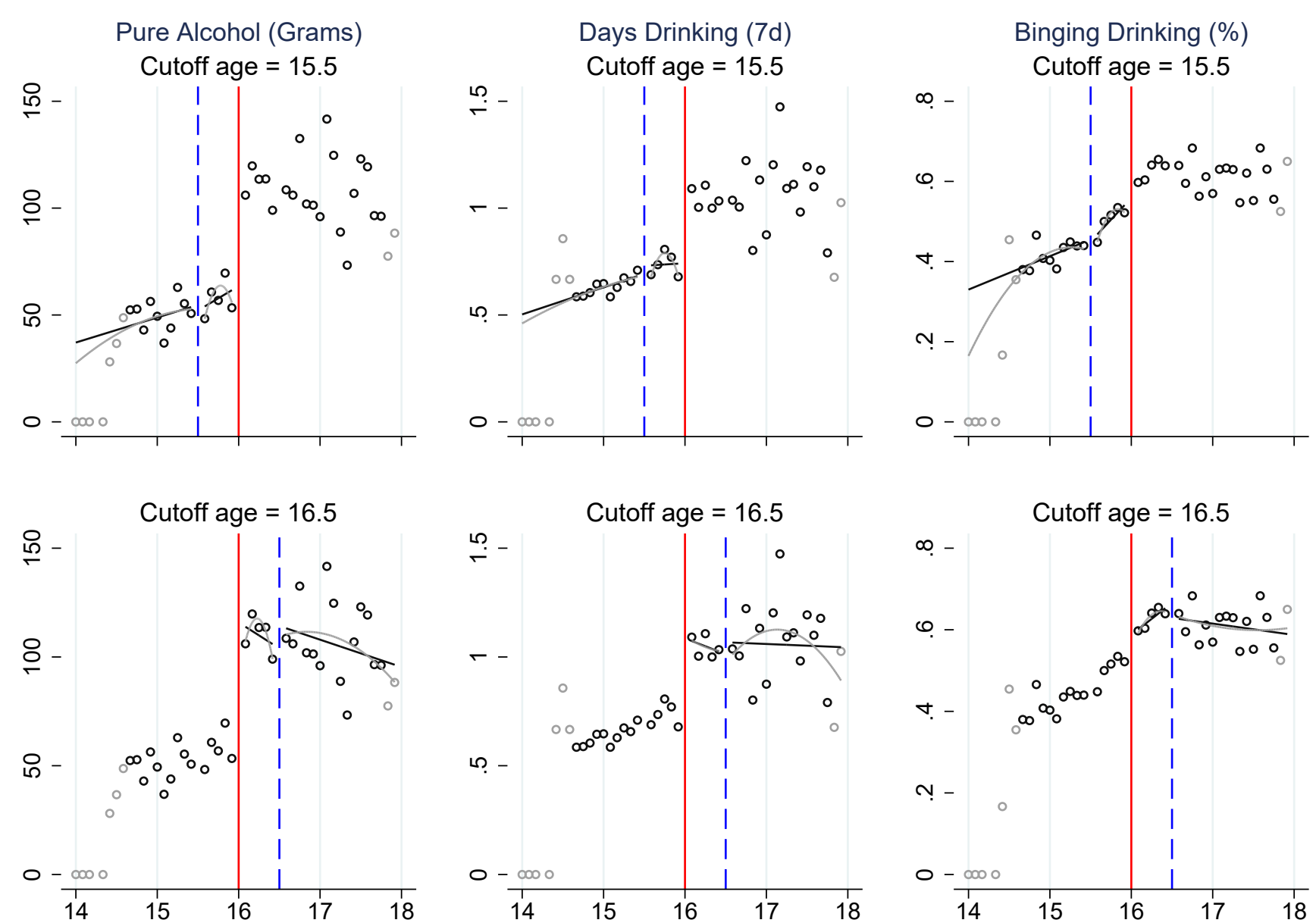

Notes: ESPAD 2015, Austria. The graphs shows RDD-plots at placebo cutoffs at 15.5 (upper row) and 16.5 (lower row) in the number of days drinking in the last 7 days (left panel), grams of pure alcohol consumed in the last 7 days (mid panel), and the incidence of binge drinking during the last 30 days (right panel). Respondents who turn 15.5 in the month of the survey, or 16.5 respectively, are dropped. For both placebo cutoffs, we make sure to do not fit through the true MLDA cutoff of 16 . The red vertical lines indicate the true MLDA of 16, while the dashed blue vertical lines indicate the placebo cut-offs of 15.5 , or 16.5 respectively. 
FIGURE A.5 - Balancing tests with ESPAD data I
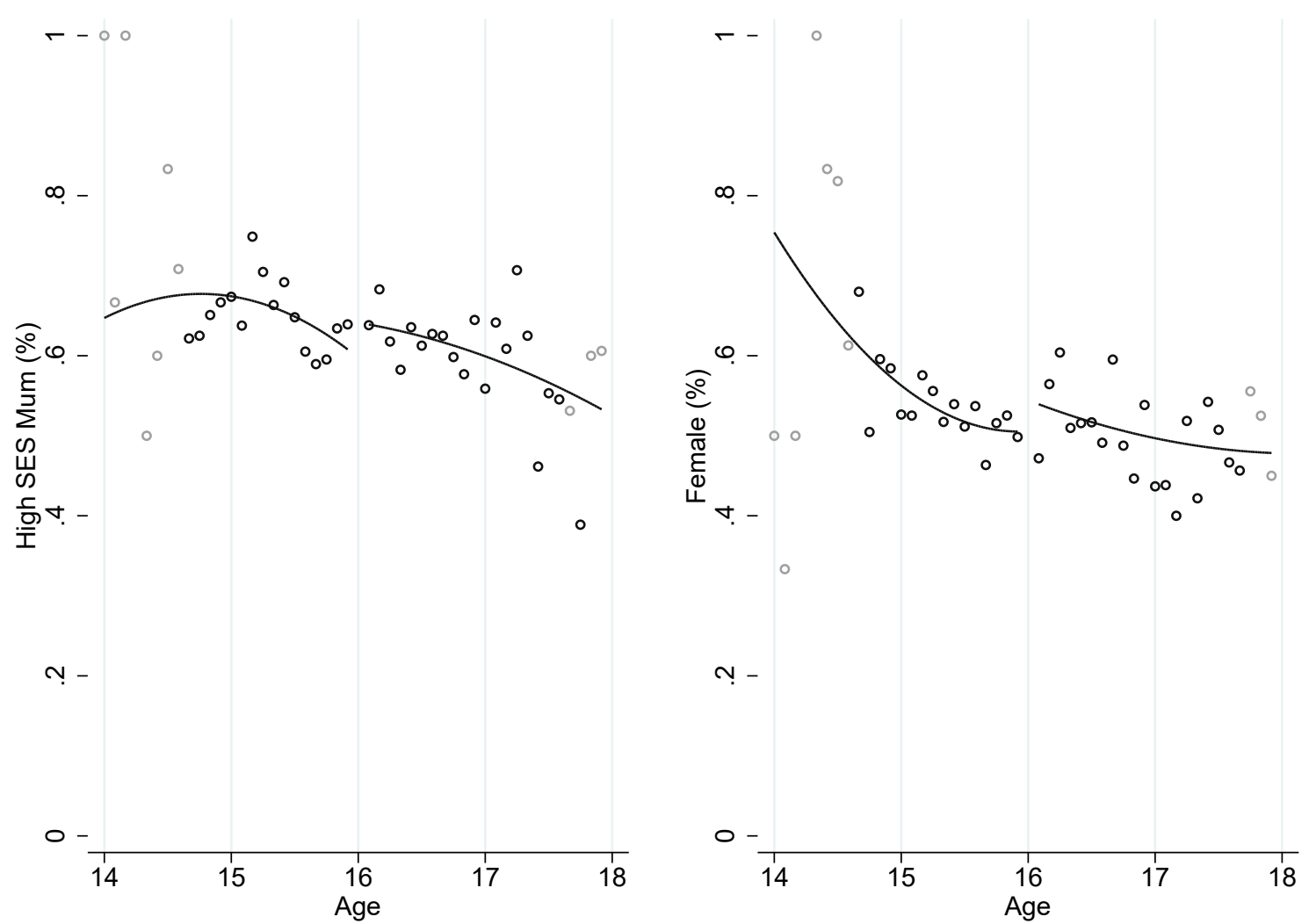

Notes: ESPAD 2015, Austria. The graphs plots the share of respondents whose mother completed at least secondary schooling (left panel) and the share of female respondents (right panel) by age (in months) bins. Respondents who turn 16 in the month of the interview are dropped. 
FIGURE A.6 - Balancing tests with ESPAD data II
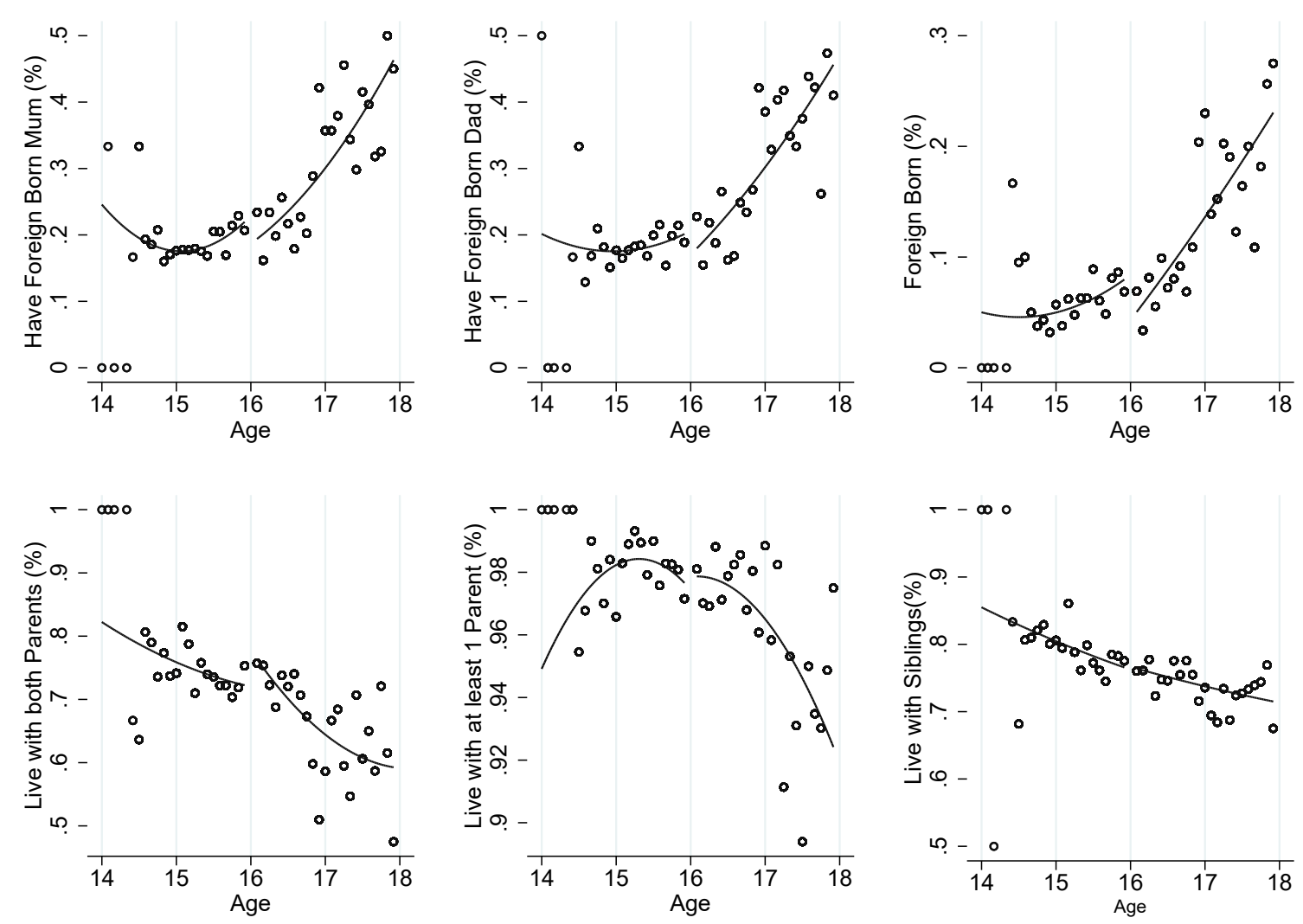

Notes: ESPAD 2015, Austria. The graphs plots the share of respondents with a foreing born mother, a foreign born father and the share of foreign born respondents (upper panel) as well as the share of respondents who live with both parents, with at least one parent, and with siblings (lower panel) by age (in months) bins. Respondents who turn 16 in the month of the interview are dropped. 
Figure A.7 - Missing survey responses
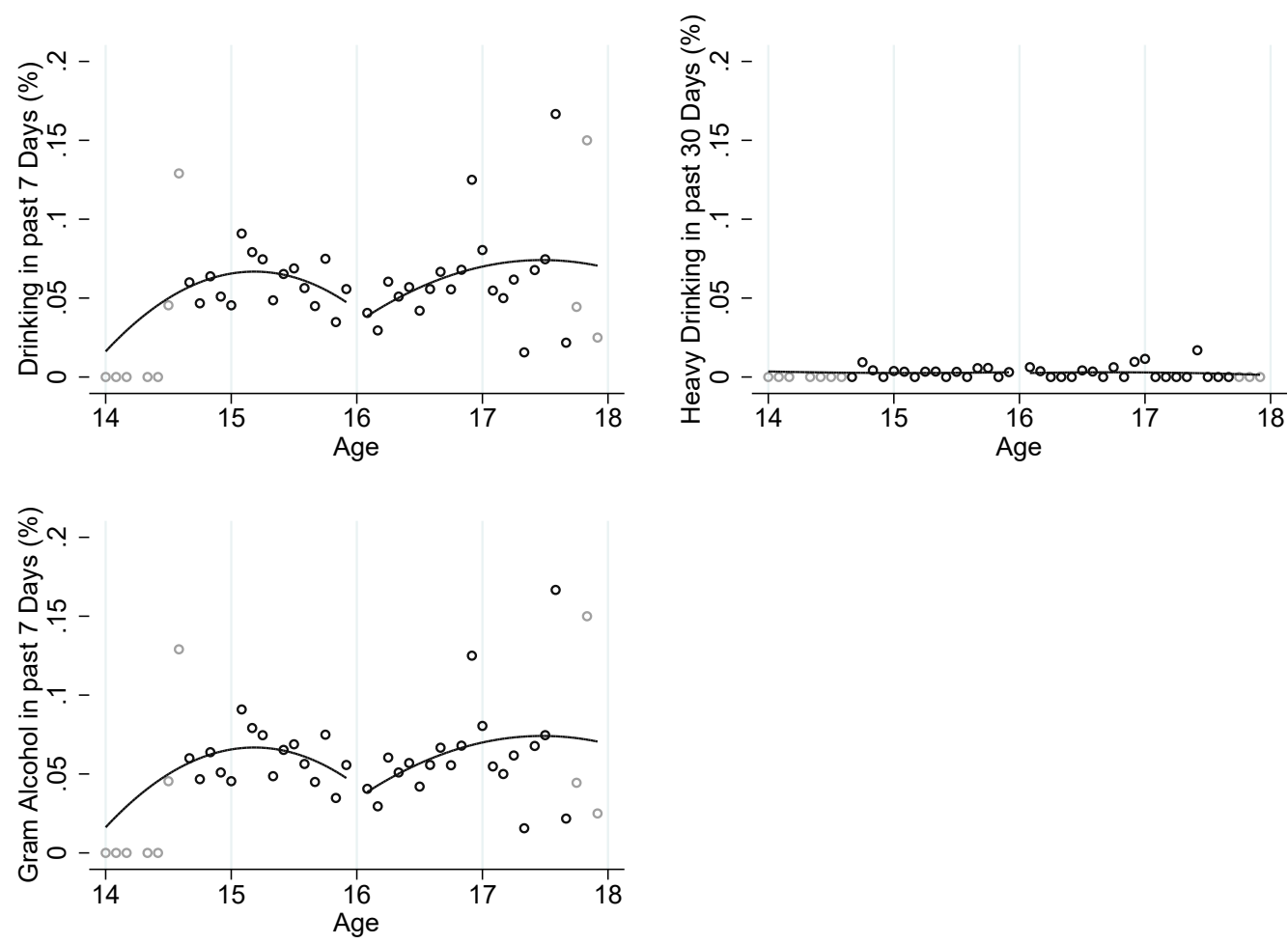

Notes: ESPAD 2015, Austria. The graphs plots the share of missings for the three alcohol consumption outcomes by age (in months) bins. Since the variables "number of days drinking in the last 7 days" and "grams of pure alcohol consumed in the last 7 days" are based on the same item battery, they have exactly the same missing structure. Respondents who turn 16 in the month of the interview are dropped. 


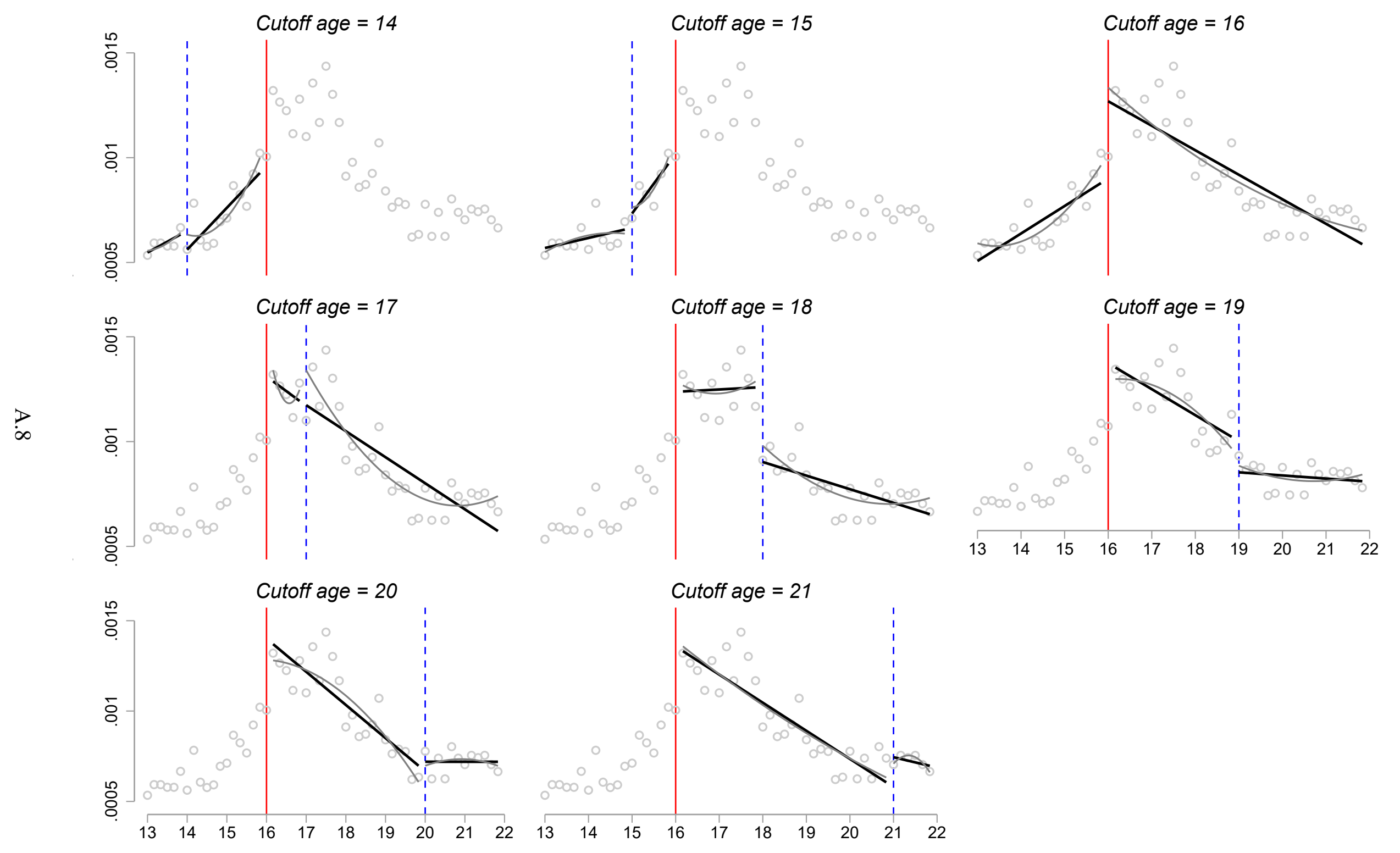

Notes: UAHIF panel. The graphs show RDD-plots at all ages from age 14 to age 21. The outcome variable is alcohol intoxication. For all placebo cutoffs, we make sure to do not fit through the true MLDA cutoff of 16. The red vertical lines indicate the true MLDA of 16, while the dashed blue vertical lines indicate the respective placebo cut-offs. 
FIGURE A.9 - Donut tests
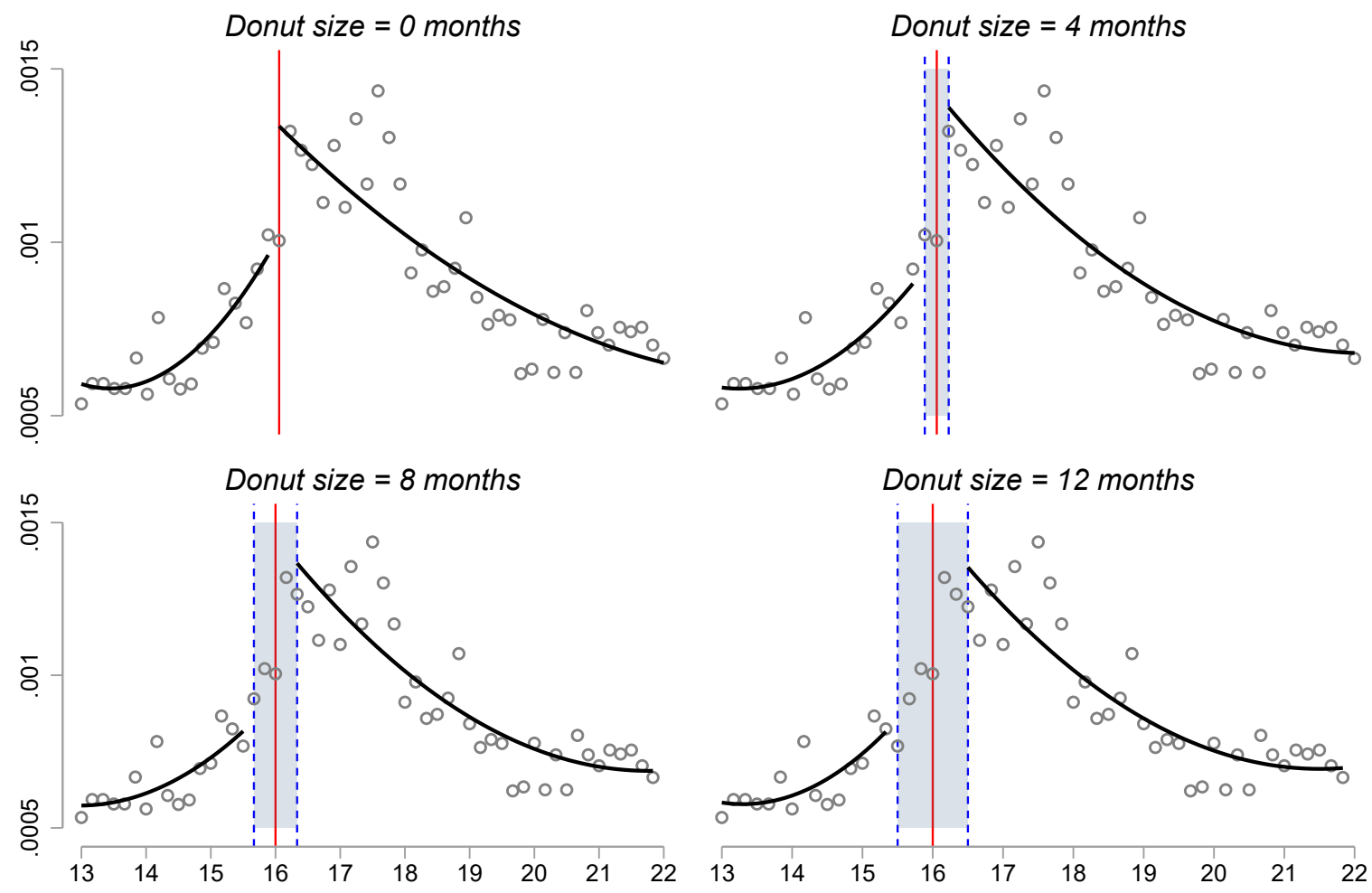

Notes: UAHIF panel. This figures show RD plots for different donut sizes, measured in months-of-age dropped on each side of the age-16 cutoff. For example, to obtain the 4-month Rd plot, we drop one two-month age bin on each side of the age 16 cutoff. For the 12-month plot, we drop 6 months on each side of the cutoff. 
FIGURE A. $10-$ RD plots with varying bandwidths
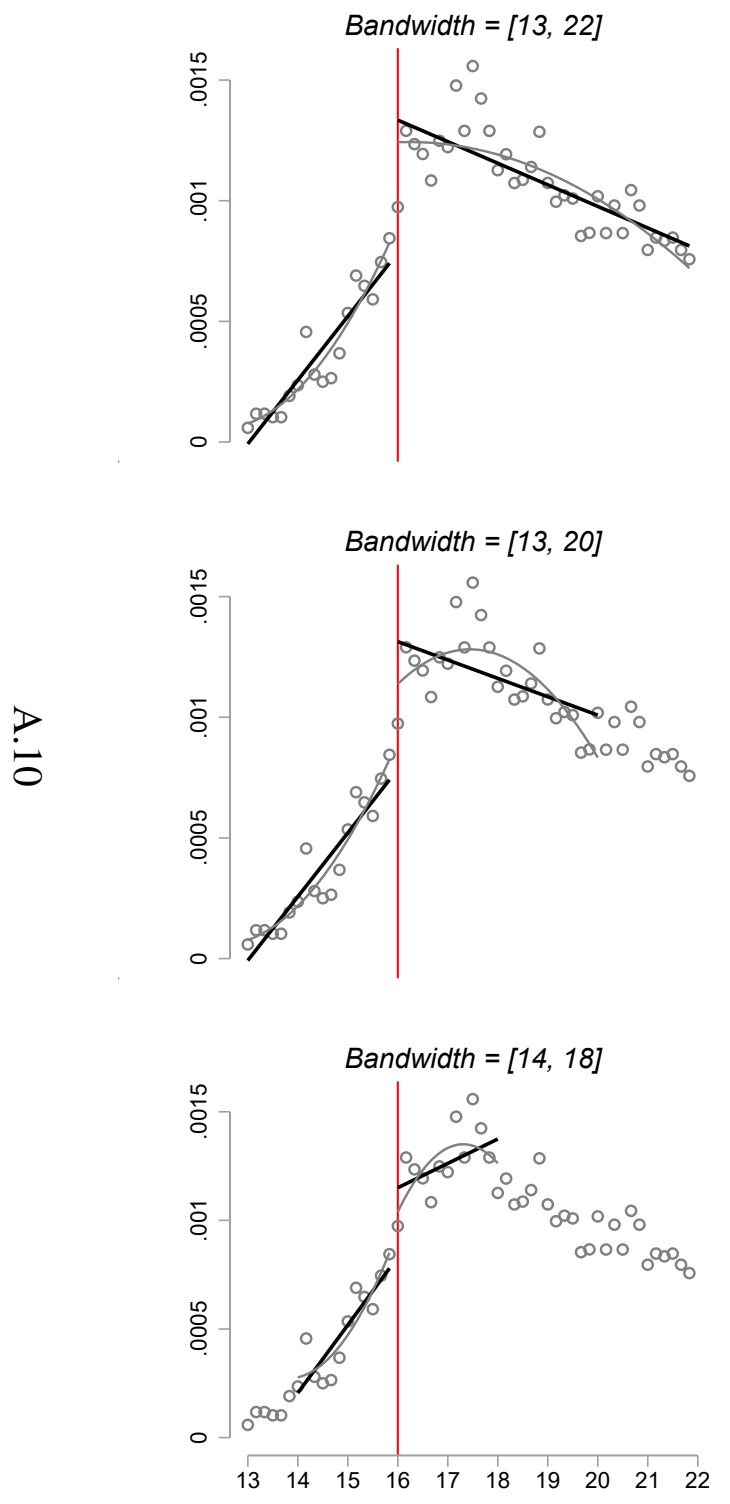
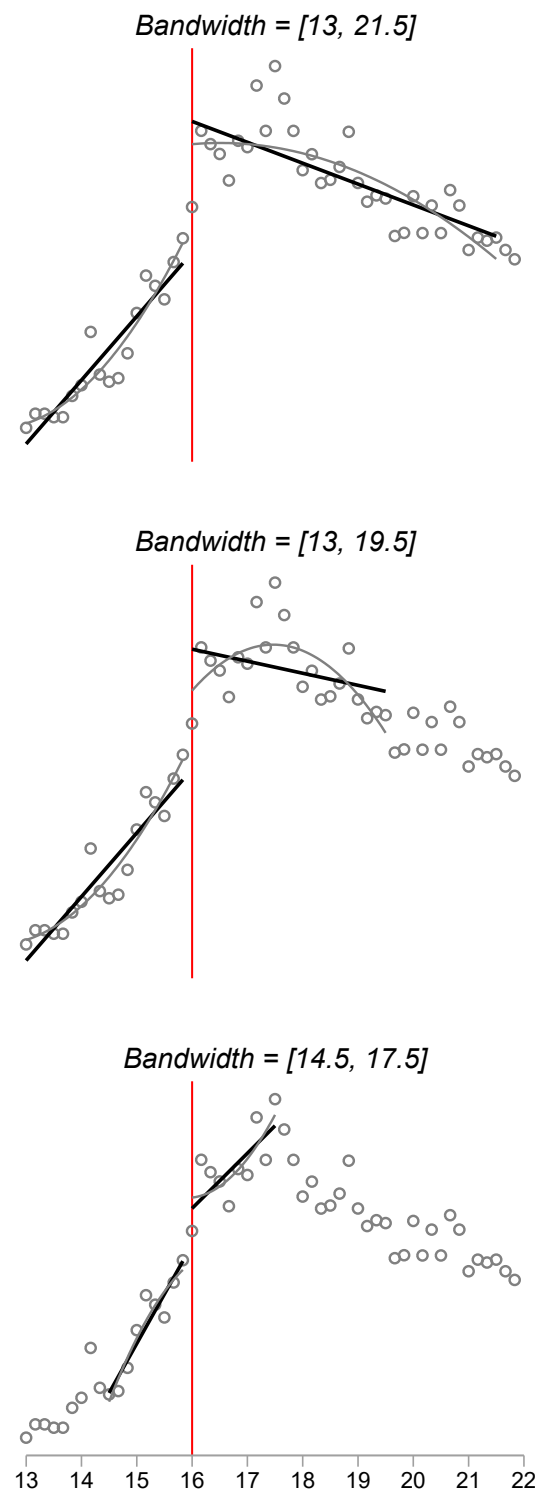
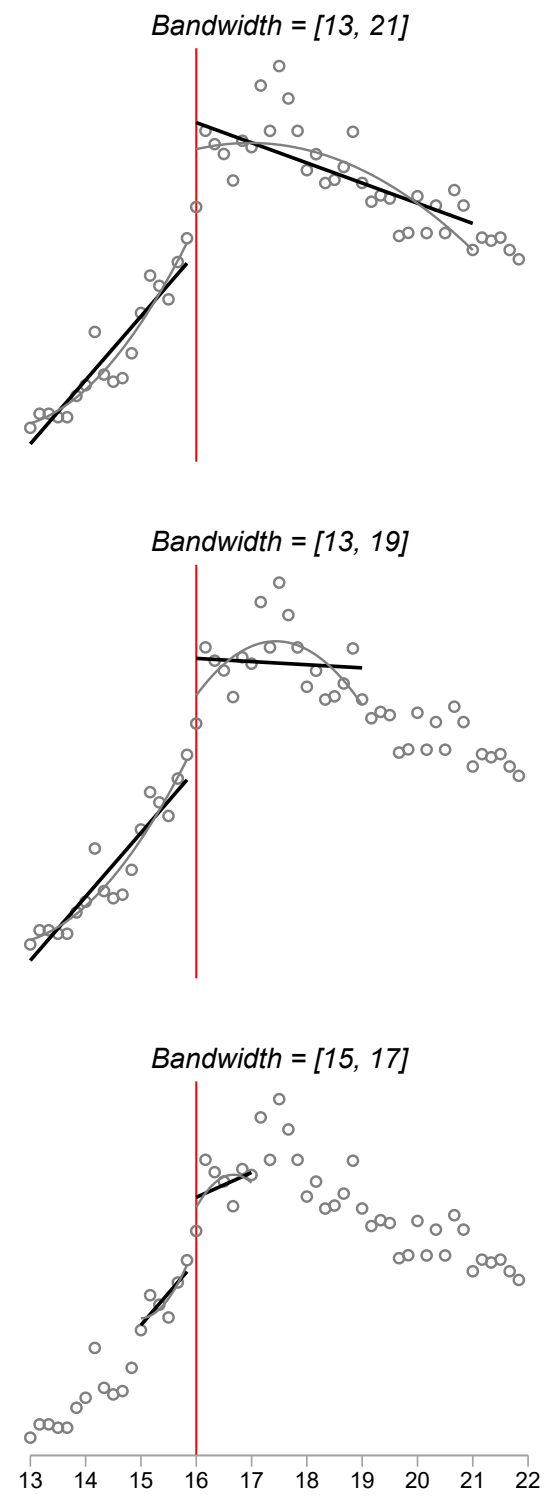
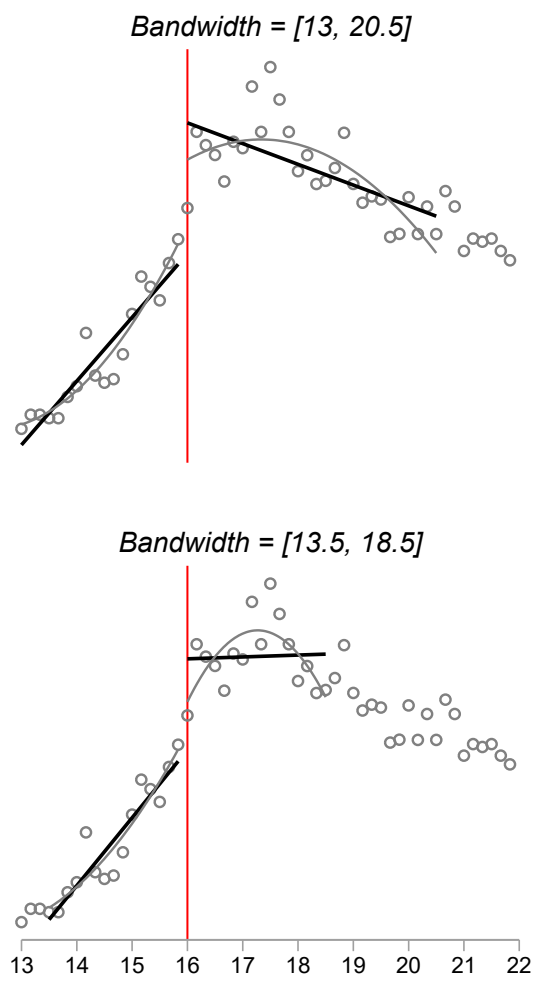

Notes: UAHIF panel. This figures show RD plots for different bandiwdths. 
Figure A.11 - Other health outcomes
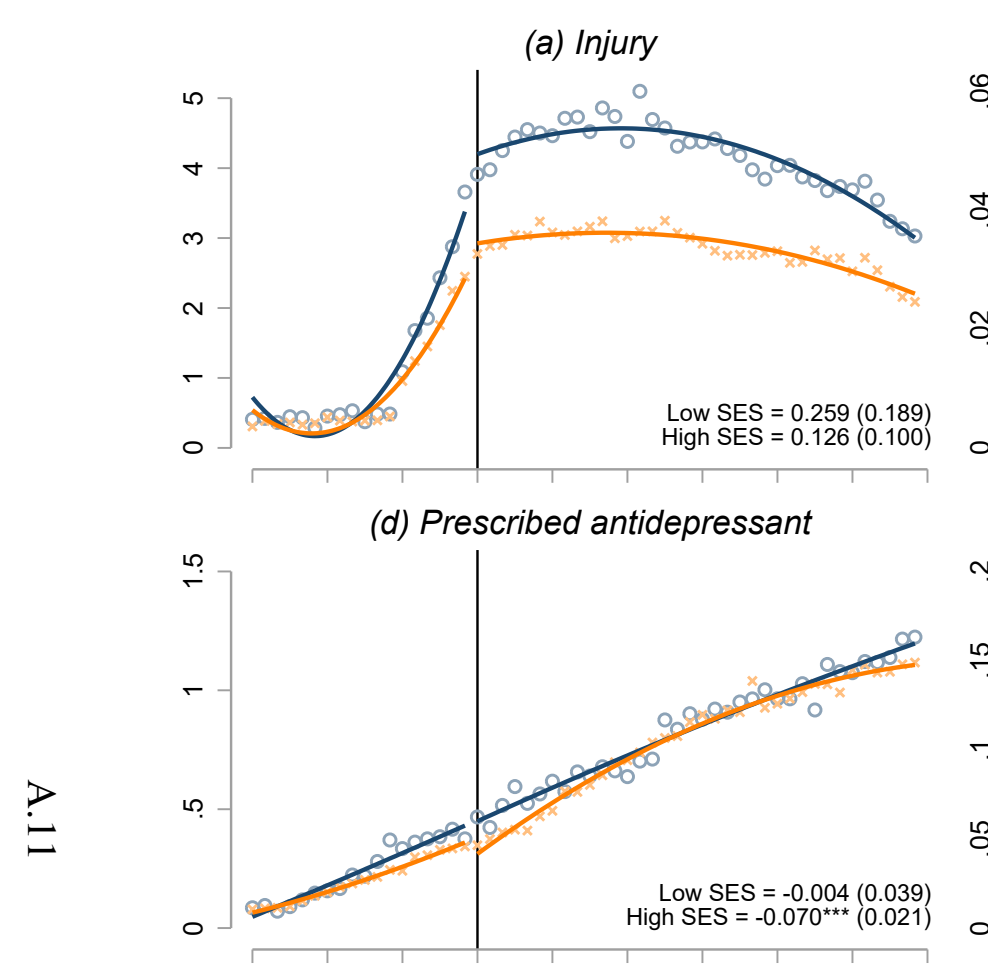

(g) Prescribed opioid

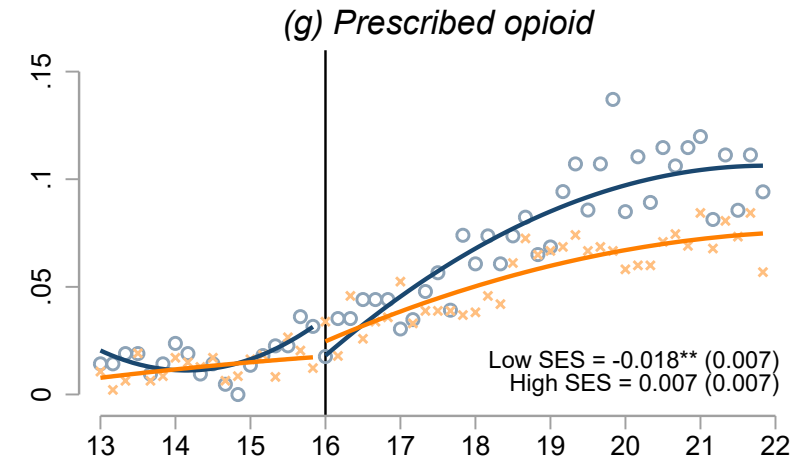

- Low education (b) Sexually transmittable disease

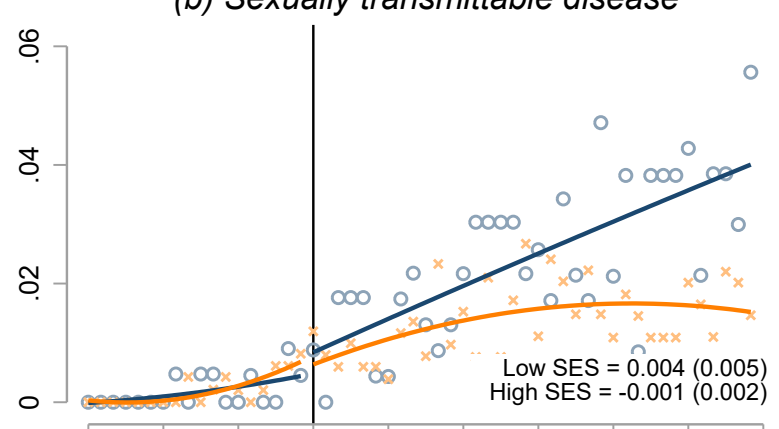

(e) Prescribed a benzodiazepine

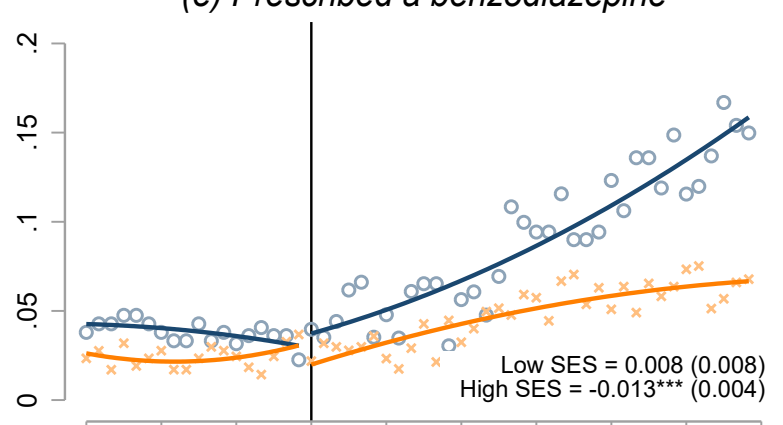

(h) Opioid addiction treatment
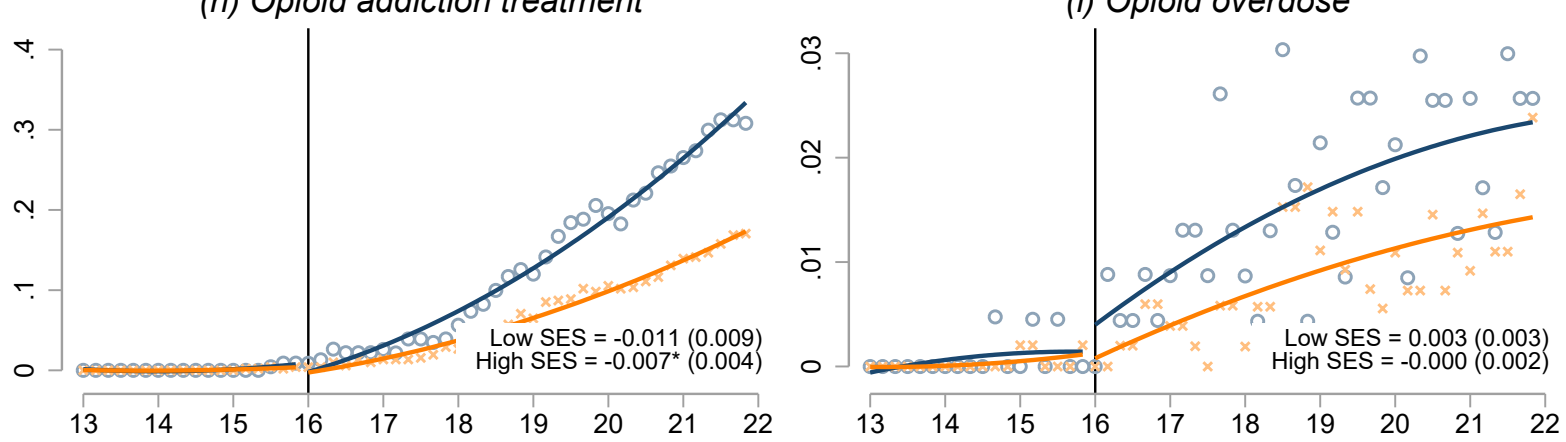

Notes: UAHIF panel. This figure plots mean probabilities in a given bimonthly age bin for each outcome. Probabilities are based on the population of children insured at a given age in Upper Austria. We multiply binary outcomes by 100 to improve readability. 
Figure A.12 - Traffic accident deaths by age

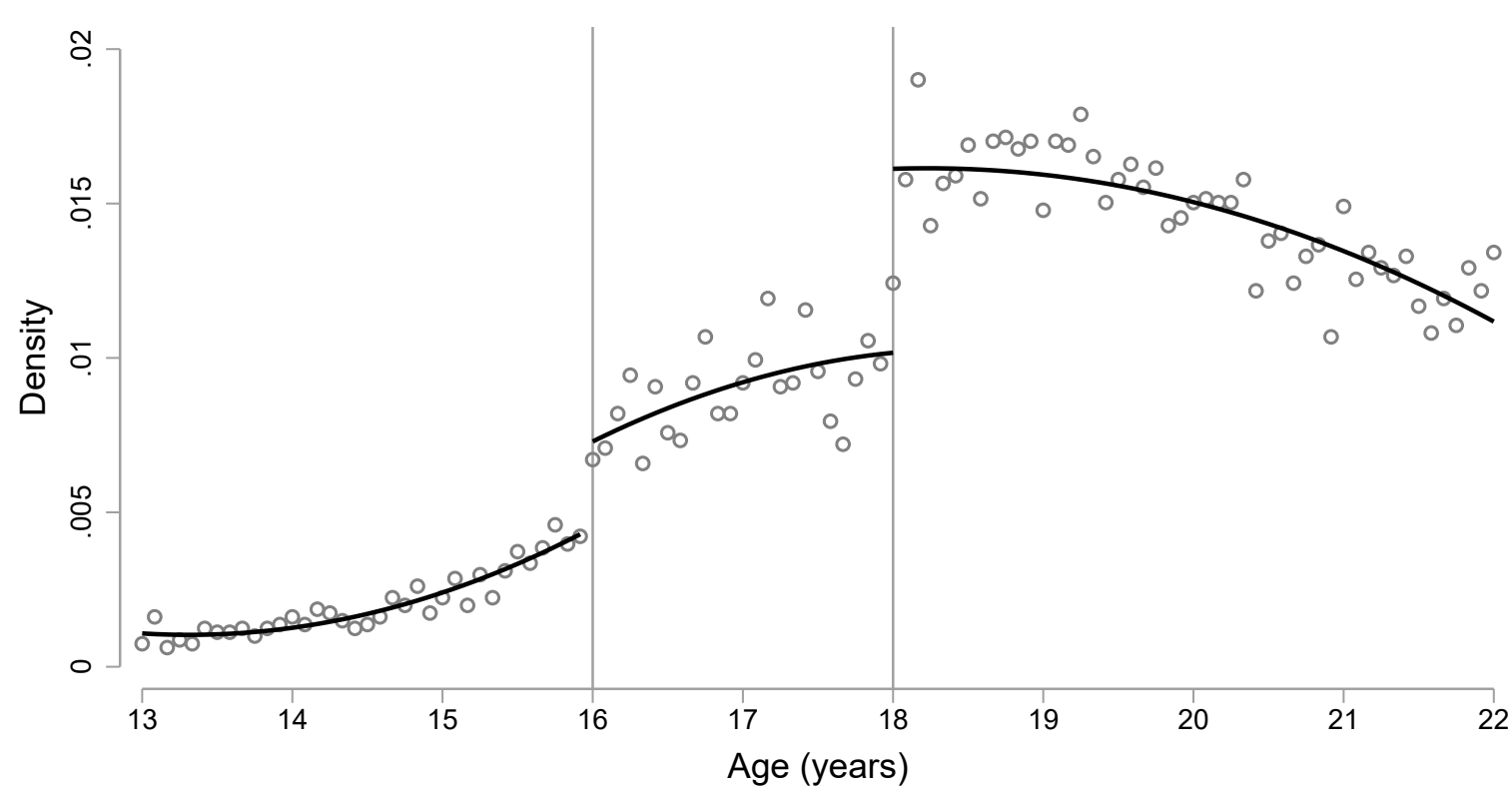

Notes: Austrian death register, 1970-2010. The graph plots the probability of traffic fatalities by age (in months). The large jump at age 18 in Austria is most likely explained by the minimum age for a driver's license for cars at age 18(17). While it has been possible to already drive a car at age 17 since 1999, this is comparably more costly. Statistics on driver's licenses show that the majority of teenagers start driving at age 18. By contrast, in the period of observation, there was no regulation in Austria that would make age 16 a relevant cutoff for driver's licenses.

FIGURE A.13 - Average success rate of underage alcohol test-buyers across months

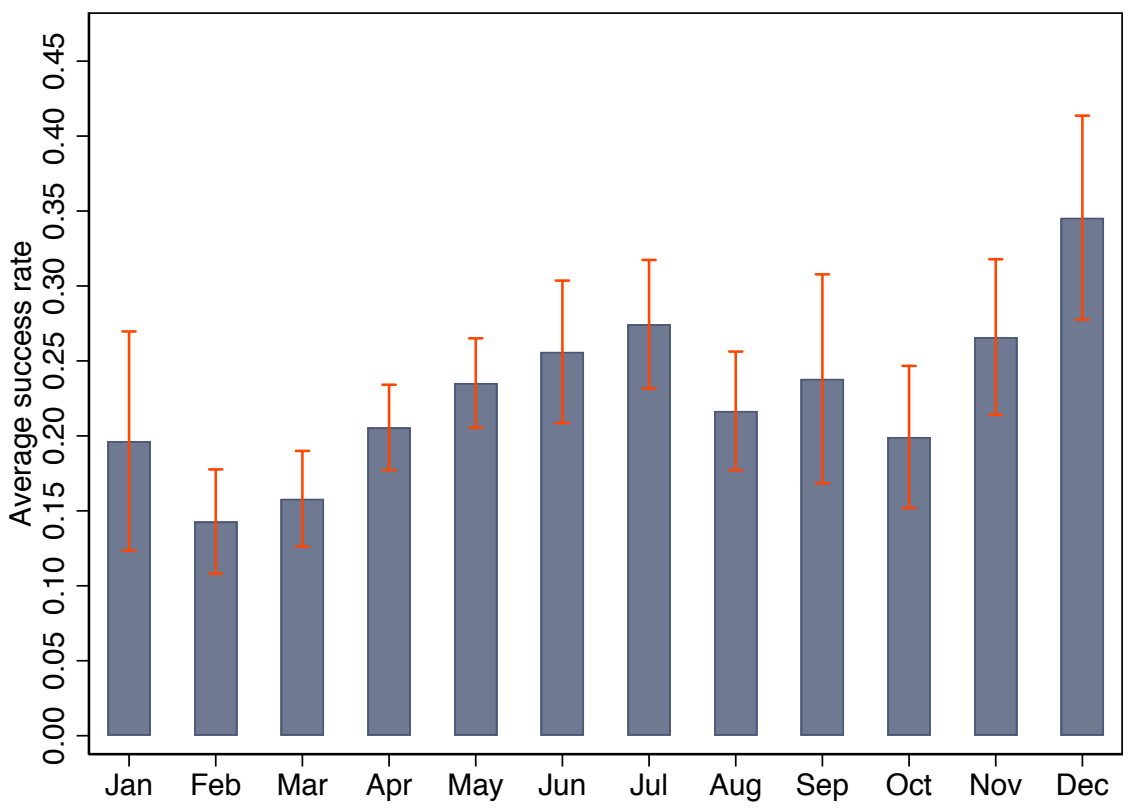

Notes: Figures are based on 4,269 alcohol test purchase attempts in Upper Austrian grocery stores and petrol station shops undertaken by underage test-buyers in the period between 2014 to 2018 . 
FIGURE A.14 - Average success rate of underage alcohol test-buyers across weekdays

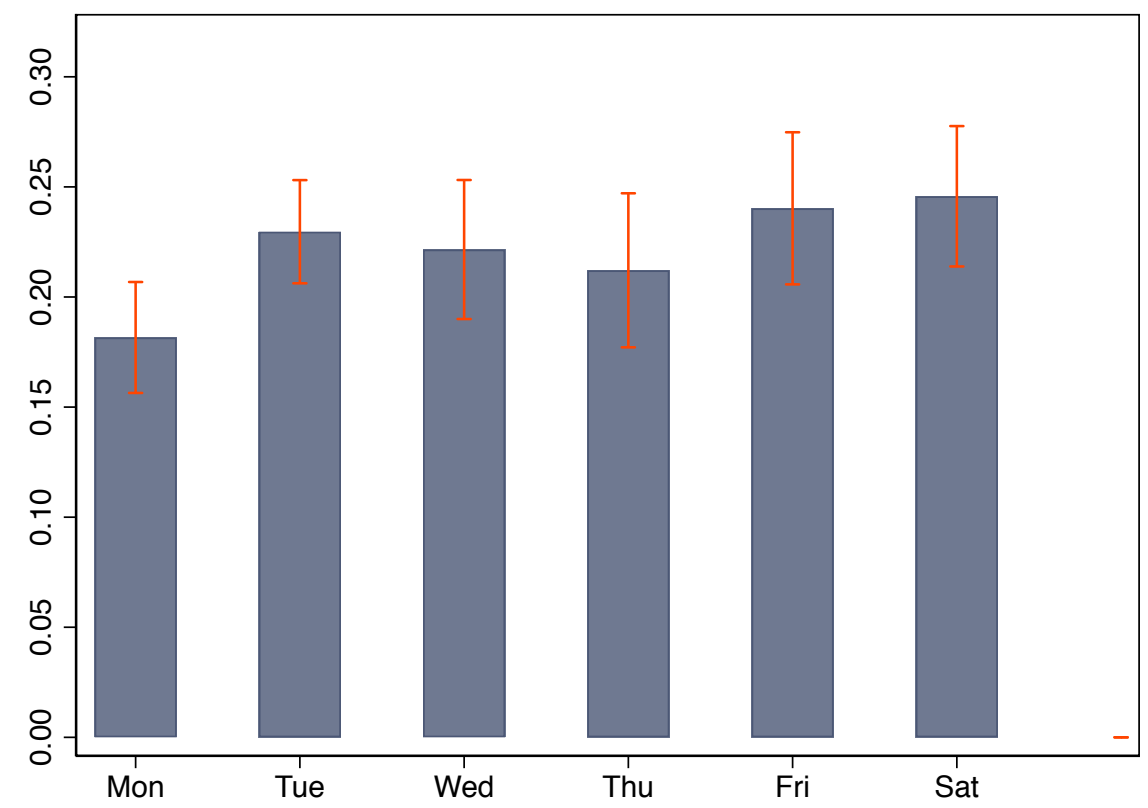

Notes: Figures are based on 4,269 alcohol test purchase attempts in Upper Austrian grocery stores and petrol station shops undertaken by underage test-buyers in the period between 2014 to 2018.

FiguRE A.15 - Average success rate of test shoppers across Upper Austrian municipalities

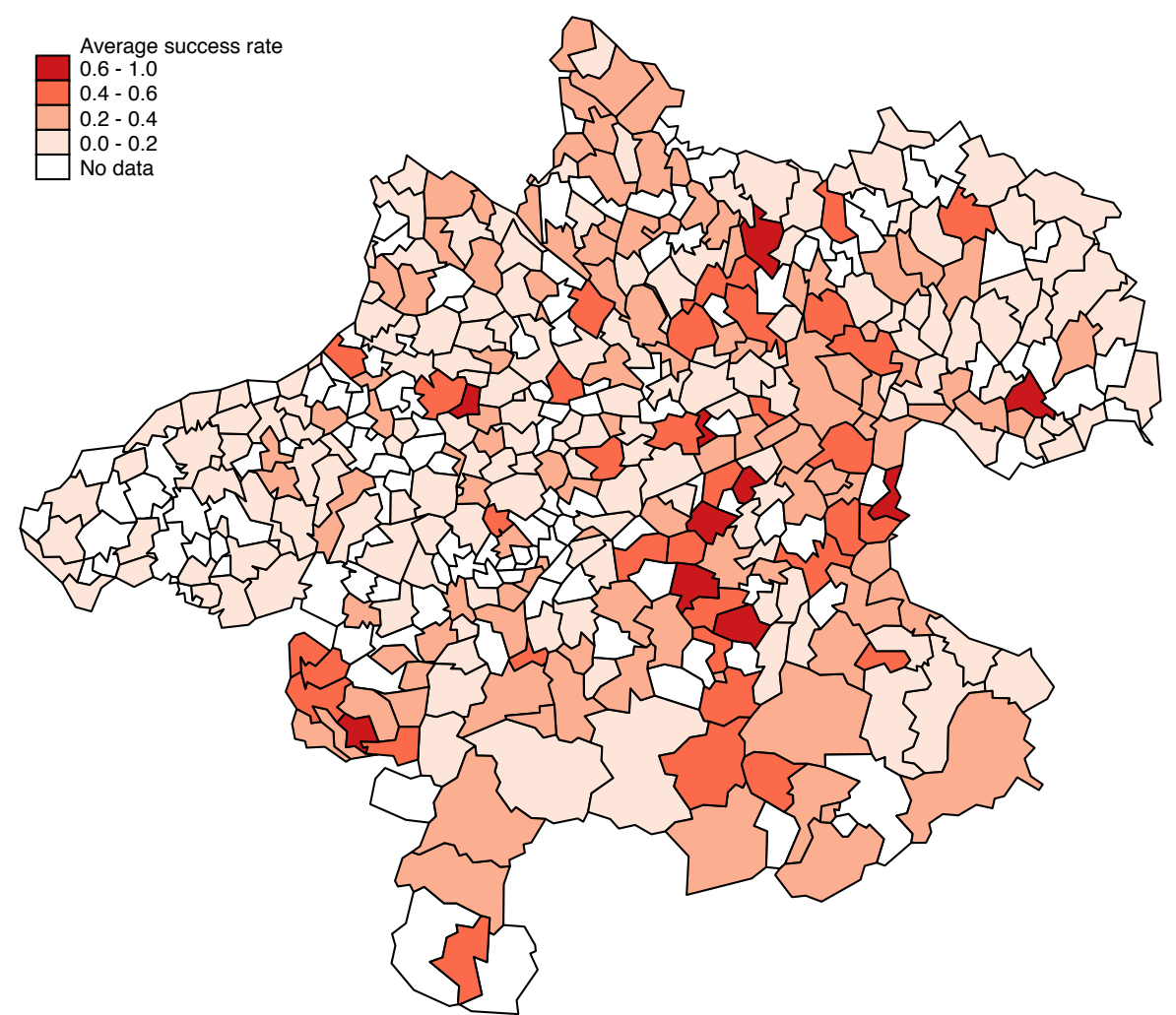

Notes: Based on 4,269 alcohol test purchases in Upper Austrian grocery stores and petrol station shops undertaken by underage testbuyers in the period between 2014 to 2018 . 
FIGURE A.16 - Access to non-distilled alcohol - various categories
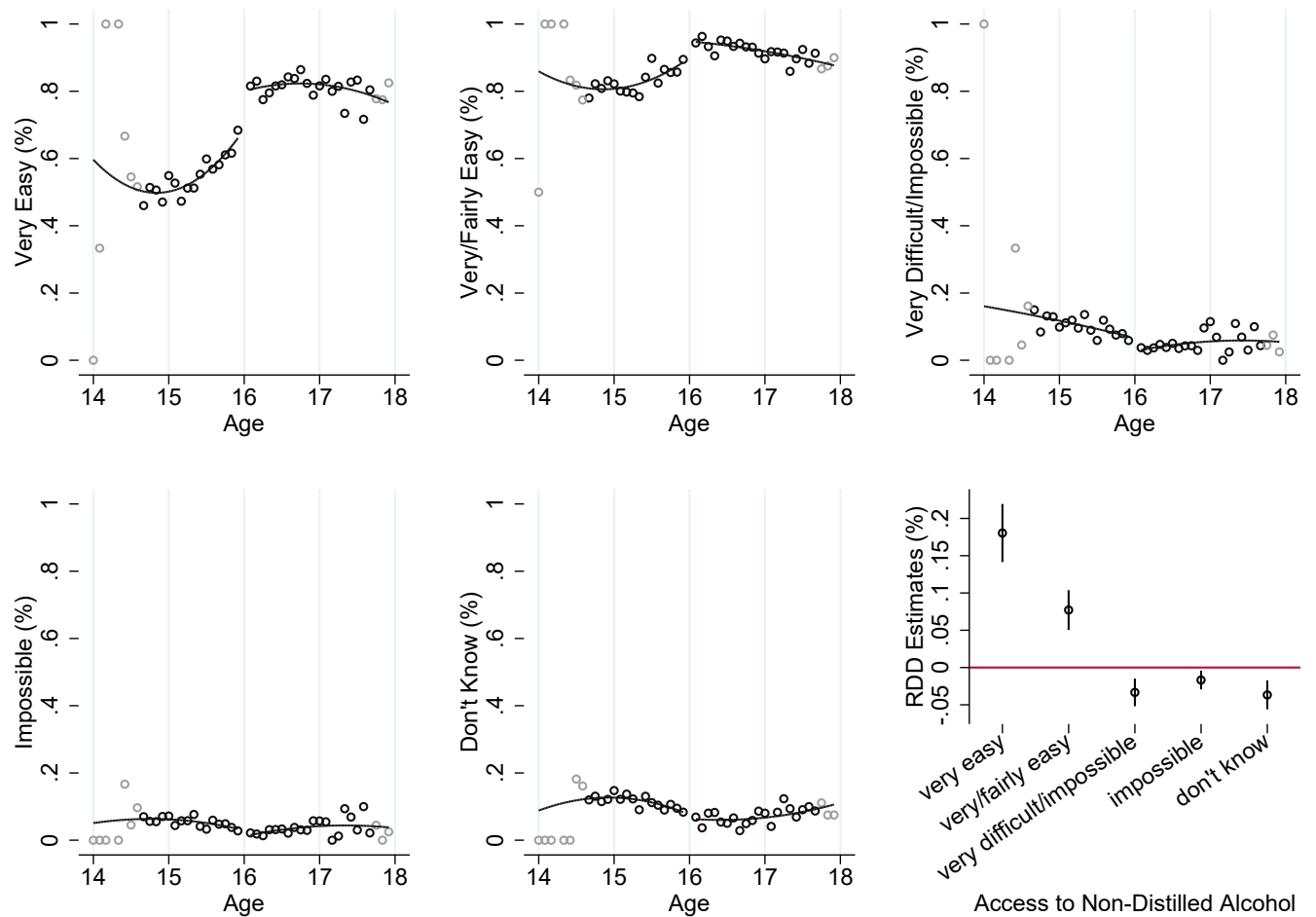

Notes: ESPAD 2015, Austria. The graphs plots the share of respondents by age (in months) bins who perceive access to distilled alcohol (spirits, alcopops) as (a) "very easy", (b) "very easy" or "rather easy", (c) "very difficult" or "impossible", (d) "impossible", and the share of those who "don't know". Note that the option "fairly difficult", "very difficult" or "impossible" is omitted because it is simply the reverse of "very easy" or "fairly easy". Grey circles indicate that the number of observations from the respective age (in months) bin is in the lower quintile of the frequency distribution. The lower right panel plots linear spline RDD estimates for the discontinuous shift in the respective perceived access categories at age 16. Respondents who turn 16 in the month of the interview are dropped. 
FIGURE A.17 - Access to distilled alcohol - various categories
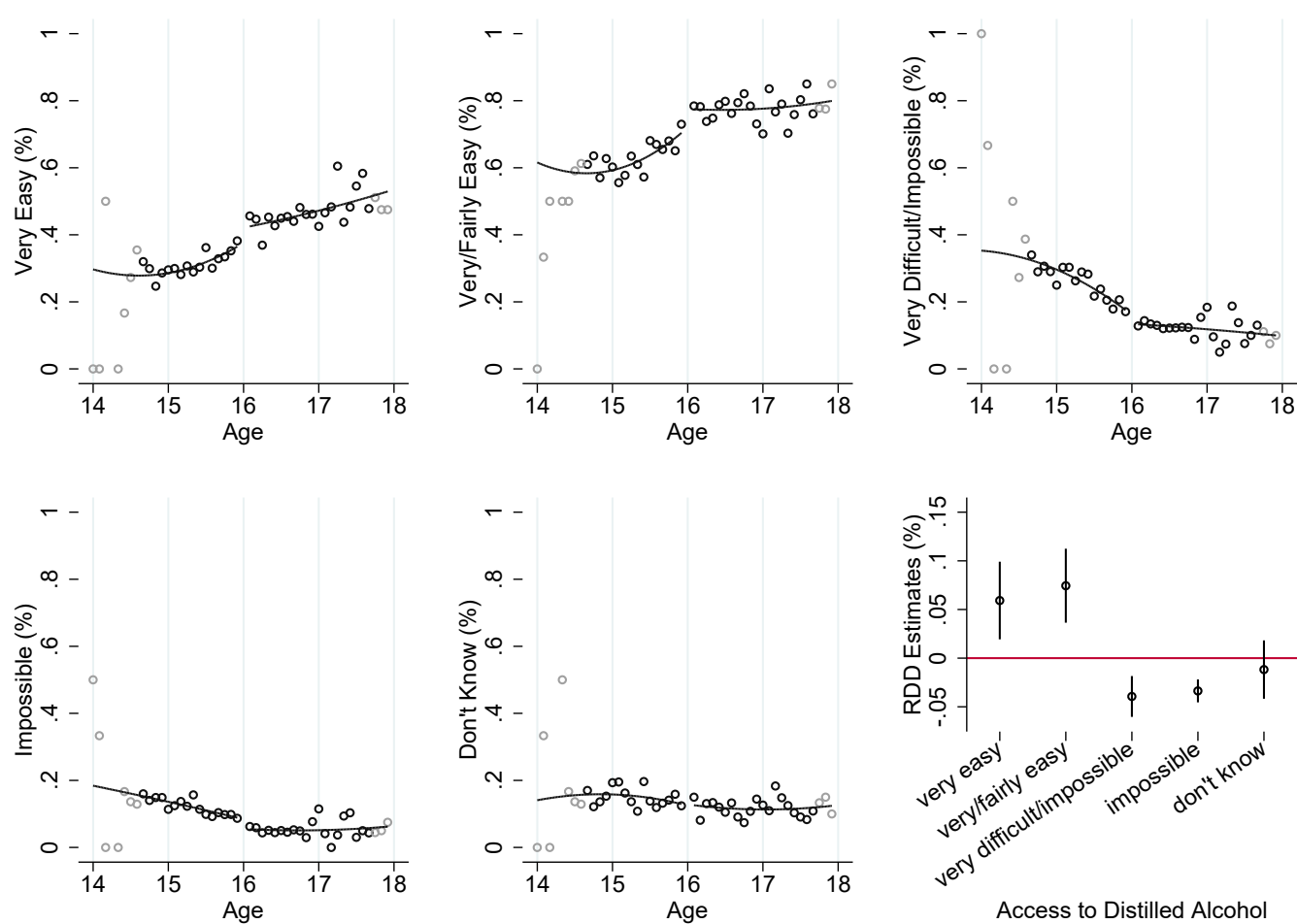

Notes: ESPAD 2015, Austria. The graphs plots the share of respondents by age (in months) bins who perceive access to non-distilled alcohol (beer, wine) as (a) "very easy", (b) "very easy" or "rather easy", (c) "very difficult" or "impossible", (d) "impossible", and the share of those who "don't know". Note that the option "fairly difficult", "very difficult" or "impossible" is omitted because it is simply the reverse of "very easy" or "fairly easy". Grey circles indicate that the number of observations from the respective age (in months) bin is in the lower quintile of the frequency distribution. The lower right panel plots linear spline RDD estimates for the discontinuous shift in the respective perceived access categories at age 16. Respondents who turn 16 in the month of the interview are dropped. 
FIGURE A.18 - Risk perception of daily drinking - various categories
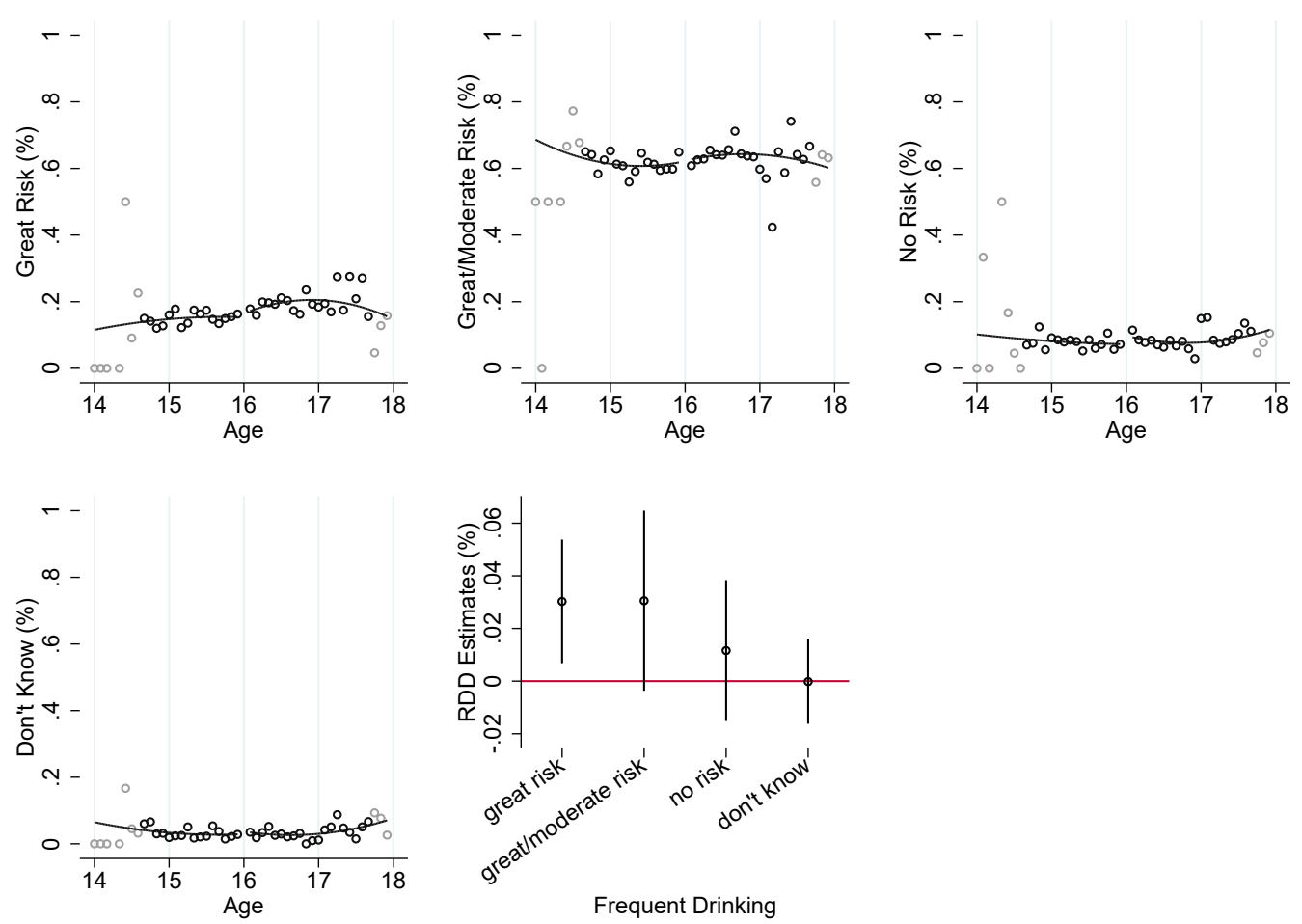

Notes: ESPAD 2015, Austria. The graphs plots the share of respondents by age (in months) bins who perceive having one or two drinks nearly every day to come with (a) "great risk", (b) "great risk" or "moderate risk", (c) "no risk", and the share of those who "don't know". Note that the option "slight risk" or "no risk" is omitted because it is simply the reverse of "great risk" or "moderate risk". Grey circles indicate that the number of observations from the respective age (in months) bin is in the lower quintile of the frequency distribution. The lower right panel plots linear spline RDD estimates for the discontinuous shift in the respective perceived risk categories at age 16. Respondents who turn 16 in the month of the interview are dropped. 
FIGURE A.19 - Risk perception of heavy drinking on weekends - various categories
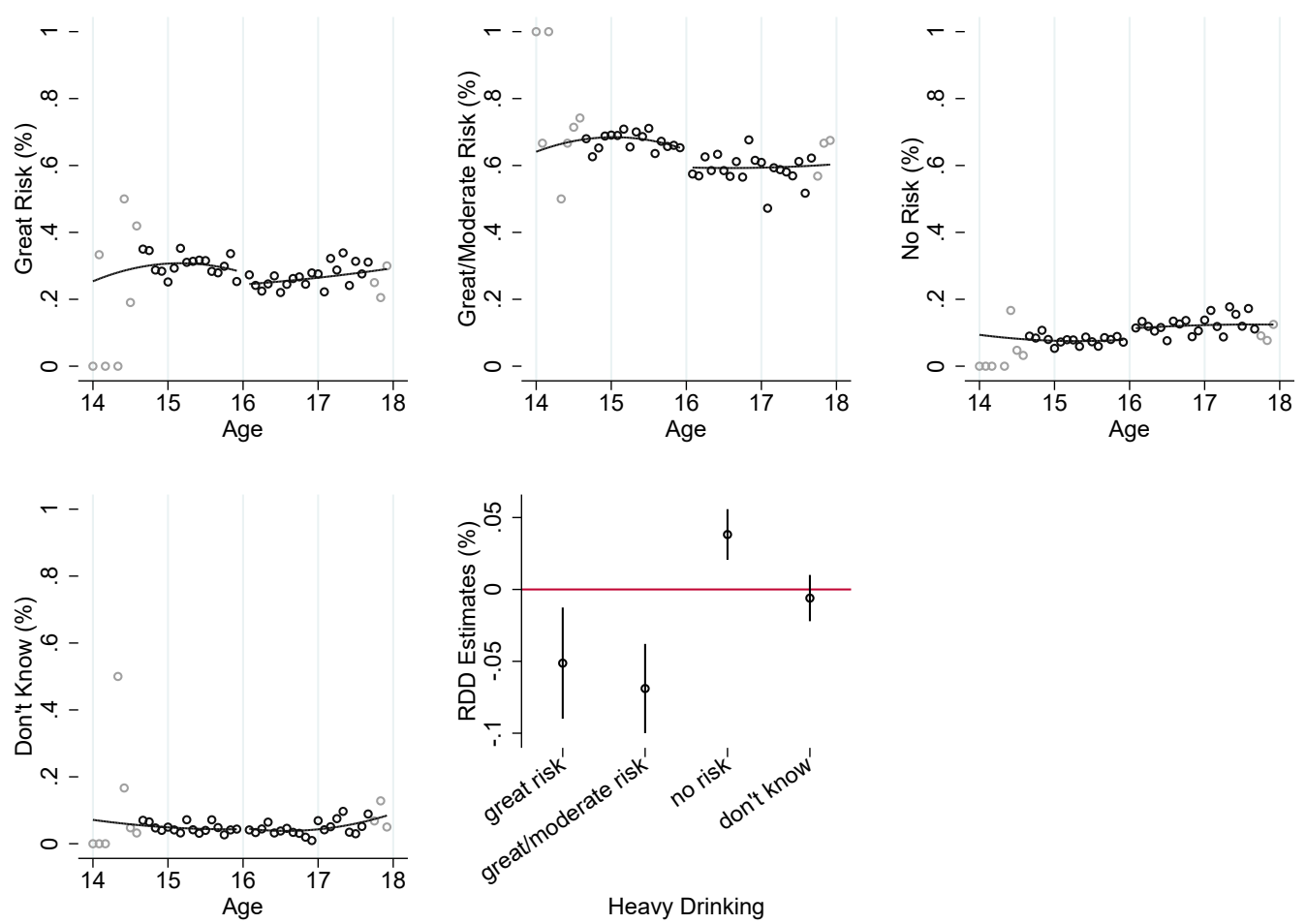

Notes: ESPAD 2015, Austria. The graphs plots the share of respondents by age (in months) bins who perceive heavy drinking on weekends, i.e., having five or more drinks in one occasion nearly every weekend to come with (a) "great risk", (b) "great risk" or "moderate risk",, (c) "no risk", and the share of those who "don't know". Note that the option "slight risk" or "no risk" is omitted because it is simply the reverse of "great risk" or "moderate risk". Grey circles indicate that the number of observations from the respective age (in months) bin is in the lower quintile of the frequency distribution. The lower right panel plots linear spline RDD estimates for the discontinuous shift in the respective perceived risk categories at age 16. Respondents who turn 16 in the month of the interview are dropped. 
FIGURE A.20 - Is there somebody close to you who drinks excessively?

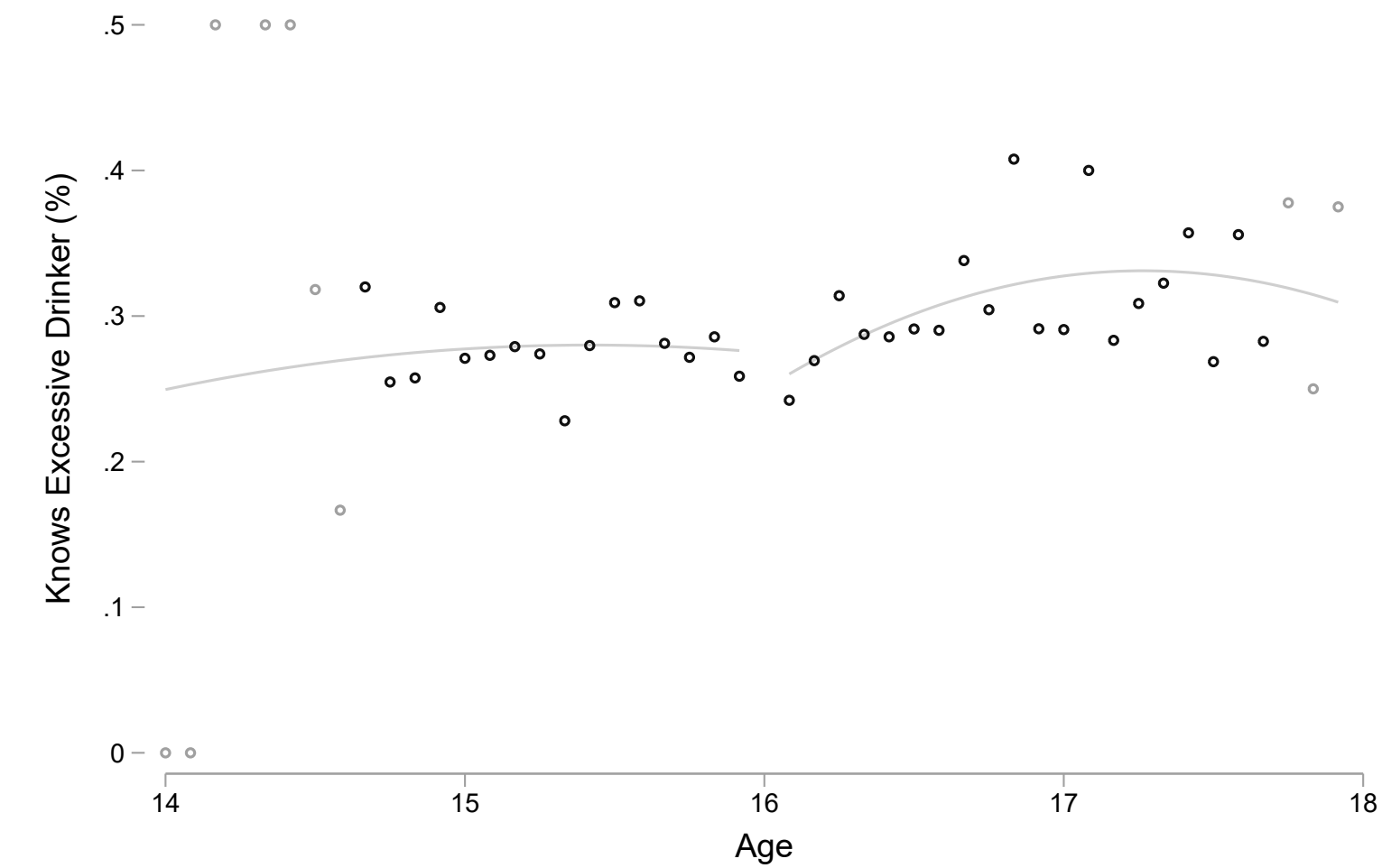

Notes: ESPAD 2015, Austria. Theis graph plots the share of respondents by age (in months) bins who report having somebody close to them who drinks excessively. Grey circles indicate that the number of observations from the respective age (in months) bin is in the lower quintile of the frequency distribution. Respondents who turn 16 in the month of the interview are dropped. 
FIGURE A.21 - Risk perception of drug use

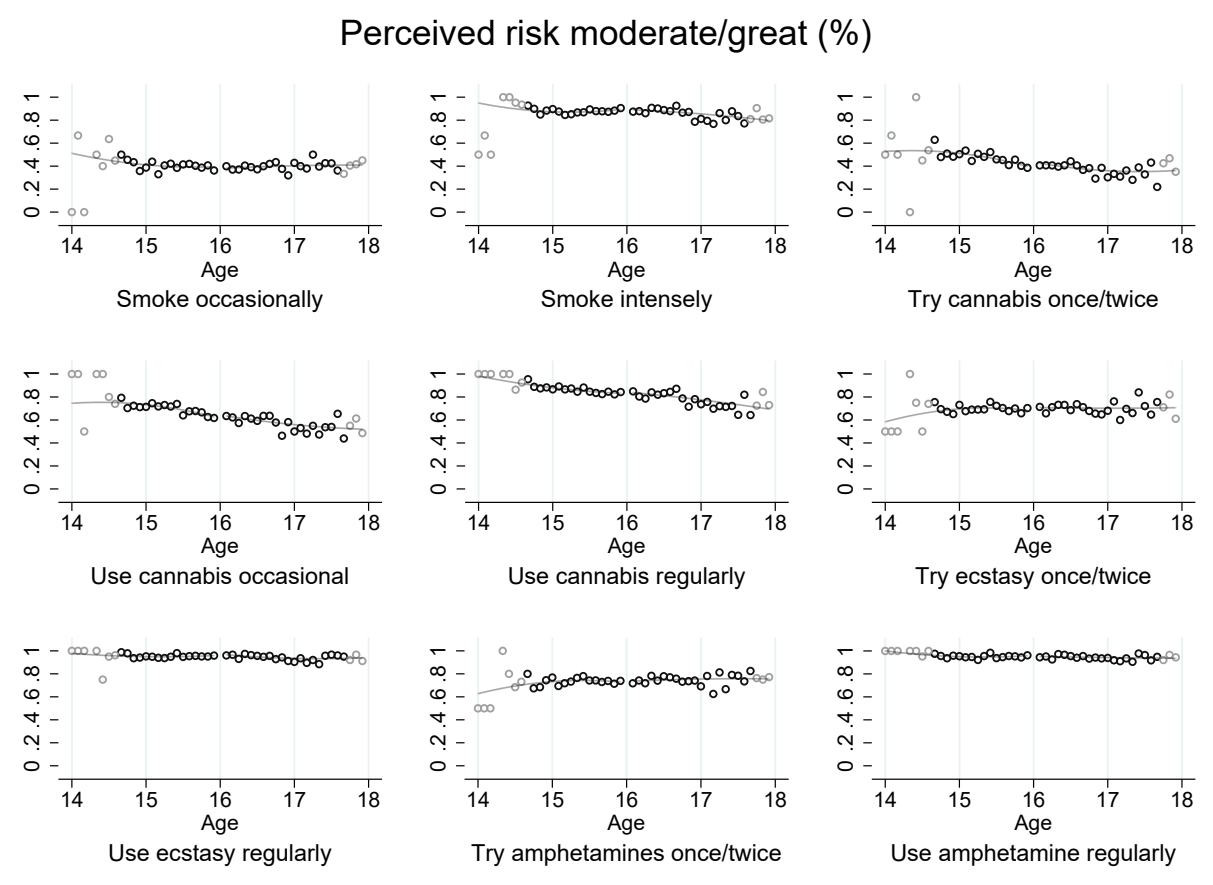

Notes: ESPAD 2015, Austria. The graph plots the share of respondents by age (in months) bins who perceive the respective consumption behavior risky. Respondents who turn 16 in the month of the interview are dropped. Grey circles indicate that the number of observations from the respective age (in months) bin is in the lower quintile of the frequency distribution. 
TABLE A.1 — Interacted model: MLDA effects by staggered vs sharp MLDA regime

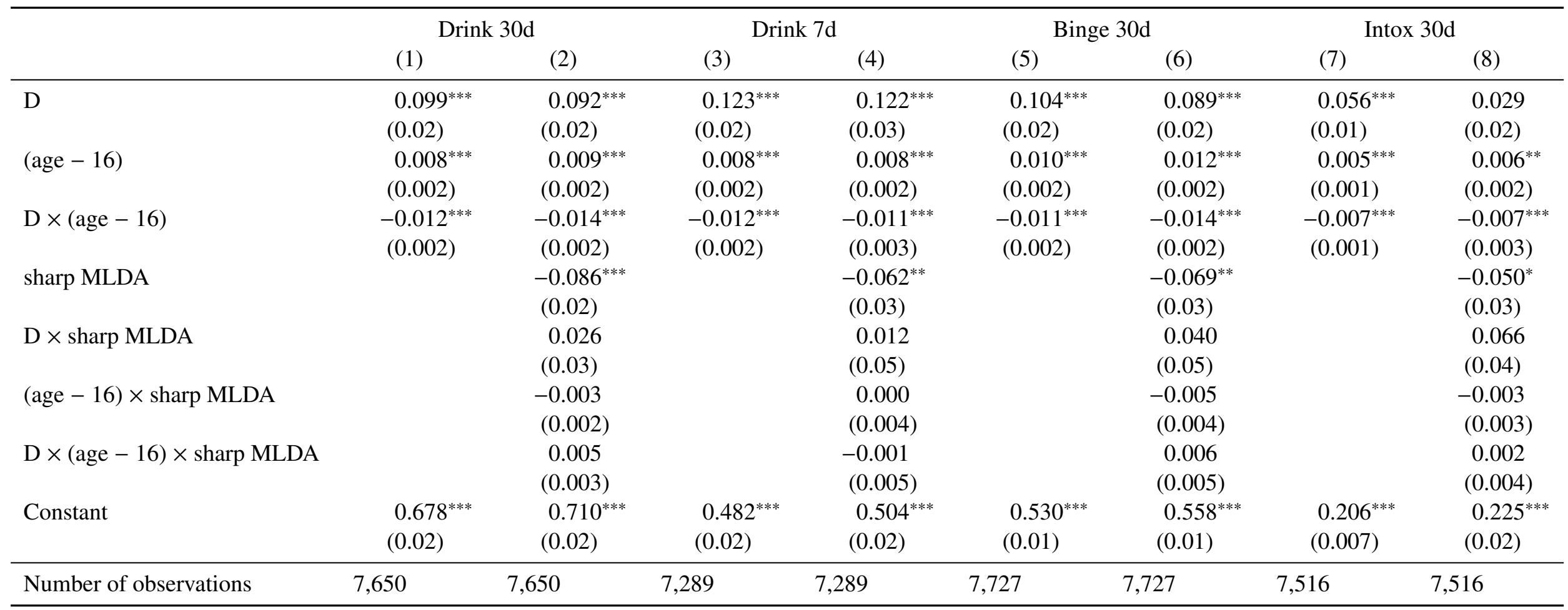

Notes: ESPAD 2015, Austria. The table shows linear spline RD estimates of the discontinuous shift at age 16 in any drinking in the last 7 days (columns 1 and 2), the number of

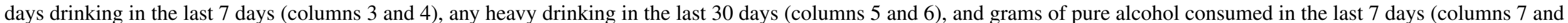

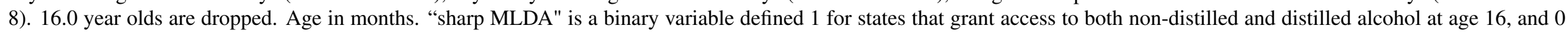
otherwise. Standard errors clustered on the running variable (age) are in parentheses, stars indicate statistical significance: $* p<0.10, * * p<0.05, * * * p<0.01$. 
TABLE A.2 - Summary of potentially relevant age-based regulations

\begin{tabular}{|c|c|c|c|c|}
\hline & Age & $\begin{array}{l}\text { Regional } \\
\text { variation }\end{array}$ & $\begin{array}{c}\text { Reform during } \\
\text { sample period } \\
(2004-2017)\end{array}$ & Law \\
\hline Age of consent & 14 & No & No & $\S 74$ Strafgesetzbuch \\
\hline \multicolumn{5}{|l|}{ Minimum age for driver's licence } \\
\hline Mopeds (AM) & 15 & No & No & $\S 6$ Führerscheingesetz \\
\hline Small motorcycles $(\mathrm{A} 1)^{*}$ & 16 & No & 2013 (before 18) & $\S 6$ Führerscheingesetz \\
\hline Large motorcycles (A2) ${ }^{\dagger}$ & 18 & No & $2013^{* *}$ & $\S 6$ Führerscheingesetz \\
\hline All motorcycles $(\mathrm{A})^{\ddagger}$ & $20 / 24$ & No & 2013 (before 21) & $\S 6$ Führerscheingesetz \\
\hline Cars (B) & $17^{\S} / 18$ & No & & $\S 6$ Führerscheingesetz \\
\hline Minimum legal age to smoke tobacco & 16 & No & $\mathrm{No}^{* * *}$ & Respective State Law \\
\hline Voting age & 16 & No & 2007 (before 18) & Respective Election Regulations \\
\hline Legal age for marriage & $(16)^{\mathrm{I} /} / 18$ & No & & $\S 1$ Ehegesetz \\
\hline Curfew hours & $14 / 16 / 18$ & Yes (See Table A.5) & & Respective State Law \\
\hline
\end{tabular}

Notes: * Motorcycles with or without a sidecar with a cylinder capacity not exceeding $125 \mathrm{cc}$ and an engine power not exceeding $11 \mathrm{~kW}(15 \mathrm{hp})$; maximum power to weight ratio of $0.1 \mathrm{~kW} / \mathrm{kg}$. ${ }^{\dagger}$ Motorcycles with or without a sidecar with an engine power not exceeding $35 \mathrm{~kW}$ (48 hp) and a power to weight ratio not exceeding $0.2 \mathrm{~kW} / \mathrm{kg}$, and which when unrestricted do not have more than double the engine power ( $35 \mathrm{~kW}$ corresponds to a vehicle weight of at least $175 \mathrm{~kg}$ ). $\$ 20$ for individuals previously in possession (for 2 years) of a category A2 licence (21 for three-wheeled motor vehicles); 24 (first-time licence holders). ${ }^{\&}$ Individuals who want to start driving before the age of 18 may undergo a so-called L17 training "early permission to drive vehicles". In this case, lessons at a driving school can be started from the age of 15 years and 6 months, and a driving licence can be issued at the age of 17 (at the earliest). ${ }^{* * *}$ Since 2019 the minimum legal age to smoke tobacco is 19. "Persons at least 16 years of age may also marry upon presentation of written, notarized consent from both parents and if the other spouse is at least 18 years old. This is a very rare event (see Table A.4). ${ }^{* *}$ Reform only affects the technical classification of motorcycles. 
TABLE A.3 - MLDA Effects for different observation periods

\begin{tabular}{lcc}
\hline & $2004-2016$ & $2004-2012$ \\
& $(1)$ & $(2)$ \\
\hline Discontinuity & $0.034 * * *$ & $0.035^{* * *}$ \\
& $(0.009)$ & $(0.010)$ \\
Outcome mean & 0.09 & 0.08 \\
Number of observations & $3,981,294$ & $2,788,702$ \\
\hline
\end{tabular}

Notes: UAHIF panel. Estimates for the discontinuous shift in the probability of having an alcohol intoxication at age 16 for the full observation period (column 1) and a shorter observation period that ends on December 31, 2012 (column 2). All regressions are based on a bimonthly age-bin panel and includes quadratic trends that might be different to the left and to the right of the cutoff (quadratic spline). The RD coefficients are multiplied by 100 to improve readability. Standard errors shown in parentheses are twoway clustered at the individual and the bimonthly age level. $* p<0.10, * * p<0.05$, *** $p<0.01$.

TABLE A.4 - Absolute number of marriages in Upper Austria between 2010 and 2020

\begin{tabular}{lccccr}
\hline & & \multicolumn{4}{c}{$\begin{array}{c}\text { At least one spouse } \\
\text { is not older than: }\end{array}$} \\
\cline { 3 - 6 } Year of marriage & All & 16 & 17 & 18 & 19 \\
\hline 2010 & 6,326 & 0 & 4 & 59 & 91 \\
2011 & 6,295 & 3 & 5 & 61 & 85 \\
2012 & 6,829 & 0 & 5 & 52 & 113 \\
2013 & 6,318 & 1 & 7 & 71 & 68 \\
2014 & 6,519 & 1 & 3 & 50 & 80 \\
2015 & 7,823 & 2 & 2 & 51 & 95 \\
2016 & 7,673 & 0 & 5 & 47 & 103 \\
2017 & 7,886 & 0 & 4 & 46 & 77 \\
2018 & 8,139 & 2 & 1 & 41 & 81 \\
2019 & 7,875 & 0 & 1 & 30 & 67 \\
2020 & 7,126 & 0 & 0 & 29 & 49 \\
\hline
\end{tabular}

Notes: Data were retrieved from STATcube-Database of Statistics Austria on $2021 / 09 / 25$. 
TABLE A.5 - Summary of age-specific curfew regulations across federal states

\begin{tabular}{|c|c|c|c|c|c|}
\hline \multirow[b]{2}{*}{ Federal state ${ }^{*}$} & \multicolumn{3}{|c|}{ Age group } & \multirow{2}{*}{$\begin{array}{l}\text { Reform during } \\
\text { sample period }^{\dagger}\end{array}$} & \multirow{2}{*}{$\begin{array}{c}\text { Curfew regulations } \\
\text { for the age-group 16-18 } \\
\text { before the respective reform }\end{array}$} \\
\hline & $12-14$ & $14-16$ & $>16$ & & \\
\hline Vienna & $10 \mathrm{pm}-5 \mathrm{am}$ & $1 \mathrm{am}-5 \mathrm{am}$ & No limit & & \\
\hline Lower Austria & $10 \mathrm{pm}-5 \mathrm{am}$ & $1 \mathrm{am}-5 \mathrm{am}$ & No limit & & \\
\hline Burgenland & $10 \mathrm{pm}-5 \mathrm{am}$ & 1 am-5 am & No limit & & \\
\hline Upper Austria & $10 \mathrm{pm}-5 \mathrm{am}$ & $12 \mathrm{pm}-5 \mathrm{am}$ & No limit & & \\
\hline Carinthia & $11 \mathrm{pm}-5 \mathrm{am}$ & $1 \mathrm{am}-5 \mathrm{am}$ & No limit & & \\
\hline Styria & 9 pm-5 am & $11 \mathrm{pm}-5 \mathrm{am}$ & No limit & & \\
\hline Vorarlberg & $11 \mathrm{pm}-5 \mathrm{am}$ & $12 \mathrm{pm}-5 \mathrm{am}$ & No limit & 2017 & $2 \mathrm{am}-5 \mathrm{am}$ \\
\hline Salzburg & $10 \mathrm{pm}-5 \mathrm{am}$ & $11 \mathrm{pm}-5 \mathrm{am}$ & No limit & & \\
\hline Tyrol & $10 \mathrm{pm}-5 \mathrm{am}$ & $1 \mathrm{am}-5 \mathrm{am}$ & No limit & & \\
\hline
\end{tabular}

Notes: Other regulations may apply if (i) a minor is accompanied by a parent or guardian, or (ii) if they face particular requirements such as work. Even though teenagers are allowed to stay out until certain hours, parents might still restrict their permitted hours to earlier hours. Permitted late night hours usually target public places (including bars and restaurants). Slightly different regulations might apply for club houses or similar locations. ${ }^{*}$ The following regulations apply in the respective order of federal states: § 8 Wiener Jugendschutzgesetz 2002; § 15 NÖ Jugendgesetz; § 8 Burgenländisches Jugendschutzgesetz $2002 ; \S 5$ OÖ. Jugendschutzgesetz 2001; § 8 Kärntner Jugendschutzgesetz; § 15 Steiermärkisches Jugendgesetz; § 12 Kinder- und Jugendgesetz; § 24 Salzburger Jugendgesetz; § 12 Tiroler Jugendgesetz. ${ }^{\dagger}$ Other regulations may apply if a minor is accompanied by a parent or guardian. ${ }^{*}$ For our administrative data for Upper Austria, the sample period is 2004 to 2017. Our ESPAD data for whole Austria is from the year 2015. Carinthia and Styria had a reform in 2013; this is not in our sample periods. 
TABLE A.6 - Interacted Model: MLDA Effects by late night hour regime

\begin{tabular}{lcccc}
\hline & Days Drink (7d) & Any Drink (7d) & Any Binging (30d) & Grams (7d) \\
& $(1)$ & $(2)$ & $(3)$ & $(4)$ \\
\hline $\mathrm{D}$ & $0.278^{* * *}$ & $0.120^{* * *}$ & $0.100^{* * *}$ & $53.775^{* * *}$ \\
& $(0.041)$ & $(0.021)$ & $(0.018)$ & $(5.225)$ \\
age -16$)$ & $0.012^{* * *}$ & $0.008^{* * *}$ & $0.010^{* * *}$ & $0.999^{* *}$ \\
& $(0.003)$ & $(0.002)$ & $(0.002)$ & $(0.393)$ \\
limited & -0.029 & -0.071 & -0.110 & 3.479 \\
& $(0.148)$ & $(0.056)$ & $(0.081)$ & $(10.225)$ \\
$\mathrm{D} \times($ age -16$)$ & $-0.014^{* * *}$ & $-0.012^{* * *}$ & $-0.011^{* * *}$ & $-1.720^{* * *}$ \\
& $(0.005)$ & $(0.002)$ & $(0.002)$ & $(0.588)$ \\
$\mathrm{D} \times$ limited & -0.040 & 0.065 & 0.094 & -20.968 \\
& $(0.244)$ & $(0.079)$ & $(0.106)$ & $(22.446)$ \\
$($ age -16$) \times$ limited & 0.012 & 0.003 & -0.001 & 1.770 \\
& $(0.016)$ & $(0.007)$ & $(0.009)$ & $(1.160)$ \\
D $\times($ age -16$) \times$ limited & 0.022 & 0.001 & 0.001 & 0.022 \\
& $(0.033)$ & $(0.011)$ & $(0.013)$ & $(2.605)$ \\
Constant & $0.793^{* * *}$ & $0.486^{* * *}$ & $0.536^{* * *}$ & $61.872^{* * *}$ \\
& $(0.033)$ & $(0.016)$ & $(0.012)$ & $(3.373)$ \\
\hline Number of observations & 7,289 & 7,289 & 7,727 & 7,289 \\
Outcome mean & 0.852 & 0.487 & 0.526 & 77.658 \\
\hline
\end{tabular}

Notes: ESPAD 2015, Austria. The table shows linear spline RD estimates of the discontinuous shift at age 16 in the number of days drinking in the last 7 days (column 1), any drinking in the last 7 days (column 2), any heavy drinking in the last 30 days (column 3), and grams of pure alcohol consumed in the last 7 days (column 4). 16.0 year olds are dropped. Age in months. "Limited"' is a binary variable defined 1, if late night hours are restricted for teenagers who are 16 years or older (this only applies to Vorarlberg: allowed hours 5am-2am), and 0 otherwise (in all other states no restrictions in 2015). Standard errors clustered on the running variable (age) are in parentheses, stars indicate statistical significance: $* p<0.10, * * p<0.05, * * * p<0.01$.

TABLE A.7 — Different confidence intervals (CIs) for nonparametric estimates

\begin{tabular}{|c|c|c|c|c|}
\hline & \multicolumn{2}{|c|}{ Uniform kernel } & \multicolumn{2}{|c|}{ Triangular kernel } \\
\hline & $\begin{array}{c}\text { Est. } \\
\text { (1) }\end{array}$ & $\begin{array}{l}\text { CI } \\
(2)\end{array}$ & $\begin{array}{c}\text { Est. } \\
\text { (3) }\end{array}$ & $\begin{array}{l}\text { CI } \\
\text { (4) }\end{array}$ \\
\hline \multicolumn{5}{|c|}{ (a) ESPAD data (outcome: number of past-week drinking days) } \\
\hline Conventional CIs & 0.276 & $(0.229,0.324)$ & 0.276 & $(0.229,0.324)$ \\
\hline Calonico et al. (2014) bias-corrected CIs & 0.268 & $(0.220,0.316)$ & 0.271 & $(0.223,0.319)$ \\
\hline Kolesár and Rothe (2018) BSD CIs & 0.276 & $(0.271,0.281)$ & 0.269 & $(0.266,0.272)$ \\
\hline \multicolumn{5}{|c|}{ (b) Administrative data (outcome: probability of alcohol intoxication) } \\
\hline Conventional CIs & 0.055 & $(0.041,0.069)$ & 0.054 & $(0.040,0.068)$ \\
\hline Calonico et al. (2014) bias-corrected CIs & 0.034 & $(0.020,0.048)$ & 0.033 & $(0.019,0.047)$ \\
\hline Kolesár and Rothe (2018) BSD CIs & 0.048 & $(0.002,0.094)$ & 0.041 & $(0.007,0.075)$ \\
\hline
\end{tabular}

Notes: ESPAD 2015, Austria and UAHIF panel. This table presents nonparametric RD estimates for the discontinuous shift in the number of days drinking during the past 7 days and the probability of having an alcohol intoxication at age 16. 
TABLE A.8 - Community-level determinants of successful purchasing attempts by underage test-buyers

\begin{tabular}{lcccccc}
\hline & $(1)$ & $(2)$ & $(3)$ & $(4)$ & $(5)$ & $(6)$ \\
\hline Share with an academic degree $^{\dagger}$ & 0.008 & & & & & 0.007 \\
& $(0.364)$ & & & & & $(0.298)$ \\
Share with a school leaving exam. ${ }^{\dagger}$ & & 0.010 & & & & 0.028 \\
& & $(0.354)$ & & & & $(0.813)$ \\
Unemployment rate $^{\dagger}$ & & & -0.002 & & & 0.007 \\
& & & $(-0.061)$ & & & $(0.149)$ \\
Share of foreigners & $\dagger$ & & & 0.007 & & 0.023 \\
& & & & $(0.248)$ & & $(0.590)$ \\
Firms per 1,000 pop & & & & & 0.013 & 0.014 \\
& & & & & $(0.737)$ & $(0.706)$ \\
Constant & Yes & Yes & Yes & Yes & Yes & Yes \\
Year FE & Yes & Yes & Yes & Yes & Yes & Yes \\
District FE & Yes & Yes & Yes & Yes & Yes & Yes \\
Pop. density & Yes & Yes & Yes & Yes & Yes & Yes \\
\hline Number of observations & 4,267 & 4,267 & 4,267 & 4,267 & 4,267 & 4,267 \\
R-squared & 0.041 & 0.041 & 0.041 & 0.041 & 0.041 & 0.041 \\
F-statistic & 9.15 & 9.15 & 9.16 & 9.18. & 9.15 & 7.82 \\
Mean of main independent var & 0.112 & 0.600 & 0.053 & 0.138 & 0.715 & - \\
\hline
\end{tabular}

Notes: Linear probability model of a successful purchasing attempt by underage test-buyers with communitylevel determinants. Beta coefficients with t-values (based on robust standard errors) in parentheses. * $p<$ 0.10 , ** $p<0.05$, *** $p<0.01$. Estimations are based on 4,267 alcohol test purchase attempts in Upper Austrian grocery stores and petrol station shops undertaken by underage test-buyers in the period between 2014 to $2018{ }^{\dagger}$ Measured in 2017. 
TABLE A.9 - Youth drinking behavior in Austria and in the US

\begin{tabular}{lccccc}
\hline & \multicolumn{2}{c}{ Drinking } & & \multicolumn{2}{c}{ Binging } \\
\cline { 2 - 3 } \cline { 5 - 6 } & $(1)$ & $(2)$ & & $(3)$ & $(4)$ \\
\hline \multirow{2}{*}{16 and older } & $0.101^{* * *}$ & $0.103^{* * *}$ & & $0.074^{* * *}$ & $0.076^{* * *}$ \\
Austria & $(0.008)$ & $(0.008)$ & & $(0.006)$ & $(0.006)$ \\
& $0.390^{* * *}$ & $0.390^{* * *}$ & & $0.337^{* * *}$ & $0.338^{* * *}$ \\
$(16$ and older X Austria) $)$ & $(0.009)$ & $(0.009)$ & & $(0.009)$ & $(0.009)$ \\
& $0.028^{* *}$ & $0.027^{* *}$ & & $0.092^{* * *}$ & $0.091^{* * *}$ \\
Female & $(0.013)$ & $(0.013)$ & & $(0.013)$ & $(0.013)$ \\
& & $0.030^{* * *}$ & & 0.002 \\
Constant & & $(0.006)$ & & $(0.006)$ \\
& $0.225^{* * *}$ & $0.209^{* * *}$ & & $0.118^{* * *}$ & $0.116^{* * *}$ \\
Number of observations & 21,308 & 21,252 & & 21,388 & 21,332 \\
Outcome mean & 0.429 & 0.430 & 0.299 & 0.300 \\
\hline
\end{tabular}

Notes: ESPAD 2015, Austria and YRBSS 2015. Drinking is a dichotomous variable that is one if the respondent consumed alcohol at least once during the last 30 days. Binging is a dichotomous variable that is one if the respondent reports at least one binge drinking incidence (five or more drinks in one single occasion) during the last 30 days. 16 and older is a dichotomous varibale that is one if the respondent is at least 16 years old. Austria is a dichotomous variable that is one for respondents from the ESPAD 2015 Austria country sample and zero for respondents from the YRBSS 2015. Robust standard errors in parentheses. $* p<0.10, * * p<0.05,{ }^{* * *} p<0.01$. 